\title{
SelfMakeup: um Sistema de Realidade Aumentada para Autoaplicação de Maquiagem Virtual
}

\author{
Aline de Fátima Soares Borges \\ DISSERTAÇÃO APRESENTADA \\ AO \\ InSTITUTO DE MATEMÁTICA E EsTATÍSTICA \\ DA \\ UNIVERSIDADE DE SÃo PAULO \\ PARA \\ OBTENÇÃO DO TÍTULO \\ $\mathrm{DE}$ \\ Mestre EM CiêNCIAS \\ Programa: Ciência da Computação \\ Orientador: Prof. Dr. Carlos Hitoshi Morimoto
}

São Paulo, dezembro de 2017 


\section{SelfMakeup: um Sistema de Realidade Aumentada para Autoaplicação de Maquiagem Virtual}

Esta versão da dissertação contém as correções e alterações sugeridas pela Comissão Julgadora durante a defesa da versão original do trabalho, realizada em 23/11/2017. Uma cópia da versão original está disponível no Instituto de Matemática e Estatística da Universidade de São Paulo.

Comissão Julgadora:

- Prof. Dr. Carlos Hitoshi Morimoto (orientador) - IME-USP

- Prof. Dr. Marcel P. Jackowski - IME-USP

- Prof ${ }^{a}$. Dra ${ }^{a}$. Fátima de Lourdes dos Santos N. M. - EACH-USP 


\section{Agradecimentos}

A Deus, por me abençoar nessa trajetória, iluminando meus passos, dando-me discernimento e sabedoria.

Ao meu orientador Prof. Dr. Carlos Hitoshi Morimoto, pela oportunidade de ser sua orientanda, pela compreensão e por tantos ensinamentos durante esses anos de mestrado, que contribuiram de forma significativa não só para a concretização desta dissertação, mas para minha vida. Agradeço por ser o maior incentivador na superação dos meus limites.

Aos meus pais Paulo e Rosimeire - minha base, meu exemplo de fé e sabedoria- pelo amor e pelo incentivo constante. Agradeço à minha mãe - meu exemplo de garra e determinação - por ter me ensinado a ter esperança, a sonhar e nunca desistir dos meus sonhos.

Aos meu irmão Paulo - meu mestre - e minha cunhada Daniele, por terem me acolhido, pelo suporte e por nunca terem medido esforços para me ajudar.

À minha irmã Patrícia - meu exemplo de coragem e de luta - por ter trazido felicidade a tantos momentos, por ser minha companheira e amiga.

Ao meu amor Túlio - meu equilíbrio - pelo carinho, por cuidar de mim, por estar sempre ao meu lado mesmo nos momentos mais difíceis e por me encorajar diante dos meus medos.

À minha tia Purcina, por ser tão presente em minha vida e por me amparar sempre que necessitei, principalmente quando minha mãe precisou se ausentar para estudar.

Às minhas amigas, em especial à Flávia, Camila, Amanda, Ariane, Cintia, Taís e Helena, por terem sido minha família aqui em São Paulo.

Aos colegas do grupo LaTIn pelas discussões e experiências compartilhadas e aos professores pelos ensinamentos.

Ao Leonardo Raposo e a todos da empresa Mazzatech, pela compreeensão e pelo apoio, que foram de fundamental importância para esta conquista.

A todos os amigos e familiares que entenderam minha ausência e torceram por mim. 


\section{Resumo}

Durante séculos, cosméticos têm sido utilizados nas mais diversas sociedades. Entretanto, quando se trata de maquiagem facial, o processo de escolha de um produto ainda é um desafio, pois é um trabalho manual que demanda tempo, além de consumir a maquiagem em si e outros materiais para aplicação e limpeza. Esse processo manual também dificulta a experimentação de vários produtos diferentes devido à necessidade de limpeza da pele para retirada de um produto aplicado anteriormente. Assim, um sistema de simulação de maquiagem utilizando realidade aumentada pode facilitar esse processo, permitindo a experimentação com a combinação de produtos e a comparação dos resultados, além de permitir experimentar os produtos virtualmente, pela internet por exemplo.

Trabalhos existentes sobre esse tema permitem ao usuário aplicar a maquiagem sobre uma foto, ou mesmo um vídeo, do próprio usuário. A interação é feita por meio de mouse ou toque de um dedo sobre um monitor sensível a toques como se o usuário aplicasse maquiagem em uma terceira pessoa.

Nesta dissertação propomos o desenvolvimento do SelfMakeup, um sistema de realidade aumentada que permite a autoaplicação de maquiagem virtual por meio de toques feitos diretamente na face ao invés de toques no monitor. A nossa hipótese é que essa forma de interação seja mais natural e forneça ao usuário uma melhor experiência ao testar produtos virtuais de maquiagem.

O primeiro passo para viabilizar o SelfMakeup foi o desenvolvimento de um método para estimar a posição de toques na face utilizando uma câmera RGBD. Realizamos testes para avaliar o desempenho desse método e verificamos que a sua acurácia e precisão se mostraram adequadas para o propósito desta pesquisa. Em seguida, projetamos a interface gráfica do sistema para aplicação de maquiagem virtual. A interface permite efeitos de destaque e sombreamento que simulam os efeitos provocados pela aplicação de produtos reais de maquiagem. Resultados de um teste piloto do nosso protótipo com 32 usuários sugerem que o SelfMakeup, por utilizar toques diretamente na face, oferece uma melhor experiência ao usuário na experimentação de produtos virtuais de maquiagem.

Palavras-chave: interação humano-computador, realidade aumentada, toque na face, maquiagem virtual. 


\section{Abstract}

Borges Soares, Aline de Fátima. SelfMakeup: an Augmented Reality System for Virtual Self-Makeup. 2017. 120 f. Dissertação (Mestrado) - Instituto de Matemática e Estatística, Universidade de São Paulo, São Paulo, 2010.

For centuries, cosmetics have been used in the most diverse societies. However, when it comes to facial makeup, the process of choosing a product is still a challenge because it is a manual work that takes time, to consumes the makeup itself and other materials for application and cleaning. This manual process also makes it difficult to experiment a number of different products due to the need to clean the face to remove a previously applied product. Thus, a makeup simulation system using augmented reality can facilitate this process, allowing experimentation with the combination of products and the comparison of the results, as well as allowing to experience the products virtually and remotely, through the internet for example. Existing works on this theme allow the user to apply the makeup on a photo or even a video of the user himself by means of a mouse or touch of a finger on a touch-sensitive monitor, as if the user applied makeup on a third person. In this dissertation we propose the development of SelfMakeup, an augmented reality system that allows the self-application of virtual makeup by means of touches made directly on the face, rather than touches on the monitor. Our hypothesis is that this interaction form is more natural and gives the user a better experience when testing virtual make-up products. The first step in enabling SelfMakeup was the development of a method to estimate the applicator touch position on the face using an RGBD camera. We performed tests to evaluate the performance of this method and verified that its accuracy and precision was adequate for the purpose of this research. Next, we designed the graphical interface of the system for applying virtual makeup. The interface allows highlighting and shading effects that simulate the effects of real makeup products. Results from a pilot experiment of our prototype with 32 volunteers suggest that SelfMakeup, by using touches directly on the face, provides a better user experience to try on virtual makeup products.

Keywords: human computer interaction, augmented reality, facial touch, virtual makeup. 


\section{Sumário}

Lista de Figuras

Lista de Tabelas $\quad$ x

1 Introdução 1

1.1 Motivação . . . . . . . . . . . . . . . . . . . . . . . . 1

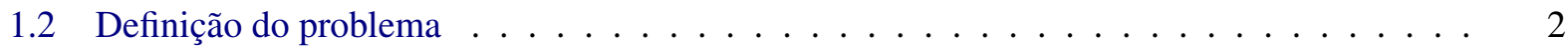

1.3 Objetivos ............................. 2

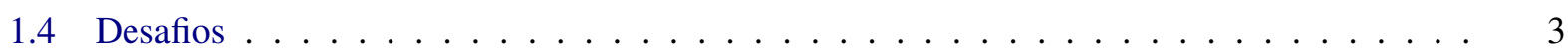

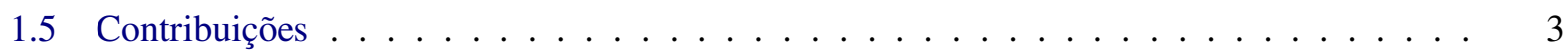

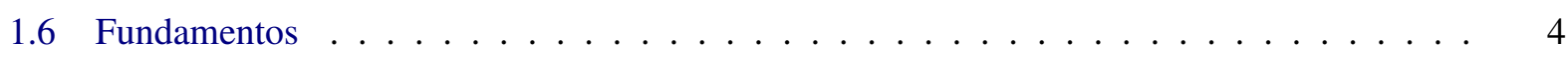

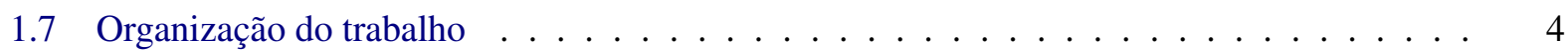

2 Revisão bibliográfica $\quad 6$

2.1 Métodos para maquiagem virtual . . . . . . . . . . . . . . . . . . 6

2.2 Sistemas com interação 3D . . . . . . . . . . . . . . . . . . . . . . . 13

2.2.1 Trabalho não acadêmico . . . . . . . . . . . . . . . . . . . . . 19

2.3 Sistemas de aplicação de maquiagem virtual . . . . . . . . . . . . . . . . . . . . . . . 19

2.3.1 Trabalhos não acadêmicos . . . . . . . . . . . . . . . . . . . . 20

2.4 Estimativa da posição das mãos e superfícies interativas . . . . . . . . . . . . . . 26

2.5 Discussão . . . . . . . . . . . . . . . . . . . . . . . . . . 29

3 Design do SelfMakeup $\quad 3$

3.1 Componentes da interface . . . . . . . . . . . . . . . . . . . . . 34

3.1.1 Sensor RGBD . . . . . . . . . . . . . . . . . . . . 34

3.2 Interface gráfica . . . . . . . . . . . . . . . . . . . . . . . 36

3.3 Módulo de processamento . . . . . . . . . . . . . . . . . . . . . 36

3.3.1 Gerenciador das informações da face . . . . . . . . . . . . . . . . 37

3.3.2 Gerenciador do evento de toque facial . . . . . . . . . . . . . . . . . 40

3.3.3 Maquiagem virtual . . . . . . . . . . . . . . . . . . 48

4 Protótipo do SelfMakeup $\quad \mathbf{5 3}$

4.1 Interação . . . . . . . . . . . . . . . . . . . . . . . 53 
5 Experimento piloto $\quad \mathbf{5 6}$

5.1 Design do protocolo experimental . . . . . . . . . . . . . . . . . 56

5.1 Materiais e métodos ....................... 57

5.2 Análise dos resultados . . . . . . . . . . . . . . . . . . . 57

5.2 .1 Caracterização da amostra . . . . . . . . . . . . . . . . 57

5.2.2 Fatores associados à experiência dos participantes na automaquiagem usando pro-

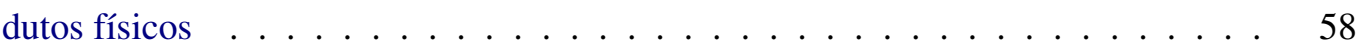

5.2.3 Fatores relacionados à ordem de utilização dos modos de interação com o SelfMakeup 62

5.2.4 Comparando os dois modos de interação . . . . . . . . . . . . . . . . . 62

5.2 .5 Discussão . . . . . . . . . . . . . . . . . . . . 67

6 Conclusão $\quad 69$

$\begin{array}{lll}\text { A Equações para os pontos fiduciais } & 71\end{array}$

B Instruções para o experimento piloto com o SelfMakeup 73

C QUESTIONÁRIO

$\begin{array}{ll}\text { Referências Bibliográficas } & \mathbf{7 6}\end{array}$ 


\section{Lista de Figuras}

2.1 Imagem modelo sem maquiagem A e imagem modelo com maquiagem $A^{*}$. Imagens retiradas de Tong et al. (2007). . . . . . . . . . . . . . . . . . . . .

2.2 Imagem modelo sem maquiagem $\mathrm{A}$, imagem modelo com maquiagem $\mathrm{A}^{*}$ e imagem alvo com maquiagem $\mathrm{B}^{*}$. Imagens retiradas de Tong et al. (2007). . . . . . . . . . . . . . .

2.3 (a) Imagem alvo. (b) Imagem modelo com o estilo de maquiagem a ser transferido. (c) Resultado da transferência de maquiagem (Guo e Sim, 2009). Imagens retiradas de (Guo e Sim, 2009) . . . . . . . . . . . . . . . . . . . . . .

2.4 Nessa imagem, a primeira linha apresenta modelos faciais sem maquiagem, a segunda maquiagens sugeridas de acordo com um mapa adquirido de uma maquiagem feita por um artista exibida na terceira linha. A quarta linha apresenta a maquiagem que mais combina, por comparação. Esses exemplos de transferência de maquiagem foram retirados de Scherbaum et al.

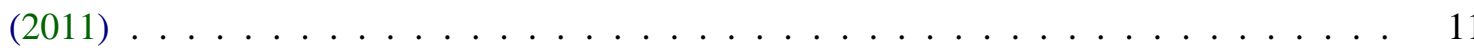

2.5 Resultado da simulação da interação da maquiagem com a pele no sistema de Jang et al. (2013). Imagem retirada de Jang et al. (2013). . . . . . . . . . . . . . . . . . . . .

2.6 Comparativo feito por Campos (2014) da simulação de batom, sombra e base. O lado esquerdo da explicita a imagem original e o direito a imagem resultante da simulação de aplicação de maquiagem. Imagem retirada de Campos (2014) . . . . . . . . . . . . . .

2.7 Interface Gráfica de Usuário do sistema proposto por Kim e Choi (2007). Imagem retirada de Kim e Choi (2007). . . . . . . . . . . . . . . . . . . . . . . .

2.8 Imagem retirada de Kim e Choi (2008) apresentando a tela de simulação do sistema pro-

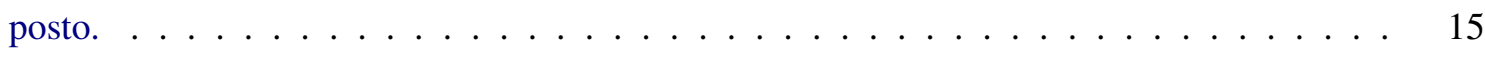

2.9 Imagem retirada de Iwabuchi et al. (2009) apresentando a Interface do sistema SMM. . . 15

2.10 Imagem de Rahman et al. (2010) explicitando a Interface de usuário do sistema SIM. . . . 17

2.11 Interface do sistema proposto por Hanafusa et al. (2010) voltado para deficientes visuais. Imagem retirada de Hanafusa et al. (2010). . . . . . . . . . . . . . . . . . . . .

2.12 Interface Gráfica de Usuário do sistema proposto por Hanafusa et al. (2010). Imagem retirada de Hanafusa et al. (2010). . . . . . . . . . . . . . . . . . . . . . . . . . .

2.13 Interface do SMS proposta por Nakagawa et al. (2011). Imagem retirada de Nakagawa et al.

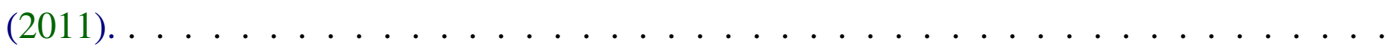

2.14 Interface do SMS que possibilita a visualização das informações do histórico de um usuário na internet. Imagem retirada de Nakagawa et al. (2011). . . . . . . . . . . . . . .

2.15 Interface de Usuário do Sistema de Simulação de Maquiagem da Natura. Essa imagem foi retirada do vídeo sobre esse sistema disponível no link https://www.youtube.com/watch?v=

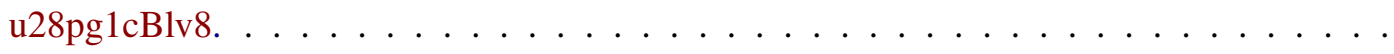


2.16 Interface do sistema de simulação de maquiagem proposto por Campos (2014), contendo um monitor sensível a toque e um Microsoft Kinect. Imagem retirada de Campos (2014).

2.17 Imagem do Sistema de Simulação da Shiseido retirada do vídeo disponível no link https: //www.youtube.com/watch?v=R5zZ5qZP5Ok. . . . . . . . . . . . . . . .

2.18 Interface Gráfica de Usuário do aplicativo YouCam Makeup obtida durante a utilização desse aplicativo. . . . . . . . . . . . . . . . . . . . .

2.19 Imagem da Interface do aplicativo Modiface Live, composta pela imagem do usuário e pelas funcionalidades de cores a serem selecionadas de estilos pré-definidos de maquiagem a serem simulados. Essa imagem foi retirada do site http://modiface.com/. . . . . . . . . . .

2.20 Interface Gráfica de Usuário disponibilizada pela Modiface em seu site. Essa imagem foi retirada do site http://modiface.com/. . . . . . . . . . . . . . . . . . . .

2.21 Resultado da simulação de aplicação de maquiagem obtida durante a utilização do sistema de simulação do site da Modiface. Essa imagem foi retirada do site http://modiface.com/. .

2.22 Interface Gráfica de Usuário do sistema de simulação de maquiagem do site da Modiface contendo a apresentação das funcionalidades de visualização dos produtos semelhantes aos utilizados na simulação. Essa imagem foi retirada do site http://modiface.com/. . . . . . .

2.23 Imagem obtida no vídeo http://modiface.com/news.php?story=540 da Interface Gráfica de Usuário do sistema da Sephora. . . . . . . . . . . . . . . . . . . . .

2.24 Interface do sistema de espelho aumentado para sugestão de maquiagem proposto pela Panasonic retirada do vídeo https://www.youtube.com/watch?v=pJubKcmsFQ4 . . . . . . . .

2.25 Imagem da interação do usuário com o sistema da Panasonic por meio de um tablet retirada do vídeo https://www.youtube.com/watch?v=pJubKcmsFQ4 . . . . . . . . . . . . .

2.26 Imagem do espelho aumentado que exibe o resultado da simulação de aplicação de maquiagem obtida no vídeo https://www.youtube.com/watch?v=pJubKcmsFQ4 . . . . . . . . .

2.27 Imagem obtida durante a simulação de maquiagem no site da Avon e que apresenta a interface desse sistema de simulação disponível em: http://www.br.avon.com/PRSuite/avon_

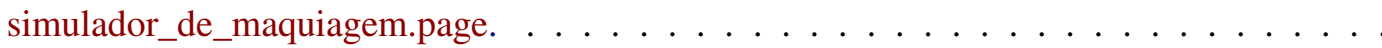

2.28 Sistema de simulação de maquiagem da Mary Kay contido em seu site: http://www.marykay. com.br/pt-br/tips-and-trends/makeover-and-beauty-tools/virtual-makeover. Imagem obtida durante a utilização do sistema. . . . . . . . . . . . . . . . . . . . .

3.1 Arquitetura do SelfMakeup, composta por componentes da interface, interface Gráfica e módulo de processamento. . . . . . . . . . . . . . . . . . . .

3.2 Pontos fiduciais da face fornecidos pelo módulo de rastreamento da face do SDK do RealSense. Imagem retirada de RealSense (2016) . . . . . . . . . . . . . . . . . .

3.3 Mapa do modelo facial $M_{\text {map }}$ contendo 124 triângulos no espaço facial normalizado 2D. Os pontos fiduciais da face em azul são os pontos fornecidos pelo SDK do RealSense. Os pontos

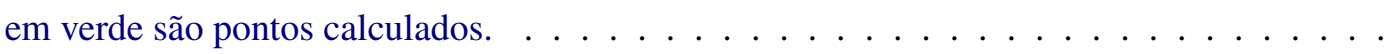

3.4 Imagem que representa o processo de transformação das coordenadas de um ponto $p_{i n}(x, y)$ de $F_{\text {map }}$ para um ponto $p_{\text {out }}(u, v)$ em $M_{\text {map }}$. Nessa imagem, $p_{\text {in }}$ está situado em $t_{i}^{\prime}$, que é formado por vértices que representam os pontos fiduciais 1 , 88 e 85 e possui como correspondente $t_{i}$. Assim, as coordenadas dos vértices 1,88 e 85 de $F_{\text {map }}$ e de $M_{\text {map }}$ são utilizadas para obter a transformação afim que será aplicada a $p_{i n}(x, y)$ para encontrar as coordenadas

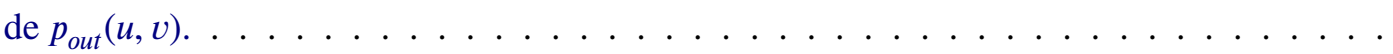


3.5 Imagem que representa o processo de transformação de uma textura com coordenadas $(u, v)$ para uma textura com coordenadas $(x, y)$ de acordo com a pose e expressão facial do usuário, utilizando as informações das transformações de $M_{\text {map }}$ para $F_{\text {map }} \ldots \ldots \ldots \ldots$

3.6 Imagem que apresenta a dispersão da posição estimada para cada toque facial, em cada uma das cinco sessões. Os círculos amarelos representam a posição dos alvos fixados na face. .

3.7 Erro médio do eixo U, do eixo $\mathrm{Y}$ e a magnitude do erro por evento de toque, em coordenadas do espaço facial normalizado. . . . . . . . . . . . . . . . . 45

3.8 Erro médio do eixo $\mathrm{U}$, do eixo $\mathrm{Y}$ e de ambos os eixos. . . . . . . . . . . . . . . 46

3.9 Erro médio em cada uma das sessões considerando cada um dos alvos. . . . . . . . . . . . . 46

3.10 Erro médio em para cada um dos alvos. . . . . . . . . . . . . . . . . 47

3.11 Erro médio em cada eixo para cada um dos sexos. . . . . . . . . . . . . . . . 48

3.12 Paralelogramo $P$ criado para preencher $m_{\text {asc }}$ na região da máscara compreendida entre $p_{0}$ e $p_{1}$. 49

4.1 Cenário no qual o usuário vai iniciar a autoaplicação de maquiagem virtual. . . . . . . . . 54

4.2 Cenário no qual o usuário está efetuando a autoaplicação de maquiagem virtual tocando em

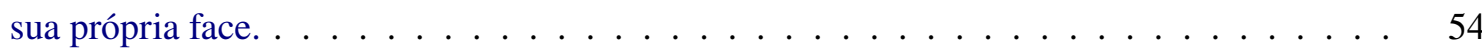

4.3 Cenário no qual o usuário parou de tocar em sua face com o aplicador, interrompendo o processo de aplicação de maquiagem virtal. . . . . . . . . . . . . . . 55

4.4 Cenário no qual o usuário está visualizando os resultados da aplicação de maquiagem virtual e comparando duas cores de semba. . . . . . . . . . . . . . . . .

5.1 Resultado experimental para a relação entre a experiência em anos dos participantes e os níveis em que foi natural interagir com o SelfMakeup no modo tocando a tela expressados por meio de uma escala Likert. Para cada grupo é mostrado como extremos os níveis máximo e mínimo de naturalidade de interação, os quartis inferior e superior como sendo extremos da caixa sombreada e a mediana como uma linha dentro da caixa. . . . . . . . . . . . . .

5.2 Resultado experimental do efeito significativo entre o nível de contentamento dos participantes em relação a habilidade na automaquiagem e a precisão na autoaplicação de maquiagem virtual no modo tocando na tela. Para cada grupo é mostrado como extremos os níveis máximo e mínimo de precisão expressados pelos participantes, os quartis inferior e superior como sendo extremos da caixa sombreada e a mediana como uma linha dentro da caixa. . .

5.3 Resultado experimental do efeito significativo entre o tempo de experiência dos participantes na automaquiagem e a precisão na autoaplicação de maquiagem virtual no modo tocando na tela. Para cada grupo é mostrado como extremos os níveis máximo e mínimo de precisão expressados pelos participantes, os quartis inferior e superior como sendo extremos da caixa sombreada e a mediana como uma linha dentro da caixa. . . . . . . . . . . . . . .

5.4 Resultado experimental do efeito significativo entre o modo de interação em que a sessão orientada terminou e o nível em que os participantes acharam agradável autoaplicar maquiagem virtual tocando na face. Para cada grupo é mostrado como extremos os níveis máximo e mínimo em que o modo de interação tocando na face foi agradável, os quartis inferior e superior como sendo extremos da caixa sombreada e a mediana como uma linha dentro da caixa.

5.5 Opinião dos participantes sobre o nível em foi agradável, fácil, natural e preciso autoaplicar maquiagem virtual usando os dois modos de interação. . . . . . . . . . . . . . . . . . . . 
5.6 Votos dos trinta e dois participantes (100\%) sobre o modo de interação que foi mais fácil, mais rápido, mais preciso e mais natural. São mostrados também os votos para o modo de interação que proporcionou maior satisfação com os resultados da autoaplicação de maquiagem virtual, para o modo que seria escolhido, caso possível e para o modo que realmente foi utilizado na sessão livre. . . . . . . . . . . . . . . . . . . . . .

5.7 Opinião dos participantes sobre características que consideraram interessantes ao interagir com o AutoMakup no experimento piloto. As características representadas em tons de roxo são referentes aos dois modos de interação e as que estão em tons de verde são relacionadas ao modo de interação tocando na face. . . . . . . . . . . . . . . . . . . .

5.8 Sugestões dos participantes de melhorias que consideram importantes. As características representadas em tons de roxo são referentes aos dois modos de interação e as que estão em tons de verde são relacionadas ao modo de interação tocando na face. A parte cinza representa os participantes que não opinaram. . . . . . . . . . . . . . . . . 


\section{Lista de Tabelas}

2.1 Comparativo dos métodos de simulação de transferência e aplicação de maquiagem. . . . . 30

2.2 Comparativo das características dos trabalhos e sistemas investigados. . . . . . . . . . . . 31

3.1 Caso de uso essencial para a autoaplicação de maquiagem virtual por meio de toques na face 34

3.2 Comparativo das principais características dos sensores Microsof Kinect e Intel RealSense. As informações foram retiradas do site dos respectivos fabricantes: https://msdn.microsoft. com/en-us/library/jj131033.aspx e https://software.intel.com/en-us/realsense/devkit. . . . 36

5.1 Perfil dos participantes do experimento piloto . . . . . . . . . . . . . . . . . 59 


\section{Capítulo 1}

\section{Introdução}

\subsection{Motivação}

Durante séculos, a maquiagem tem sido utilizada em todo mundo nas mais diversas sociedades e se faz cada vez mais presente no cotidiano das pessoas. Maquiagem facial é uma forma de mudar a aparência da face, modificando as propriedades ópticas e de textura da pele e pode ser utilizada em diversos contextos sociais, como para compor a personalidade de um artista ou modelo, para disfarçar procedimentos médicos e até mesmo para entretenimento. No entanto, o processo de escolha de um produto ou maquiagem adequados ao gosto e ao tipo e cor de pele ainda é um desafio, porque a experimentação de maquiagem facial real é trabalhosa e requer o uso de muitos produtos, como a própria maquiagem, produtos de limpeza, aplicadores, etc., o que resulta em gastos. Assim, um sistema virtual de aplicação de maquiagem que usa a realidade aumentada oferece várias vantagens ao processo de experimentação, permitindo que o usuário visualize os resultados de forma rápida e sem desperdícios.

Um sistema para aplicação de maquiagem virtual pode ser útil em vários contextos. Para lojas de produtos de maquiagem, esse tipo de sistema é interessante porque permite aos consumidores experimentar virtualmente, reduzindo custos com produtos de teste em lojas físicas e possibilitando a experimentação online. Para maquiadores profissionais, é uma forma de mostrar para os clientes os resultados da aplicação de uma combinação de produtos antes mesmo da aplicação e possibilita a experimentação de várias composições. Para usuários domésticos, um sistema de maquiagem virtual auxilia na visualização e escolha de um ou mais produtos adequados à ocasião, ao preço e a outros parâmetros envolvidos em compras online.

Exemplos comerciais de sistemas de maquiagem virtual são os aplicativos Modiface e YouCam Makeup, que já alcançaram a casa de milhares de downloads em todo o mundo. De acordo com a Forbes, esse tipo de sistema tem sido alvo de investimento de muitos fabricantes de produtos de maquiagem como Sephora, Natura, Mary kay, Avon, L’Oréal, Clinique, Shiseido e outros. ${ }^{1}$ Existem também muitos sistemas de maquiagem descritos na literatura, como será apresentado no Capítulo 2. Entretanto, apesar dos resultados interessantes, ainda há muitos desafios e limitações, particularmente no que se refere à falta de realismo na renderização da maquiagem virtual e à experiência do usuário na interação com esse tipo de sistema, foco desta investigação.

\footnotetext{
${ }^{1}$ https://www.forbes.com/sites/deborahweinswig/2016/07/28/beauty-shopping-augmented-with-new-mobile-apps. Último acesso: 20 de julho de 2017.
} 


\subsection{Definição do problema}

Uma característica dos sistemas atuais para maquiagem virtual é a aplicação usando mouse ou tela sensível ao toque. Embora seja exibida na tela a imagem da própria face do usuário, ele deve efetuar ações empregadas para aplicar maquiagem no rosto de outra pessoa. Isso significa que o uso da metáfora de espelho virtual é contraditória, pois uma experiência mais natural seria que o usuário tocasse sua própria face em vez da tela.

A experiência do usuário é essencial para o design de interação, pois leva em conta como um produto se comporta e é usado por pessoas no mundo real. De acordo com Hassenzahl (2012), para proporcionar ao usuário uma boa experiência, é preciso remover as barreiras de entrada para um sistema; diminuir a lacuna existente entre o conhecimento atual do usuário e o conhecimento alvo; tornar as informações fáceis de encontrar e compartilhar; e apresentar conteúdo em formatos compreensíveis. Nesse sentido, há diversos aspectos que devem ser considerados no design de sistemas interativos, dentre os quais a funcionalidade e a usabilidade.

A funcionalidade conglomera metodologias a fim de definir "o que" e "como" fazer (Hassenzahl, 2012). Enquanto a usabilidade visa assegurar que produtos interativos sejam fáceis de aprender a usar, eficazes e agradáveis na perspectiva do usuário. Isso implica em otimizar as interações estabelecidas pelas pessoas com sistemas interativos (Rogers et al., 2013).

Em alguns contextos, para adequar a escolha das interfaces de um sistema às necessidades do usuário, com vista em sua experiência na utilização desse sistema, são utilizados modelos conceituais. As metáforas de interface são um tipo de modelo conceitual e objetivam fornecer entidades familiares que permitam às pessoas compreenderem facilmente o funcionamento de um sistema e saberem quais ações podem ser realizadas para utilizarem determinada funcionalidade. Entretanto, a utilização de metáforas deve ser cuidadosa pois pode contrariar a expectativa do usuário sobre como o sistema deve se comportar (Rogers et al., 2013).

Ainda no contexto de propiciar ao usuário a interação de modo mais natural, o propósito de sistemas de realidade aumentada é conservar o usuário em seu ambiente físico e trazer o ambiente virtual para seu espaço, dispensando treinamento e adaptação (Tori et al., 2006). Assim, é importante que o design de interação de um sistema de realidade aumentada para a autoaplicação de maquiagem virtual leve em conta a forma com que esse processo é realizado no mundo real.

\subsection{Objetivos}

O processo de automaquiagem com produtos físicos é efetuado livremente por meio do contato dos dedos das mãos com a face, com utilização de pincéis ou diretamente com o aplicador de um produto. Desse modo, este trabalho tem como hipótese que ao autoaplicar maquiagem virtual tocando na sua própria face, o usuário tem uma experiência melhor do que utilizando toques na tela. Como não foram encontrados sistemas que proporcionam ao usuário esse tipo de interação, este estudo teve por objetivo arquitetar e implementar um sistema de realidade aumentada para autoaplicação de maquiagem virtual por meio de toques na face. Nessa direção, os objetivos específicos dessa pesquisa foram:

- investigar e definir uma abordagem para detecção de toque facial e avaliar a adequação dessa abordagem para utilização em sistemas de automaquiagem virtual em tempo real.

- investigar e definir um método para aplicação de maquiagem virtual na imagem do usuário em tempo real. 
- validar a arquitetura e implementação do sistema de realidade aumentada para autoaplicação de maquiagem virtual.

\subsection{Desafios}

No âmbito de proporcionar ao usuário uma forma natural de interação com um sistema para autoaplicação de maquiagem virtual, o primeiro aspecto considerado no processo de design da solução para detectar toques faciais foi que, com base nos cenários de automaquiagem com produtos físicos, o aplicador pode ser de diversos tamanhos, formas e cores. Então, foi necessário arquitetar e construir uma solução capaz de detectar uma grande variedade de tipos de aplicadores mantendo a acurácia durante a interação. Ainda, construir uma abordagem generalizável, em tempo real, foi um grande desafio.

Além da diversidade de aplicadores, foi preciso levar em consideração que, no momento em que o aplicador toca a face para aplicar a maquiagem virtual, uma parte da face é ocultada, o que dificulta a estimativa da posição do toque com acurácia e precisão.

Apesar do foco deste trabalho não ter sido no realismo da renderização, essa etapa também é importante. Assim, diante do fato de que o usuário pode mover a cabeça e mudar a expressão facial ao longo dos quadros, efetuar a renderização da maquiagem virtual em uma região facial com acurácia e em tempo real consistiu em outro desafio.

Por fim, unir todas essas características em um sistema que ofereça uma boa experiência de interação ao usuário e tenha desempenho em tempo real utilizando recursos de hardware de baixo custo foi outro grande desafio.

\subsection{Contribuições}

O capítulo 2 apresenta uma revisão dos trabalhos sobre ambientes virtuais para a simulação da aplicação de maquiagem e produtos existentes no mercado. Tais trabalhos não possibilitam ao usuário a experiência de autoaplicar um produto virtual na face, realizando movimentos semelhantes aos empregados no processo de maquiagem facial com produtos físicos. Assim, o presente trabalho contribui, primeiramente, com um método que detecta, em tempo real, o toque de um aplicador físico na face do usuário com acurácia adequada para sistemas de maquiagem virtual. Além disso, contribui com a arquitetura e implementação de um sistema de realidade aumentada denominado SelfMakeup, que proporciona ao usuário:

- tocar na própria face para aplicar maquiagem virtual utilizando um dedo da mão ou qualquer bastão que se assemelhe a pincéis de maquiagem com aproximadamente 15 milímetros de diâmetro;

- aplicar livremente um produto de maquiagem virtual e comparar essa aplicação com a de outros produtos;

- visualizar os resultados da aplicação de produtos virtuais na imagem da sua própria face, em tempo real;

Este estudo contribui ainda com a validação da arquitetura e implementação do SelfMakeup, mostrando a viabilidade de utilização desse sistema para investigar sobre a experiência do usuário. 


\subsection{Fundamentos}

Estabelecido o contexto no qual este trabalho está inserido, é necessário entender alguns conceitos que fundamentam esta investigação e permitem compreender seu desenvolvimento. Em relação à maquiagem, Ferreira (1993) define o termo como o ato ou efeito de maquiar, um conjunto de cosméticos utilizados para maquiar, ou ato que é realizado com o objetivo de alterar superficialmente o aspecto de algo. Em particular, $\mathrm{o}$ ato de maquiar corresponde a aplicar produtos cosméticos na pele para embelezar ou ocultar imperfeições (Ferreira, 1993). No contexto deste trabalho, a maquiagem é responsável pelas alterações de propriedades óticas e de textura da pele, modificando a aparência da pele na imagem do usuário. $\mathrm{O}$ termo maquiagem virtual será empregado para referir a representação de propriedades computacionais relacionadas a maquiagem física.

O termo aplicar, de acordo com Dilguerian (1998), significa por uma coisa sobre outra ou sobrepor. Assim, será utilizado o verbo aplicar para referir ao processo de sobrepor a maquiagem virtual à imagem do usuário, efetuando alterações nessa imagem com o intuito de reproduzir efeitos causados por produtos de maquiagem física. Além disso, a palavra aplicador será empregada para referir ao objeto que toca a superfície facial para escolher a posição de aplicação da maquiagem virtual. Assumir-se-á que esse aplicador será um dedo da mão do usuário ou qualquer bastão que se assemelhe à pincéis comumente usados para a aplicação de maquiagem física.

Diante da proposta desta pesquisa de possibilitar ao usuário aplicar maquiagem virtual tocando na sua própria face, a expressão toque facial será utilizada para fazer alusão à ação de colocar a ponta do aplicador físico em contato com a superfície da face. Além disso, no contexto do presente estudo, a realidade aumentada propicia ao usuário um ambiente de simulação de maquiagem que agrega à imagem original do usuário capturada em tempo real os resultados da simulação de maquiagem.

Atualmente, existem diversos tipos de produtos de maquiagem no mercado e o efeito provocado pela sua aplicação na pele varia de acordo com as características desse produto. Esses efeitos que alteram as propriedades óticas e de textura da pele podem ser simulados virtualmente com a utilização de texturas. Em computação, uma textura é uma função ou imagem que contém informações de refletância que podem ser mapeadas para uma superfície (Shirley e Marschner, 2009). Assim, no contexto deste estudo, cada produto de maquiagem virtual possui uma textura associada denominada maquilet, como definido por (Campos ,2014). Para referir ao conjunto dessas texturas, empregar-se-á o termo maquilets.

No capítulo 2 mostramos que muitos sistemas de maquiagem virtual não possibilitam ao usuário escolher livremente a região facial onde sse deseja aplicar um produto. Isso porque, esses sistemas utilizam estilos pré-definidos de maquiagem, os quais consistem em modelos contendo as áreas faciais e informações sobre os produtos virtuais que devem ser aplicados nessas áreas. Isso significa que um estilo pré-definido contendo sombra, por exemplo, determina as regiões dos olhos que receberão a aplicação virtual produto. Computacionalmente, esses estilos pré-definidos são constituídos de máscaras previamente definidas que delimitam regiões faciais e de dados sobre textura e cor que devem ser mapeados para essas regiões.

\subsection{Organização do trabalho}

Quanto à organização deste trabalho, o capítulo 2 explicita um cenário de trabalhos acadêmicos e sistemas existentes no mercado destinados ao contexto de automaquiagem facial. No capítulo 3 são descritas as características da arquitetura de um sistema de realidade aumentada projetada de acordo com o objetivo deste estudo. A implementação da arquitetura proposta para o sistema de maquiagem virtual SelfMakeup 
são abordadas no capitulo 4. O experimento piloto é descrito no capítulo 5. Por fim, o capítulo 6 apresenta as conclusões e os resultados obtidos com a realização desta pesquisa. 


\section{Capítulo 2}

\section{Revisão bibliográfica}

Considerando a hipótese que norteia esta pesquisa, após a realização de estudos exploratórios, foi efetuada uma revisão da literatura sobre os trabalhos acadêmicos que abordam sobre sistemas que possuem funcionalidades destinadas para contexto de maquiagem. O intuito dessa revisão de literatura foi investigar sobre as formas de interação propostas por esses sistemas e averiguar sobre outros aspectos relacionados à experiência do usuário considerados no design desses sistemas. Além disso, considerando a detecção do toque facial, foram incluídos, nessa revisão, trabalhos acadêmicos que abordam sobre a estimativa da posição das mãos e sobre de superfícies interativas. Assim, este capítulo apresenta os resultados dessa revisão de literatura e, ainda, descreve algumas iniciativas não-acadêmicas.

\subsection{Métodos para maquiagem virtual}

Embora o foco desta pesquisa não seja o realismo na renderização da maquiagem virtual, esse é um fator importante para a experiência do usuário na interação com sistemas voltados para essa finalidade. Os trabalhos existentes na literatura que abordam sobre a simulação de maquiagem podem ser classificados em dois grupos: os que realizam a transferência de maquiagem e os que efetuam a aplicação de maquiagem. Nesta sessão serão apresentados os trabalhos encontrados que pertencem a ambos os grupos.

Dada uma imagem $A$ contendo uma face $F$ sem maquiagem; uma imagem $A$ * contendo uma face $F$ com maquiagem $M$; e uma imagem B contendo uma face $\mathrm{G}$ sem maquiagem, o processo de transferência de maquiagem é definido como a composição de uma imagem $B^{*}$ contendo $G$ com a maquiagem $M$, da mesma forma que $F$ está maquiada em $A *$ (Campos, 2014).

Nesse contexto, Tong et al. (2007) apresentaram um procedimento de transferência de um estilo de maquiagem para a imagem de uma pessoa qualquer, utilizando como base duas imagens de uma pessoa modelo, uma capturada sem maquiagem e outra com maquiagem feita por um artista (Figura 2.1). O objetivo desse artigo foi criar um método para mapear a contribuição da cor da maquiagem considerando a geometria da pele do modelo e da pessoa na imagem a receber a maquiagem.

Para realizar a transferência de maquiagem com realismo, Tong et al. (2007) propuseram que as características como sardas, pintas ou manchas na pele não deveriam ser transferidas do modelo para o alvo e ainda, que, tais imperfeições, se presentes na pele da pessoa da imagem alvo, deveriam permanecer.

O processo de transferência de maquiagem inicia com o cálculo da mudança de cor da pele e condições de iluminação entre as imagens modelo sem e com maquiagem. Em seguida, são realizadas as etapas de pré-processamento; mapeamento da maquiagem; correção de aparência e transferência dos olhos. No préprocessamento são extraídos as sobrancelhas e cílios utilizando o método proposto por Chuang et al. (2001) 


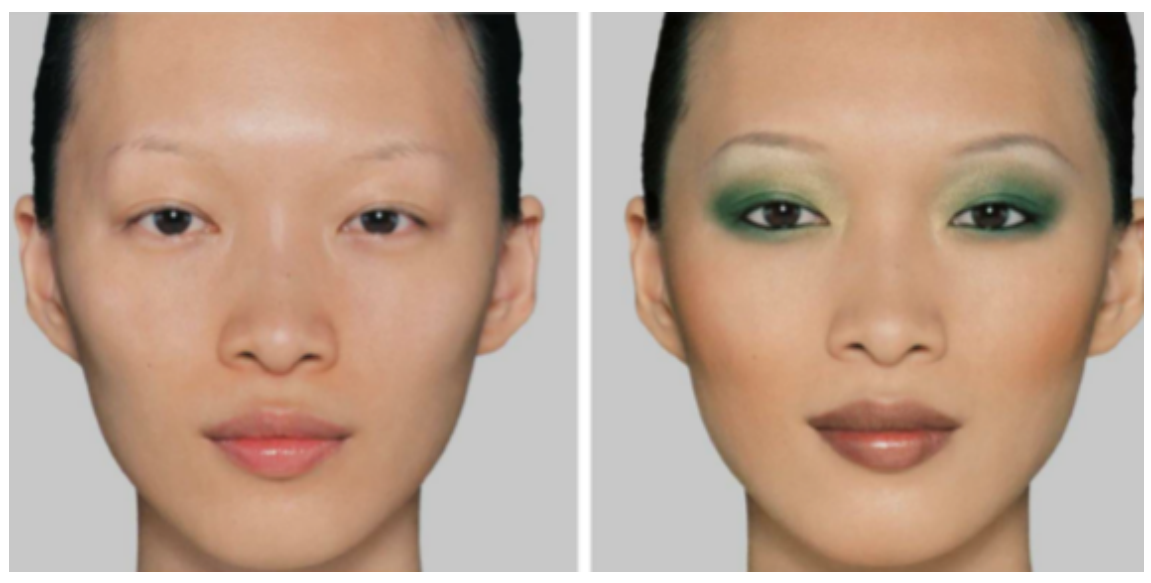

Figura 2.1: Imagem modelo sem maquiagem A e imagem modelo com maquiagem A*. Imagens retiradas de Tong et al. (2007).

e os locais da face em que esses pelos estavam presentes são preenchidos com o uso do algoritmo que Kwatra et al. (2003) propuseram para a síntese de textura fundamentado em corte de grafos. Então, são removidas as imperfeições da pele em todas as imagens $\left(A, A^{*}\right.$ e $\left.B\right)$ com o uso do método Independent Component Analysis (ICA), o qual fornece uma matriz de separação capaz de distinguir os pigmentos da pele facial e consequentemente, manchas e imperfeições que são visíveis pela diferença de pigmentação. Por fim, as faces de todas as imagens $\left(A, A^{*}\right.$ e $\left.B\right)$ são deformadas para acomodarem-se em um modelo canônico de face de acordo com o método Thin Plate Splines.

Ao final do pré-processamento, é realizado o mapeamento da maquiagem computando pixel a pixel das três imagens $\mathrm{A}, \mathrm{A}^{*}$ e $\mathrm{B}$, utilizando a mesma geometria facial $2 \mathrm{D}$ e a ideia de representação intrínseca de Barrow e Tenenbaum (1978). Isso significa que, a transferência de maquiagem representa a mudança de características da pele como cor e refletância. Para tanto, Tong et al. (2007) assumem a pele da face como uma superfície lamberciana, a qual reflete a luz uniformemente em todas as direções.

Considerando que a aplicação de maquiagem poderia acarretar em pequenas mudanças na geometria da face, na etapa de correção de aparência, Tong et al. (2007) consideram que um operador Laplaciano poderia capturar essas alterações e uma constante $\beta$ ficaria responsável por ponderar a intensidade da mudança geométrica transferida de um pixel p da imagem A* para B. Assim, considerando que $a_{p}, a_{p}^{*}$ e $b_{p}$ são, respectivamente, a intensidade de $\mathrm{p}$, a intensidade do pixel $b_{p}$ depois da transferência seria:

$$
\left.\Delta b_{p}^{*}=\Delta\left(\beta b_{p}+(1-\beta) a_{p}^{*}\right)\right)
$$

Na última etapa do processo proposto por Tong et al. (2007), os cílios e as sobrancelhas retirados da imagem original B são transferidos para B*. A Figura 2.2 apresenta um exemplo do resultado desse processo de transferência de maquiagem.

Como conclusões, Tong et al. (2007) colocaram que a transferência de maquiagem realizada pelo procedimento proposto é realizada de maneira a preservar fielmente o tom e textura da pele, além da cor e densidade dos pelos faciais, possibilitando a verificação de diversos estilos e tipos de maquiagem sem a necessidade de aplicar a maquiagem física.

O estudo de Guo e Sim (2009) propõe a transferência de maquiagem para uma face com base na maquiagem aplicada em outra imagem, diferindo do artigo de Tong et al. (2007) ao usar apenas uma imagem modelo. Para tanto, Guo e Sim (2009) utilizaram uma abordagem análoga à maquiagem física, modificando a cor e a textura da pele de acordo com a imagem modelo e conservando a estrutura da face. A Figura 2.3 


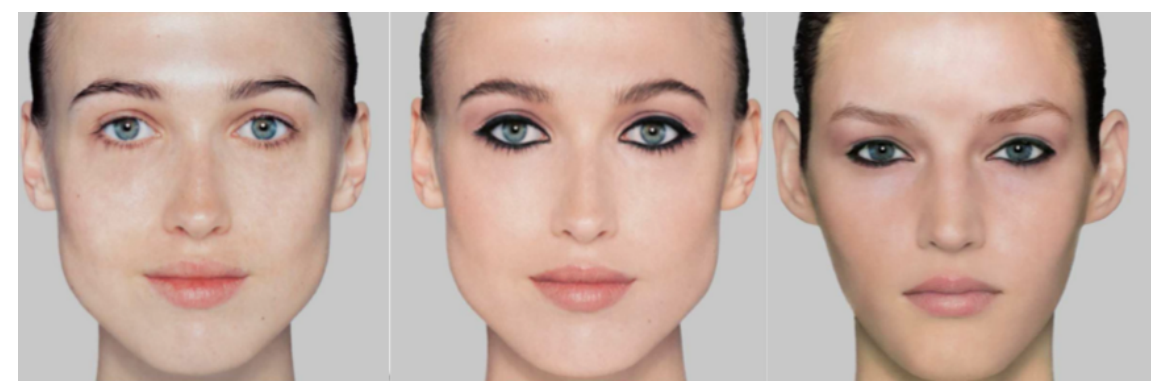

Figura 2.2: Imagem modelo sem maquiagem A, imagem modelo com maquiagem $A *$ e imagem alvo com maquiagem $B^{*}$. Imagens retiradas de Tong et al. (2007).

apresenta a imagem modelo, a imagem alvo e o resultado do processo da transferência de maquiagem.

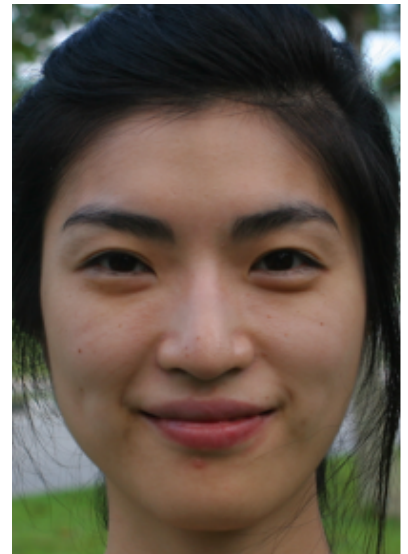

(a)

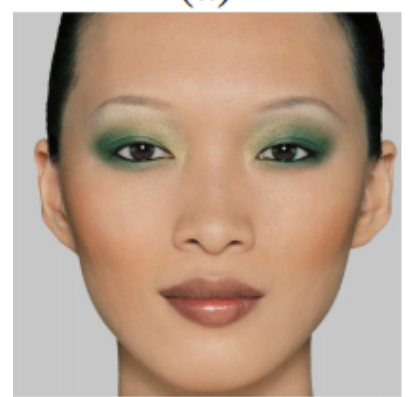

(b)

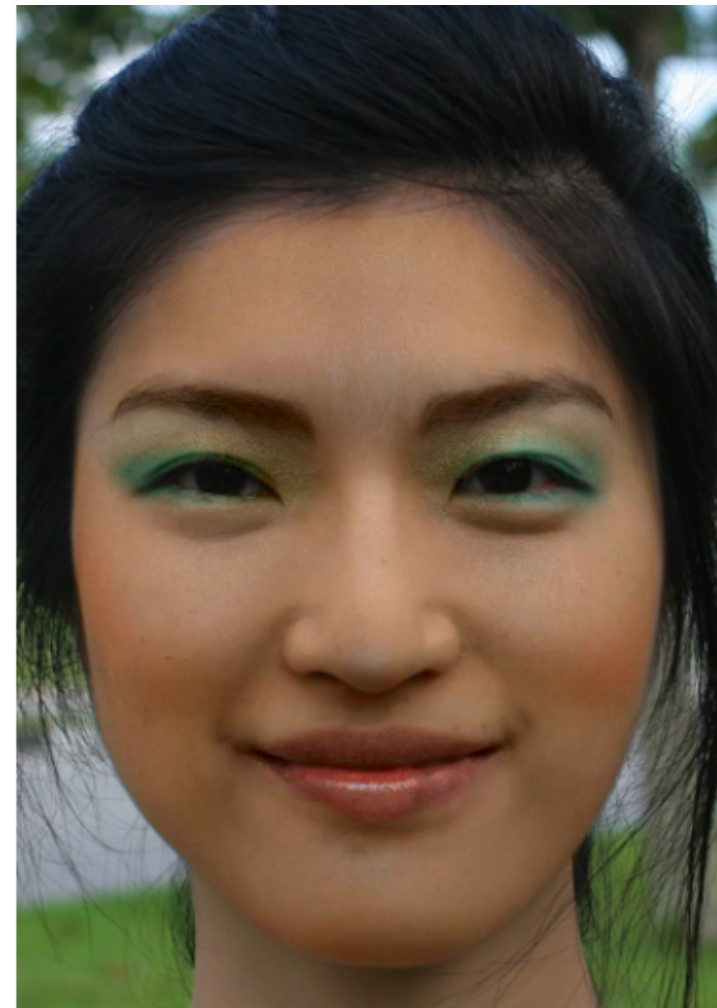

(c)

Figura 2.3: (a) Imagem alvo. (b) Imagem modelo com o estilo de maquiagem a ser transferido. (c) Resultado da transferência de maquiagem (Guo e Sim, 2009). Imagens retiradas de (Guo e Sim, 2009).

Na primeira etapa, são obtidos os 83 pontos de controle da face com o método Active Shape Model (ASM), de Milborrow e Nicolls (2008) (2008), que são, então, ajustados manualmente devido a problemas de precisão acarretados pela maquiagem. Para alinhar esses pontos fiduciais da face da imagem modelo $\mathcal{I}$ com os pontos da imagem alvo $\mathcal{E}$, utilizam Thin Plate Splines de Bookstein (1988), o mesmo método que Tong et al. (2007). Em seguida, esses pontos são divididos em três classes $C_{1}, C_{2}$ e $C_{3}$, de acordo com as características faciais como sobrancelhas, nariz, narinas, lábios, cavidade de boca e restante da face. Desse modo, $C_{1}$ é a região da face excluindo $C_{2}$ e $C_{3}$; $C_{2}$ corresponde à região dos lábios; e $C_{3}$ é a região correspondente aos olhos e a cavidade da boca e não recebe maquiagem.

Depois que as imagens são deformadas para ficarem alinhadas, é realizada a decomposição das imagens em duas camadas, a de cor e a de luminosidade. Na sequência, a camada de luminosidade é decomposta 
em uma camada da estrutura da face e outra de detalhes da pele. Para tanto, inicialmente as imagens são convertidas para o espaço de cor $\mathrm{La}^{*} \mathrm{~b}^{*}$, onde $\mathrm{L}^{*}$ é utilizado para luminosidade e $\mathrm{a}^{*} \mathrm{e} \mathrm{b*}$ para cor. Segundo Guo e Sim (2009), a ideia essencial é efetuar uma suavização na camada de luminosidade preservando as bordas para então obter a camada da estrutura facial. Em seguida, a camada de detalhes é obtida subtraindo a camada de estrutura da camada de luminosidade.

Com as imagens decompostas em camadas, a transferência de maquiagem do processo proposto por Guo e Sim (2009) é realizada em quatro etapas: transferência dos detalhes da pele facial, transferência da cor, transferência de sombreamento e destaque de maquiagem dos lábios. A transferência dos detalhes é realizada calculando uma soma ponderada para obter a camada de detalhes resultante $R_{d}$ de acordo com a equação:

$$
R_{d}=\delta \mathcal{I}_{d}+\delta \mathcal{E}_{d}
$$

onde $\delta_{\mathcal{I}}$ e $\delta_{\mathcal{E}}$ dentam a contribuição de cada imagem e $0 \leq \delta_{\mathcal{I}}, \delta_{\mathcal{E}} \leq 0$.

A cor da camada de cor resultante $R_{c}$ é transferida pixel a pixel, utilizando a equação:

$$
R_{c}(p)= \begin{cases}1-\gamma \mathcal{I}_{c}(p)+\gamma \mathcal{E}_{c}(p) & \text { para } p \in C_{3} \\ \mathcal{I}_{c}(p) & \text { caso contrário }\end{cases}
$$

na qual $p$ é um pixel da imagem e $\gamma$ é responsável por controlar o peso de cada imagem.

Em relação à transferência de sombreamento e destaque, o processo de Guo e Sim (2009) utiliza a camada de estrutura da face, pois é nessa camada que residem os efeitos importantes para a maquiagem. Com o objetivo de conservar características inerentes a face da imagem alvo $\mathcal{I}$, utilizam um método baseado em gradiente, para adicionar somente grande mudanças de $\mathcal{E}_{s}$ para $\mathcal{I}_{s}$, considerando a iluminação uniforme. Assim, o calculo é feito de acordo com a equação:

$$
\nabla R_{s}(p)= \begin{cases}\nabla \mathcal{E}_{s}(p) & \beta(p)\left\|\nabla \mathcal{E}_{s}(p)\right\|>\left\|\nabla \mathcal{I}_{s}(p)\right\| \\ \nabla \mathcal{I}_{s}(p) & \text { caso contrário }\end{cases}
$$

De acordo com Guo e Sim (2009), o processo de transferência de maquiagem labial proposto por eles diferente de outras abordagens pois, em vez de ocultar os detalhes dos lábios, preserva esses detalhes e realça a textura. Para tanto, para cada pixel $p \in \mathcal{I}$, é realizada uma busca pelo pixel $q \in \mathcal{E}$, tal que $\mathcal{E}(q)$, e $\mathcal{I}(p)$ sem o mais similar possível, ao mesmo tempo que $q$ e $p$ sejam o mais próximo possível. Considere $\mathcal{M}$ a região dos lábios depois da aplicação de maquiagem, para cada $p \in c_{2}$ tem-se:

$$
\mathcal{M}(p)=\mathcal{E}(\tilde{q})
$$

onde

$$
\tilde{q}=\arg \max _{q \in C_{2}} \mathcal{G}(|q-p|), \mathcal{G}(|\mathcal{E}(q)-\mathcal{E}(p)|)
$$

na qual $\mathcal{G}$ é a função Gaussiana e para $|\mathcal{E}(q)-\mathcal{E}(p)|$ é utilizada somente a diferença entre os valores do pixel o canal $L^{*}$, após ter sido realizada uma equalização de histograma. Por fim, a região dos lábios de cada canal $\mathrm{L}^{*}, \mathrm{a}^{*}$ e $\mathrm{b}^{*}$ de $\mathcal{M}$ é substituída para o canal respectivo de $\mathcal{R}$. Os resultados apresentados por Guo e Sim (2009) foram analisados qualitativamente e comparados com os resultados de Tong et al. 
(2007). Assim, Guo e Sim (2009) afirmam que o resultado do método proposto, quando comparados com o método de Tong et al. (2007), possui as seguintes vantagens: são mais fiéis ao estilo de maquiagem do modelo; apresentam cores mais vivas; melhoria na preservação da estrutura facial; melhoria da aparência dos lábios. Além disso, em relação ao método de Tong et al. (2007), Guo e Sim (2009) afirmam que seu método difere pelo fato de aprender os efeitos de maquiagem após a sua aplicação, ao passo que o de Tong et al. (2007) aprende a forma com que maquiagem altera os pixels da imagem.

Ainda no contexto de transferência de maquiagem, o trabalho de Scherbaum et al. (2011) apresenta um sistema que sugere um estilo de maquiagem para uma determinada face de usuário, com base em imagens presentes em um banco de dados. Para criar o modelo 3D da face do usuário, esse sistema captura imagens utilizando uma câmera de alta resolução e raios de luz nas direções X, Y e Z. O processo de aplicação da maquiagem nesse modelo 3D é feito com a transferência de maquiagem da imagem selecionada como ideal no banco de dados. Para o processo de transferência, a imagem da face é decomposta em camadas, quais sejam: cor difusa em RGB, normal em 3D, posição em 3D, brilho, especularidade e espalhamento. Assim como o método de Tong et al. (2007), o proposto por Scherbaum et al. (2011) utilizam duas imagens modelo de uma mesma pessoa, uma com maquiagem $\mathcal{Y}$ e outra sem maquiagem $\mathcal{X}$. Nesse sentido, a maquiagem é denotada por:

$$
M_{X \rightarrow Y}=A_{X} / A_{Y}
$$

Então, para aplicar maquiagem:

$$
A_{Y}=A_{X} * M_{X \rightarrow Y}=A_{X} / A_{Y}
$$

Segundo Scherbaum et al. (2011), a mudança mais importante ocorre na camada de cor difusa, assim a equação (2.8) é usada nos três canais RGB. Em relação ao cálculo para a camada de espalhamento, foi efetuada uma multiplicação monocromática e para as camadas de brilho e especularidade, uma soma. Levando em conta que os autores não consideram rugas e manchas na ple antes do processo de transferência, essas características são transferidas também. Desse modo, para resolver esse problema foram utilizadas dois métodos, o Principal Analalysis Component (PCA) e o Eigenfaces de Turk e Pentland (1991), criando eigen-maquiagens, nas quais os dez menores autovalores correspondem as variações de características faciais e os dez maiores relativos as variações ocasionadas pela maquiagem. Desse modo, utiliza-se apenas os responsáveis pela maquiagem.

O resultado é, então, apresentado em uma tela 2D. A Figura 2.4 apresenta exemplos de resultados de transferência de maquiagem apresentados por Scherbaum et al. (2011).

O principal desafio, conforme apresentado por Scherbaum et al. (2011), foi sugerir a maquiagem ideal ao usuário. Concluíram que a ideia proposta pode ser utilizada também por outras aplicações na mesma linha. Para trabalhos futuros, indicaram a inserção de funcionalidades que levem em consideração outros aspectos como: a cor da pele; estilo do indivíduo; e, ainda, a ocasião de utilização da maquiagem.

O trabalho de Dhall et al. (2009) apresenta um procedimento para aplicação de maquiagem automático fundamentado no gênero e cor de pele de uma pessoa. Esse procedimento inicia com a segmentação da face na imagem por cor da pele e, então, para encontrar a região dos olhos e boca, utiliza-se Viola-Jones (Viola e Jones, 2001) e Active Shape Models (?). Em seguida, com o objetivo de remover marcas na pele, é aplicada uma suavização Gaussiana e depois uma dilatação. Assim, a imagem está pronta para receber a maquiagem, que é aplicada modificando os valores de matiz e saturação do espaço de cor HSV. 

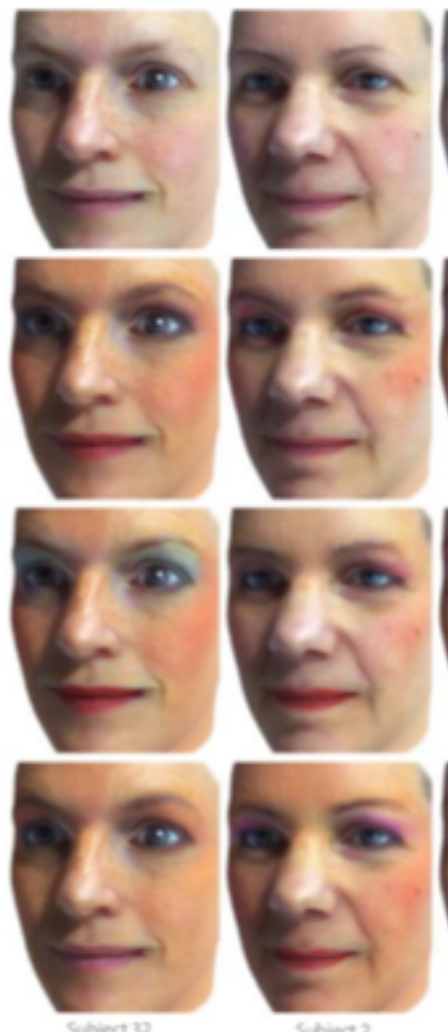

Subieat 2
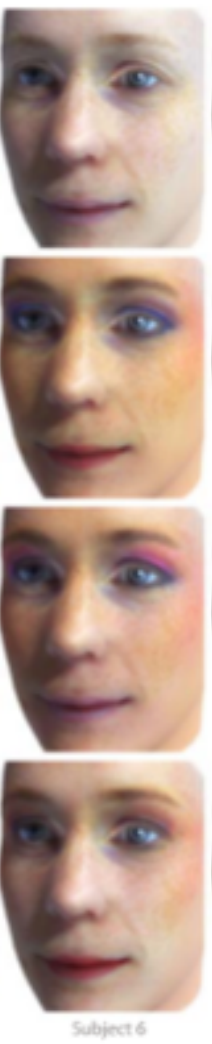
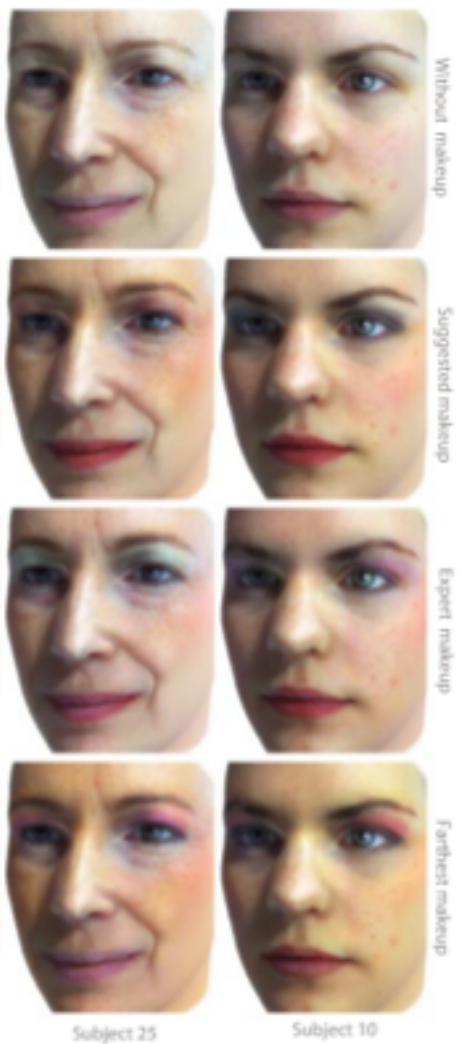

Figura 2.4: Nessa imagem, a primeira linha apresenta modelos faciais sem maquiagem, a segunda maquiagens sugeridas de acordo com um mapa adquirido de uma maquiagem feita por um artista exibida na terceira linha. A quarta linha apresenta a maquiagem que mais combina, por comparação. Esses exemplos de transferência de maquiagem foram retirados de Scherbaum et al. (2011)

Para aplicar a maquiagem nos lábios, é utilizada a equação:

$$
p_{\text {novoRBG }}=p_{\text {antigoRGB }} *(\max -\alpha)+\operatorname{labioRGB} * \alpha
$$

na qual max não foi definido no artigo, labioRGB é a cor a ser aplicada nos lábios de acordo as informações presentes no banco de dados, assim como $\alpha$.

O trabalho de Kim e Choi (2008), já explicitado na sessão 2.3 no contexto de sistemas com interação do usuário para a simulação de aplicação de maquiagem sem estilos pré-definidos, aborda sobre a aplicação de maquiagem realizando a combinação da cor da maquiagem almejada com as cores da textura da pele, utilizando a média ponderada da equação:

$$
C=C_{b}(1-\beta)+C_{p} \beta
$$

na qual C é a cor resultante, $C_{b}$ é a cor da pele facial, $C_{p}$ é a cor da maquiagem e $\beta$ é a intensidade da pressão exercida pelo usuário no dispositivo háptico.

O estudo de Huang et al. (2013) teve como objetivo simular de forma realista a aplicação do cosmético na pele do usuário por meio da renderização de um modelo facial 3D que leva em consideração a interação da luz com a pele e com o cosmético. Para a captura da geometria e aparência dos modelos, foi utilizado um equipamento especial denominado Light Stage X. Depois de construído o modelo facial 3D, esse sistema permite a aplicação de base, blush e batom, além da modificação da maquiagem aplicada em tempo real. Para tanto, utilizaram o modelo Kubelka-Munk de Kortüm (2012) para calcular a transmitância total quando a 
luz passa através das camadas de cosméticos e o método screen-space de Jimenez et al. (2009) para simular o espalhamento dos raios de luz na pele humana.

As características da tela de apresentação desses resultados não foram especificadas.

Como limitações, Huang et al. (2013) apontaram: a apresentação da simulação de aplicação de cosméticos com alta translucidez; a diferenciação do estado líquido, creme ou pó da maquiagem; e, ainda, consideração do componente de perolização da maquiagem. Em relação a trabalhos futuros, indicaram simulações que contemplem as limitações acima citadas e substituição de algumas ferramentas 2D utilizadas por 3D, como a malha da maquiagem aplicada no modelo facial 3D.

Jang et al. (2013) apresentam um sistema para simular procedimentos de maquiagem em avatares renderizados com o objetivo de tornar mais realística a cor resultante da aplicação da maquiagem em tom de pele específico. A captura de imagens pelo sistema é feita com um escâner 3D. Inicialmente, ocorre a calibração de cores do sistema com a utilização de LEDs das três câmeras do escâner. Em seguida, efetua a estimativa das cores da pele do avatar com base em dados de espectro da pele e do cosmético, após a aplicação de cosméticos específicos.

Jang et al. (2013) realizaram um experimento com vinte participantes para avaliar o erro do espectro de cor de doze tons de base, blush e batom. Para exibir o efeito dessa simulação (Figura 2.5) foram utilizados dois tablets e dois notebooks nos experimentos. Os resultados do experimento mostraram que o método proposto tem a capacidade de simular a aplicação dos produtos avaliados na pele e que as telas dos tablets e notebooks utilizados apresentam uma diferença de cor que fica abaixo do valor limite de perceptibilidade de imagens complexas.
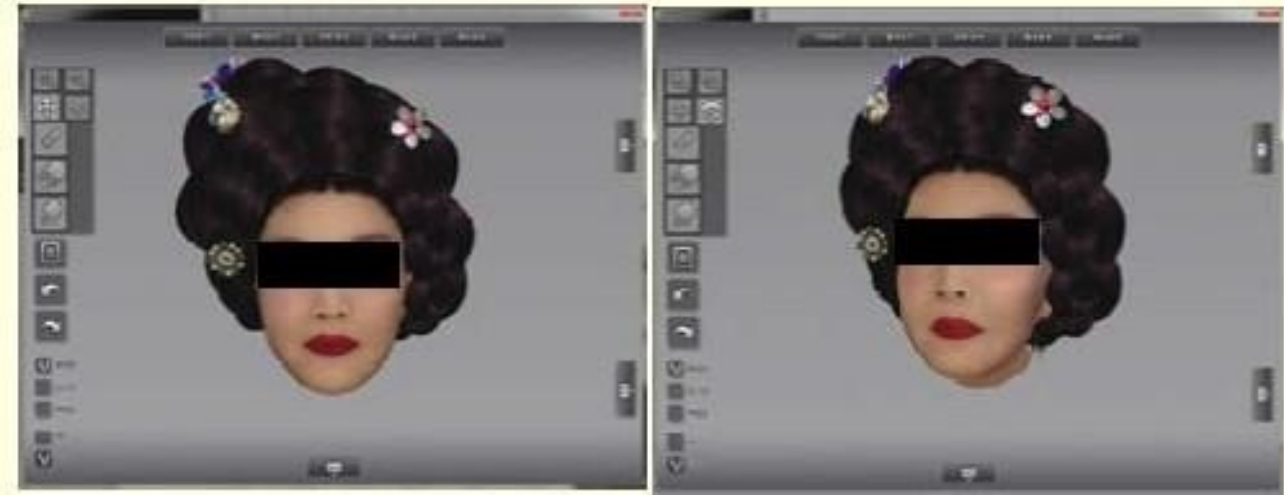

Figura 2.5: Resultado da simulação da interação da maquiagem com a pele no sistema de Jang et al. (2013). Imagem retirada de Jang et al. (2013).

Não foram ressaltados os principais desafios encontrados por Jang et al. (2013) e para futuras pesquisas, sugeriram que seja considerada a componente de perolização da maquiagem na simulação.

O trabalho de Campos (2014), abordado sessão 2.3 no contexto de interação humano computador, explicitou também sobre o processo de aplicação de maquiagem em um vídeo. O método de Campos (2014), assim como Guo e Sim (2009), possui como essência a decomposição da imagem facial em camadas, de acordo com as características faciais.

O processo de simulação de aplicação de maquiagem proposto por Campos (2014) foi dividido em alteração de textura e cor da pele de uma imagem I. Para alteração de textura, é realizada a suavização das características da pele da face e a imagem facial é decomposta em cinco camadas distintas seguindo faixas de frequência, quais sejam:

- $C_{f a}=$ Camada de alta frequência; 
- $C_{f b}=$ Camada de baixa frequência;

- $C_{f 1}=$ Camada de frequência intermediária 1;

- $C_{f 2}=$ Camada de frequência intermediária 2;

- $C_{f 3}=$ Camada de frequência intermediária 3;

As camadas $C_{f a}$ e $C_{f b}$ não são alteradas pois contêm detalhes que caracterizam a face.

No que tange à simulação de cor da maquiagem, $I$ é modificada para o espaço de cor La*b*, obtendo-se $I_{L} a * b *$ Então, cada canal torna-se uma camada, $C_{L}, C_{a} *$ e $C_{b} *$. Como o objetivo era modificar apenas cor, o $C_{L}$, responsável pela iluminação, não é alterado. Enquanto para cada pixel de $C_{a} *$ é calculada uma média ponderada do pixel de $I$ e do pixel de uma imagem contendo o modelo de maquiagem a ser aplicada escolhido pelo usuário, de acordo com a equação abaixo:

$$
r_{p}=\left(1-\alpha_{p}\right) * I_{p}+\alpha_{p} * m_{c}
$$

onde $r_{p}$ é a cor do pixel resultante, $\alpha_{p}$ é um valor correspondente ao efeito da variação da intensidade da maquiagem escolhida pelo usuário e depende a região de aplicação, $I_{p}$ é a cor original do pixel de $I$ e $m_{c}$ é a cor do pixel do modelo de maquiagem a ser aplicado. A Figura 2.6 apresenta o resultado da aplicação do método de Campos (2014).

\subsection{Sistemas com interação 3D}

Uma forma de apresentar o resultado da aplicação de maquiagem virtual ao usuário, é renderizando o modelo geométrico da face construído em 3D. Seguindo essa alternativa, o estudo de Kim e Choi (2007) propuseram um ambiente imersivo 3D que permite a simulação de maquiagem facial. Inicialmente, a distância entre o usuário é calibrada, e se cria um modelo 3D da face do usuário com um escâner 3D. Esse modelo é renderizado em estéreo para promover a sensação de profundidade.Durante um passo de pré-processamento, o sistema possibilita ao usuário alterar o tom e a textura da pele utilizando métodos como: brilho automático e ajuste de contraste, suavização e remoção de ruído. Na sequência, o usuário pode interagir com o sistema por meio de uma caneta do dispositivo háptico, controlando um modelo gráfico semelhante a uma esponja na tela, que entra em contato com o modelo facial 3D. O resultado desse processo é apresentado em uma tela LCD e constitui-se da renderização do modelo 3D que acompanha os movimentos da cabeça do usuário, capturados com sensores de infravermelho (Figura 2.7).

Como possibilidades para trabalhos futuros, Kim e Choi (2007) apontaram a melhoria da velocidade do algoritmo para renderização do modelo 3D, representação multi-resolução e aprimoramento da interação háptica.

Kim e Choi (2008) também propuseram melhorias na interação com o usuário. Desse modo, além de funcionalidades para modificar o aspecto da pele na imagem do usuário, o novo sistema permite a simulação de aplicação de maquiagens coloridas e brilho labial por meio da pressão exercida no dispositivo háptico desse sistema para estabelecer a quantidade de maquiagem a ser aplicada. Esse dispositivo háptico controla uma ferramenta de aplicação de maquiagem que é renderizada na tela, juntamente com a imagem do usuário, como pode ser observado na Figura 2.8.

O processo de automaquiagem é considerado trabalhoso e difícil por muitas pessoas. Pensando nisso, Iwabuchi et al. (2009) apresentaram um sistema de espelho inteligente denominado "Smart Makeup Mirror" (SMM) que auxilia os usuários no processo de aplicação de maquiagem com produtos físicos, tornando-o 


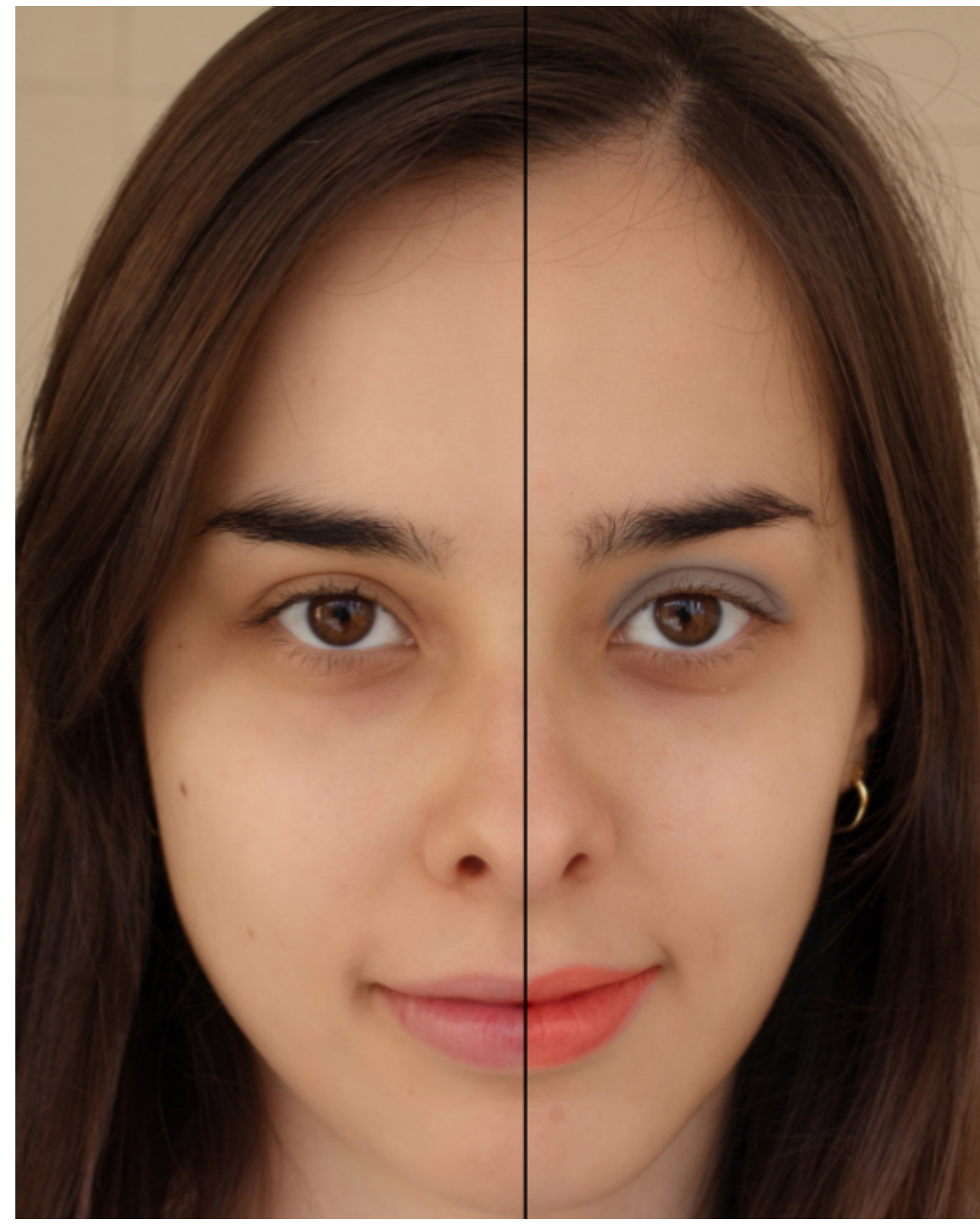

Figura 2.6: Comparativo feito por Campos (2014) da simulação de batom, sombra e base. O lado esquerdo da explicita a imagem original e o direito a imagem resultante da simulação de aplicação de maquiagem. Imagem retirada de Campos (2014)

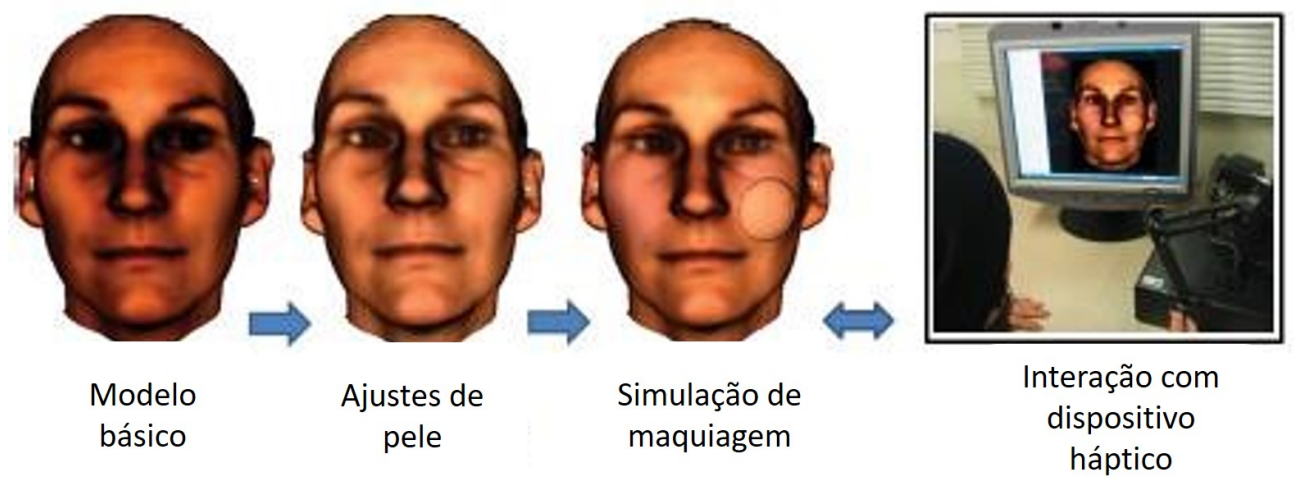

Figura 2.7: Interface Gráfica de Usuário do sistema proposto por Kim e Choi (2007). Imagem retirada de Kim e Choi (2007).

mais fácil e agradável. O SMM conta com uma câmera de alta resolução, sensores de proximidade infravermelhos e uma câmera de baixa resolução, como pode ser observado na Figura 2.9.

Como funcionalidades, esse sistema possui capacidade para: zoom automático para uma parte específica 


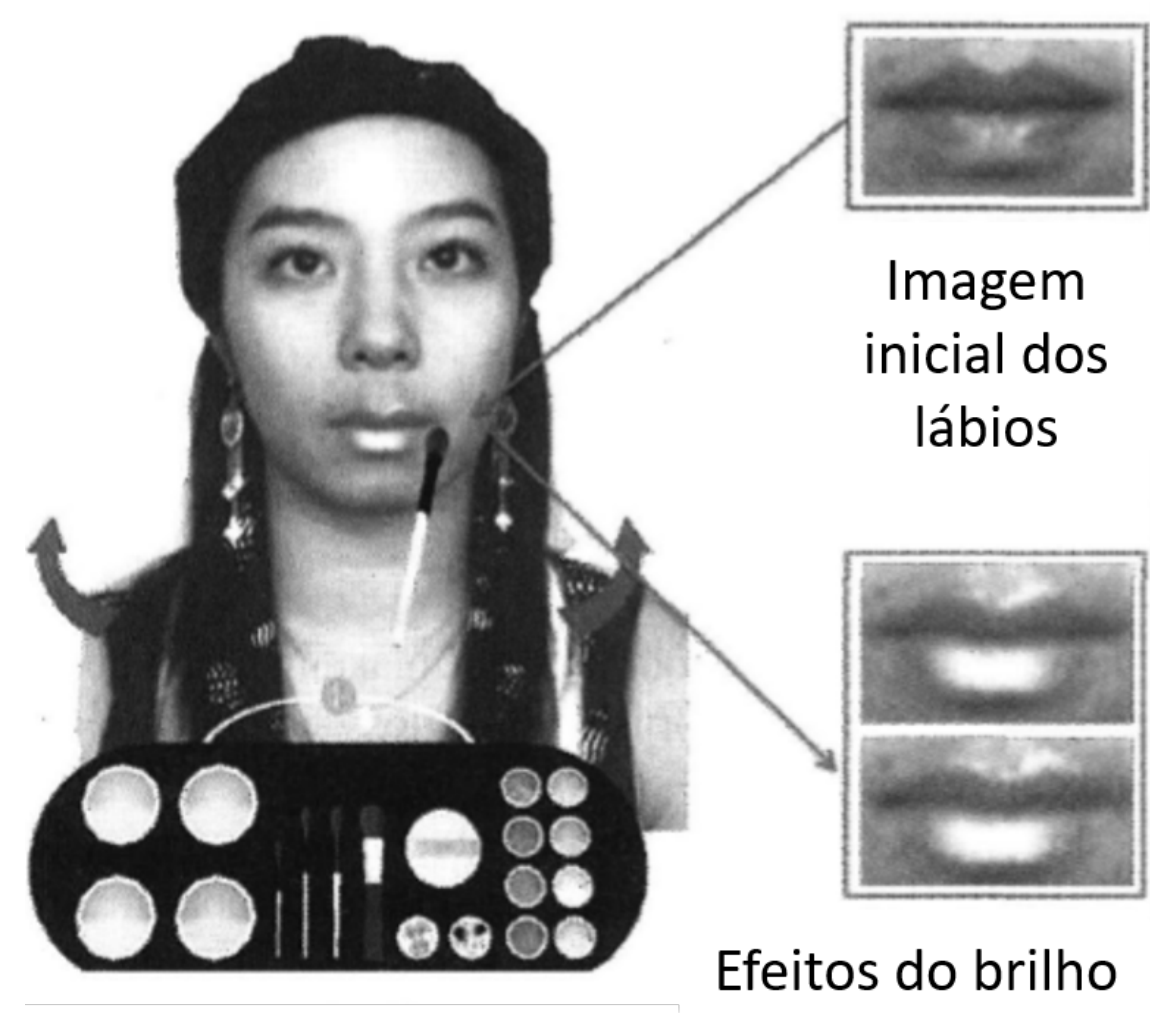

Figura 2.8: Imagem retirada de Kim e Choi (2008) apresentando a tela de simulação do sistema proposto.

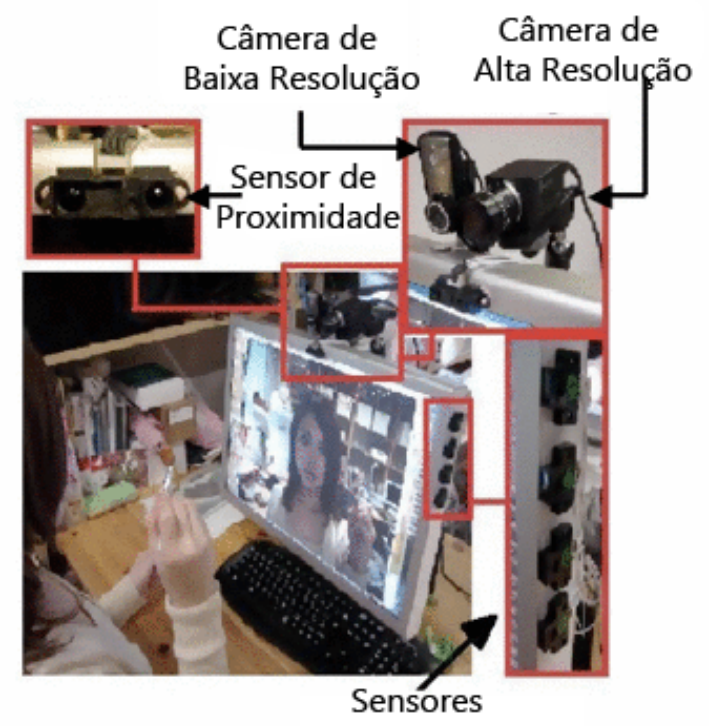

Figura 2.9: Imagem retirada de Iwabuchi et al. (2009) apresentando a Interface do sistema SMM.

do rosto; realizar modificações na escala da imagem; exibir a face em vários ângulos; simular condições de iluminação; salvar a imagem e ainda possui uma página na internet que possibilita a votação do melhor resultado de maquiagem. Entretanto esse sistema não realiza simulação de maquiagem.

Para o zoom automático, o referido sistema, utilizando a câmera de baixa resolução, detecta um marcador colorido fixado no aplicador da maquiagem e, com base na informação sobre a posição desse marcador, aplica o zoom na imagem. Em relação às modificações na escala da imagem, verifica as alterações das distâncias 
do usuário em relação aos sensores e, assim, aumenta a imagem quando o usuário se aproxima e diminui quando ele se afasta. Para exibir a face em vários ângulos, esse sistema permite a utilização de um espelho invertido para simular a visualização da imagem do ponto de vista de um observador posicionado à frente do usuário e, ainda, congela a imagem por alguns segundos para que o usuário possa observá-la.

No que tange à simulação de condições de iluminação, esse sistema propicia que o usuário alterne entre alguns modos de iluminação como: modo maquiagem, modo nublado, modo escritório, modo céu aberto, modo luz de velas e modo pôr-do-sol avermelhado. O usuário pode gravar sua imagem, comparar com imagens salvas anteriormente, publicar imagens e receber a opinião de outros usuários sobre a imagem publicada. Para interagir com esse sistema, além de marcadores coloridos fixados no aplicador para zoom e movimento de aproximação ou afastamento para a mudança de escala da imagem, o usuário pode escolher as outras funcionalidades aproximando as mãos dos sensores de proximidade.

Iwabuchi et al. (2009) realizaram um teste de usabilidade com três participantes: um autor e dois indivíduos do mesmo laboratório de pesquisa. Como resultados, Iwabuchi et al. (2009) apontaram que os participantes acharam fácil de usar, gostaram do zoom automático, consideraram útil poder alterar características de iluminação, mas não gostaram de ver mais claramente as imperfeições da pele. Ainda, foram identificadas no experimento as seguintes limitações: o atraso acarretado pelo processamento do sistema; o fato de que a câmera estar posicionada no topo do monitor não possibilita que o olhar se alinhe com a imagem do usuário; a falta de foco quando o usuário realiza o movimento de aproximação ou afastamento da câmera. Como atividades futuras, planejam a utilização em longo prazo para avaliar a usabilidade desse sistema.

Ainda no contexto de espelho virtual, Rahman et al. (2010) propuseram um "espelho inteligente" para maquiagem denominado Sensory Augmented Smart Interaction Mirror (SIM), que facilita a escolha de produtos de maquiagem. Para o funcionamento desse sistema são utilizadas duas câmeras, uma para capturar a imagem do usuário e outra infravermelha para rastrear seus movimentos da face e das mãos. Essas câmeras são utilizadas em conjunto com emissores de infravermelho fixados nas orelhas do usuário e em cada um dos produtos.

O processo de calibração do SIM consiste na criação de um modelo 3D da face a partir da deformação de um modelo 3D básico com combinação de fotografias da face do usuário em três ângulos. Depois de criar esse modelo 3D, detecta qual produto de maquiagem foi selecionado pelo usuário por meio de um marcador RFID fixado no produto e um leitor RFID. Isso possibilita que esse sistema identifique a textura virtual correspondente ao produto de maquiagem selecionado. Além de aplicar tal textura ao modelo 3D da face do usuário, o SIM, com base em estatísticas obtidas com sua utilização, sugere outros produtos semelhantes ao produto selecionado. O resultado da aplicação do produto, que leva em consideração a geometria do modelo 3D construído da face, é apresentado em um monitor de 21 polegadas, mimetizando os movimentos do usuário (Figura 2.10).

Como resultados dos experimentos com cinco participantes e questionários aplicados, Rahman et al. (2010) explicitaram que os usuários avaliaram que a interação com SIM é fácil, pois o sistema apresenta recomendações intuitivas de uso. Entretanto, os usuários não ficaram satisfeitos com a qualidade visual da imagem do usuário apresentada no sistema.

O estudo de Hanafusa et al. (2010) abordou sobre um sistema que fornece informações sobre a aplicação de maquiagem, voltado para pessoas com pouca experiência no processo de aplicação de maquiagem e com suporte para portadores de deficiência visual. Esse sistema é composto por uma câmera USB para capturar a imagem da face do usuário e um computador pessoal com alto-falante, como pode ser observado na Figura 


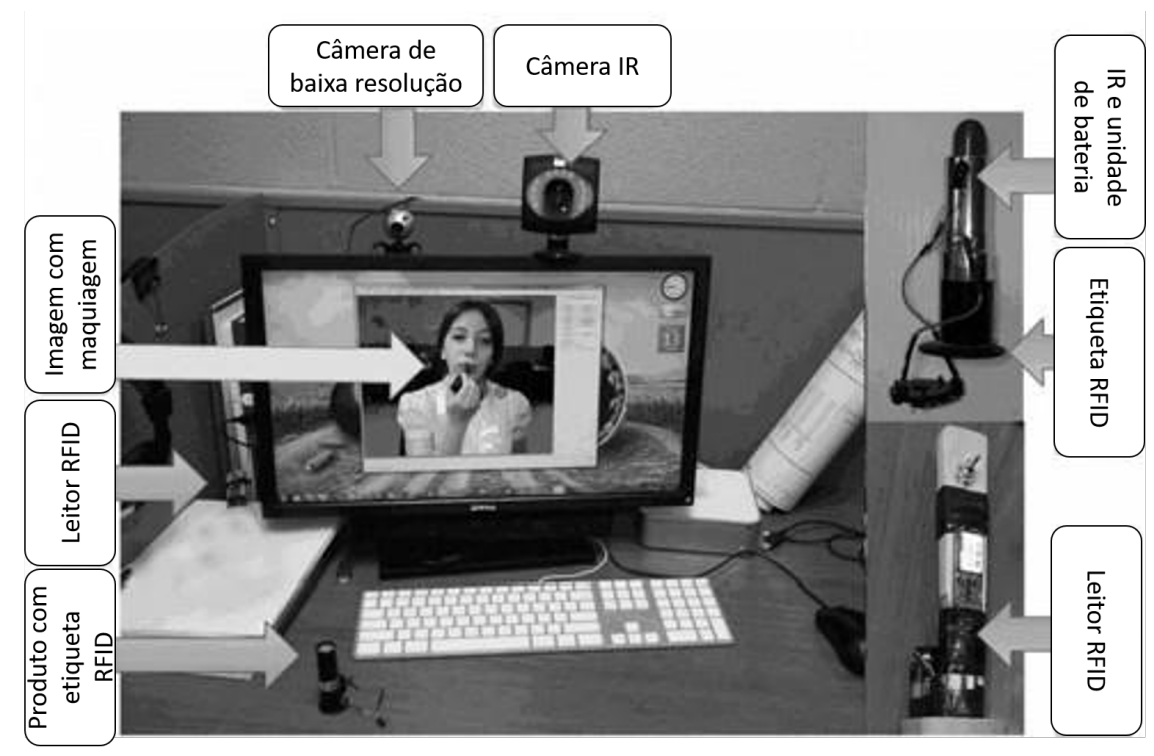

Figura 2.10: Imagem de Rahman et al. (2010) explicitando a Interface de usuário do sistema SIM.

2.11 .

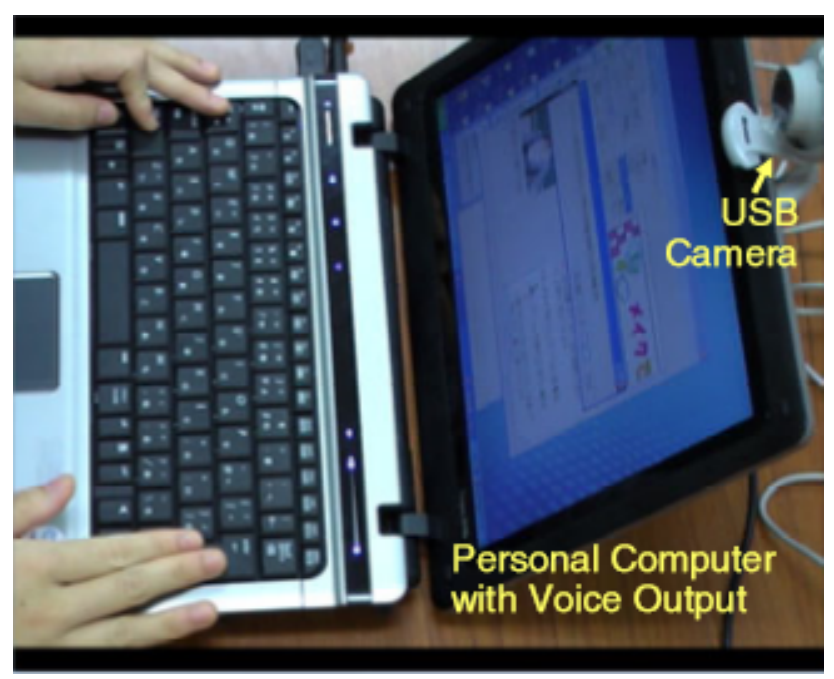

Figura 2.11: Interface do sistema proposto por Hanafusa et al. (2010) voltado para deficientes visuais. Imagem retirada de Hanafusa et al. (2010).

O sistema implementado por Hanafusa et al. (2010) tem como funcionalidade a apresentação de um guia interativo contendo passos para aplicação de maquiagem que podem ser visualizados e ouvidos pelo usuário. A figura 2.12 mostra a interface gráfica que apresenta esse guia.

Além do guia de aplicação, o sistema de Hanafusa et al. (2010) efetua o processamento da imagem para verificar o resultado dessa aplicação de maquiagem pelo usuário. Para tanto, é realizada uma comparação com uma imagem sem maquiagem ou com uma imagem com maquiagem aplicada corretamente, com o intuito de checar se existem diferenças indesejáveis.

Nakagawa et al. (2011), motivados pela identificação da dificuldade que as pessoas têm de variar a maquiagem, propuseram um Sistema Inteligente de Maquiagem (Smart Makeup System, SMS), o qual possibilita aos usuários o compartilhamento de informações sobre produtos de maquiagem e fotos com amigos. A interface de usuário do SMS (Figura 2.13) é composta por: um leitor de código de barras e um leitor RFID que permitem que os usuários registrem produtos; uma cesta com leitor RFID para colocar produtos de ma- 


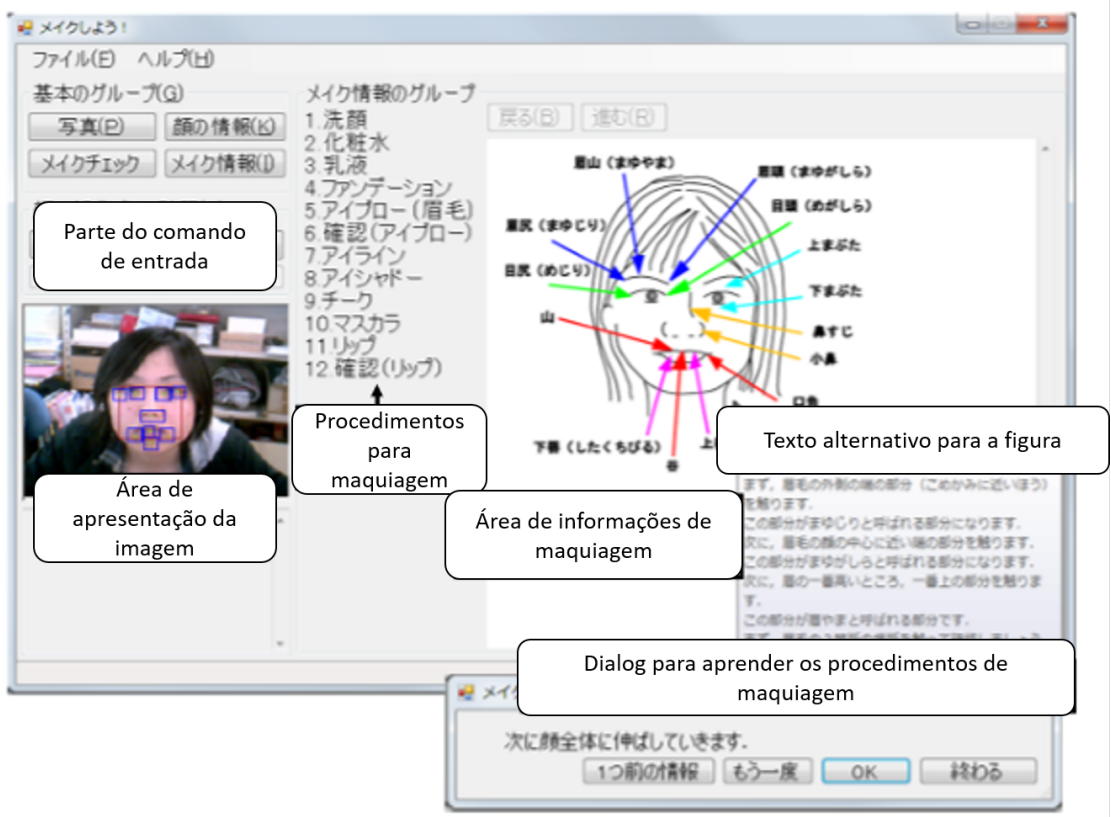

Figura 2.12: Interface Gráfica de Usuário do sistema proposto por Hanafusa et al. (2010). Imagem retirada de Hanafusa et al. (2010).

quiagem; um espelho físico dividido em três áreas; e, fixados nesse espelho, uma câmera USB e um monitor LCD localizados em sua área direita e uma luz fixada na parte central. A função do espelho físico é a de possibilitar a visualização da roupa do usuário.

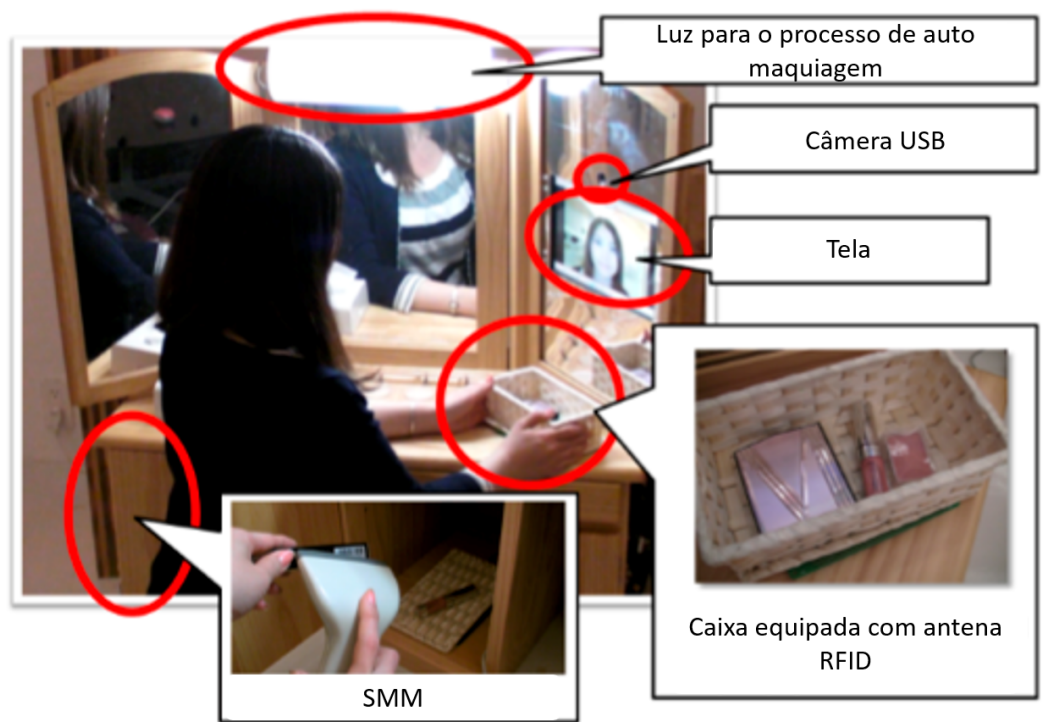

Figura 2.13: Interface do SMS proposta por Nakagawa et al. (2011). Imagem retirada de Nakagawa et al. (2011).

Como funcionalidades, o SMS é um espelho digital com características especiais, dentre as quais a simulação de modos de luz e zoom, e permite o registro de cosméticos, a gravação do histórico de utilização e o compartilhamento desse histórico na internet pelo usuário com o intuito de encorajar a variação do estilo de maquiagem. A Figura 2.14 mostra a interface gráfica que apresenta o histórico do usuário na internet. 


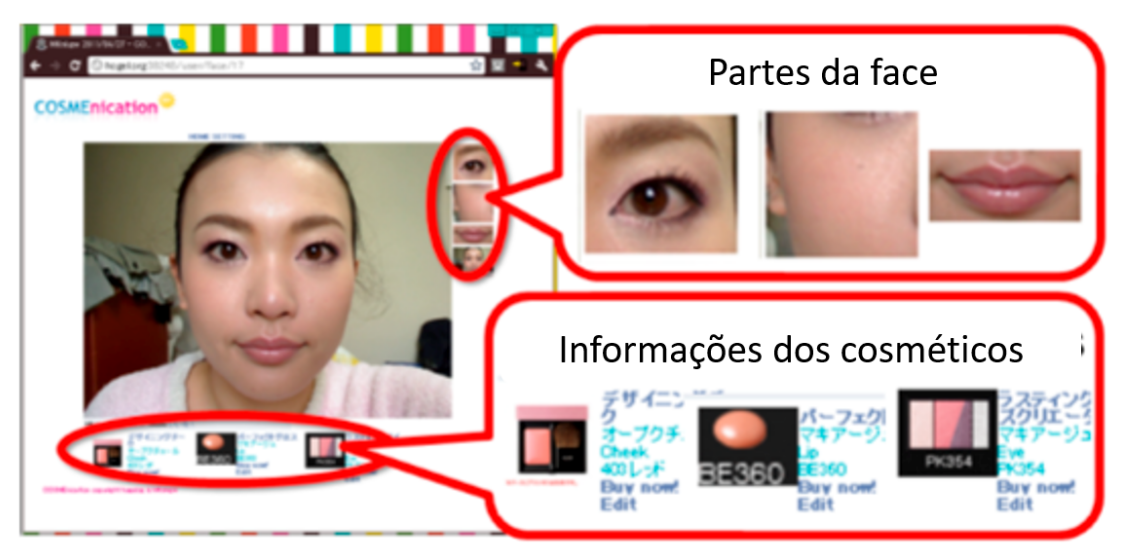

Figura 2.14: Interface do SMS que possibilita a visualização das informações do histórico de um usuário na internet. Imagem retirada de Nakagawa et al. (2011).

\subsubsection{Trabalho não acadêmico}

Campos (2014) cita um projeto não acadêmico desenvolvido pela Natura em 2012, um ambiente 3D para simulação de maquiagem (que ficou disponível para experimentação durante um tempo determinado) que se assemelhava ao desenvolvido por ele. Nesse sistema, para capturar a imagem e gestos do usuário, utilizou-se o Microsoft Kinect. Como funcionalidade, o sistema apresentou a possibilidade de simulação da aplicação de sombra, batom e blush. O produto que seria aplicado podia ser escolhido via toque no monitor e a aplicação ocorria por meio de gestos na face semelhantes aos gestos reais para aplicação de produtos. $\mathrm{O}$ resultado era apresentado em uma tela sensível ao toque. A Figura 2.15 mostra a Interface de Usuário desse sistema.

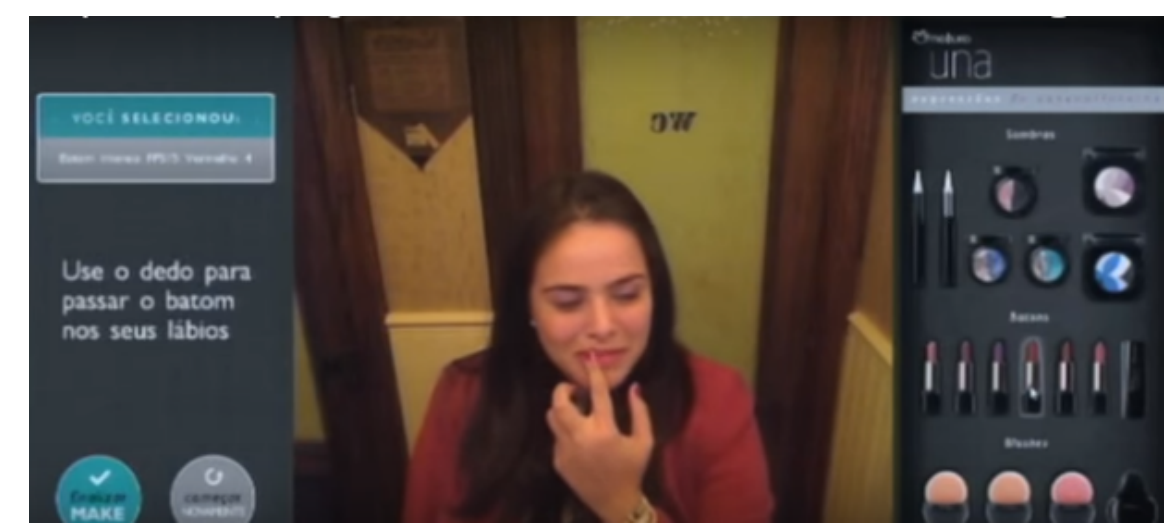

Figura 2.15: Interface de Usuário do Sistema de Simulação de Maquiagem da Natura. Essa imagem foi retirada do vídeo sobre esse sistema disponível no link https://www.youtube.com/watch?v=u28pg1cBlv8.

Como limitações desse sistema da Natura, Campos (2014) apontou a baixa resolução da imagem, erros na região de aplicação da maquiagem e apresentação por vezes, da figura geométrica que delimitava a região.

\subsection{Sistemas de aplicação de maquiagem virtual}

O sistema desenvolvido por Campos (2014) consiste em um espelho virtual que permite ao usuário experimentar produtos de maquiagem de maneira rápida, observando os resultados da aplicação e remoção da maquiagem instantaneamente. Para capturar a imagem do usuário e localização de pontos faciais, foi 
utilizado o sensor RGBD Microsoft Kinect. Esses pontos faciais são empregados na triangulação da face, o que permite manter a aplicação da maquiagem mesmo com a movimentação do rosto.

Esse espelho virtual, implementado por Campos (2014), conta com funcionalidades gerais como pausar a imagem e salvá-la, além de possibilitar a escolha dos produtos de maquiagem a serem aplicados, suavizados ou removidos da face, quais sejam: base, batom e sombra. Para tanto, é apresentada uma interface gráfica, em um monitor sensível ao toque, que permite a interação do usuário com as funcionalidades do sistema.

Após a escolha da funcionalidade requerida, o usuário pode visualizar o resultado em sua imagem, exibida ao lado dessa GUI no monitor, conforme apresentado na Figura 2.16.

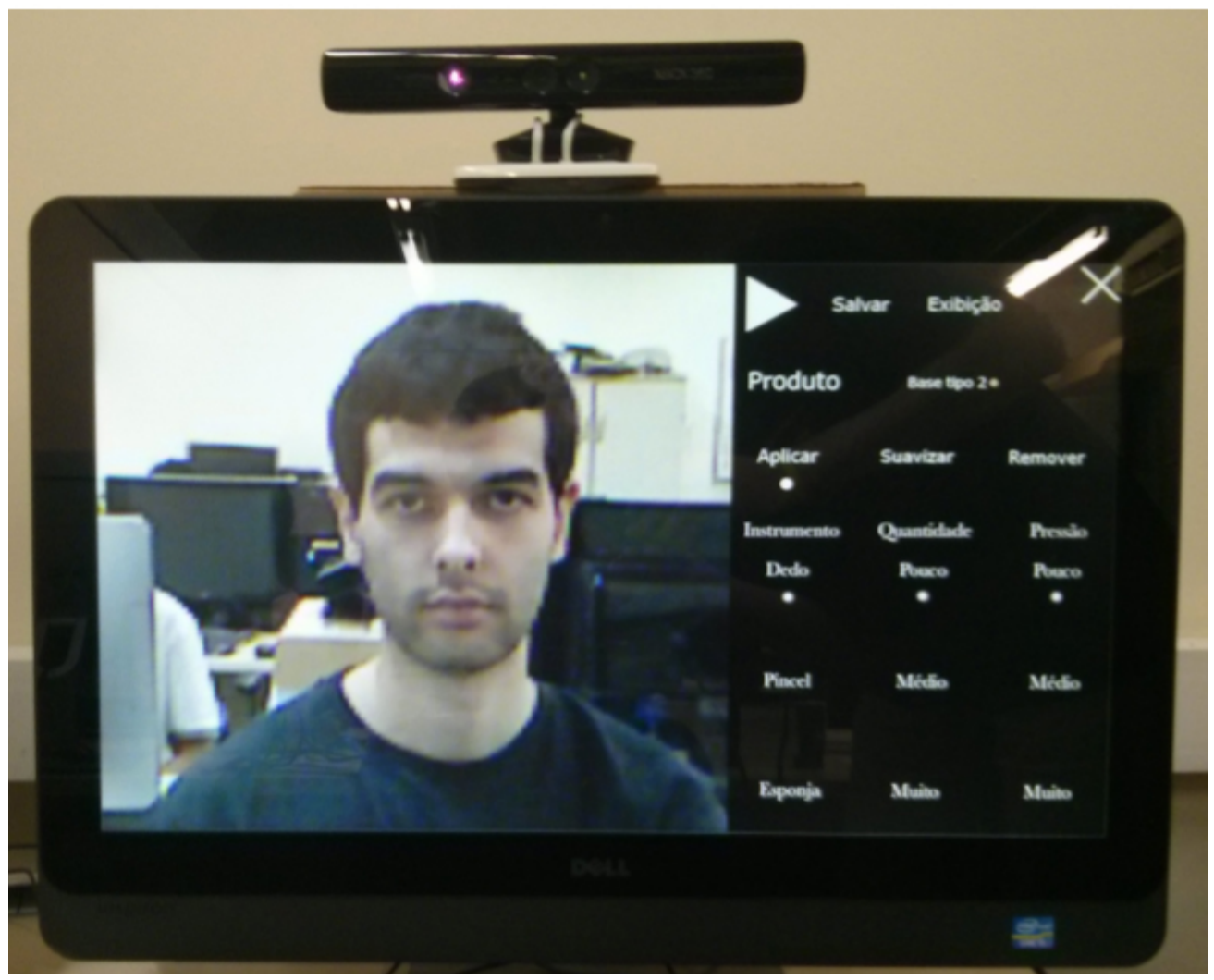

Figura 2.16: Interface do sistema de simulação de maquiagem proposto por Campos (2014), contendo um monitor sensivel a toque e um Microsoft Kinect. Imagem retirada de Campos (2014).

Campos (2014) apontou que os objetivos propostos inicialmente foram atingidos, mas as limitações de hardware foram os maiores desafios encontrados na construção do protótipo desse espelho virtual. Quanto à forma de interação utilizada, ressaltou que não necessita de etapas preparatórias ou marcadores, o que facilita a sua utilização. Como trabalhos futuros, além da evolução do hardware, Campos (2014) sugeriu melhorias na forma de interação com o sistema de simulação, adaptação à iluminação não uniforme, utilização de câmeras de baixo custo, ajuste da direção do olhar com a imagem do espelho virtual e utilização de texturas que simulem uma maquiagem real.

\subsubsection{Trabalhos não acadêmicos}

Em 2010, a Shiseido lançou um sistema de simulação de maquiagem que inicialmente monta o modelo 3D da face do usuário e captura a imagem sua imagem em tempo real. Como funcionalidades, recomenda estilos e produtos de maquiagem e permite que o usuário interaja com o sistema por meio de toques na tela para escolher produtos de sombra, batom e blush. 


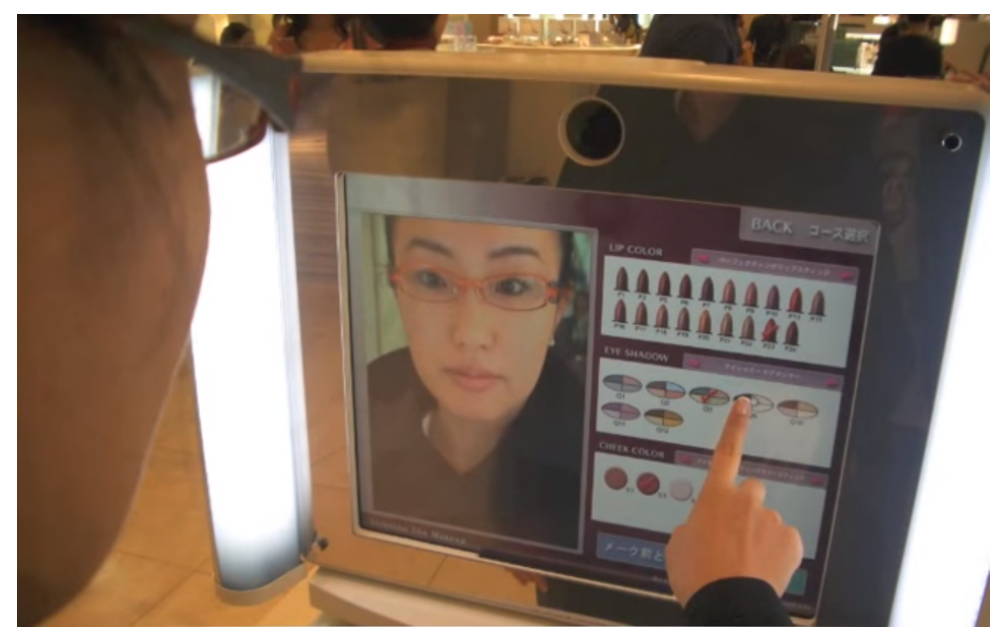

Figura 2.17: Imagem do Sistema de Simulação da Shiseido retirada do vídeo disponível no link https://www.youtube. com/watch? $v=R 5 z Z 5 q Z P 5 O k$.

Em 2015, a Perfect Corp lançou o aplicativo YouCam Makeup que permite simular a utilização de estilos de cabelo, acessórios e maquiagem. A simulação pode ser realizada em uma imagem do usuário ou em um vídeo capturado em tempo real pela câmera do dispositivo móvel. Como funcionalidades para simulação de maquiagem em vídeo, o aplicativo oferece: remoção das imperfeições da pele facial; escolha de estilos prédefinidos de maquiagem compostos por sombra, blush e batom; a escolha de cor e estilos sombra, delineador, blush, batom e cílios postiços. Além disso, é possível comparar o resultado atual com imagens já gravadas no dispositivo. A interação do usuário com as funcionalidades é realizada por meio de toques na tela do dispositivo. A Figura 2.18 explicita a Interface Gráfica de Usuário do YouCam Makeup.

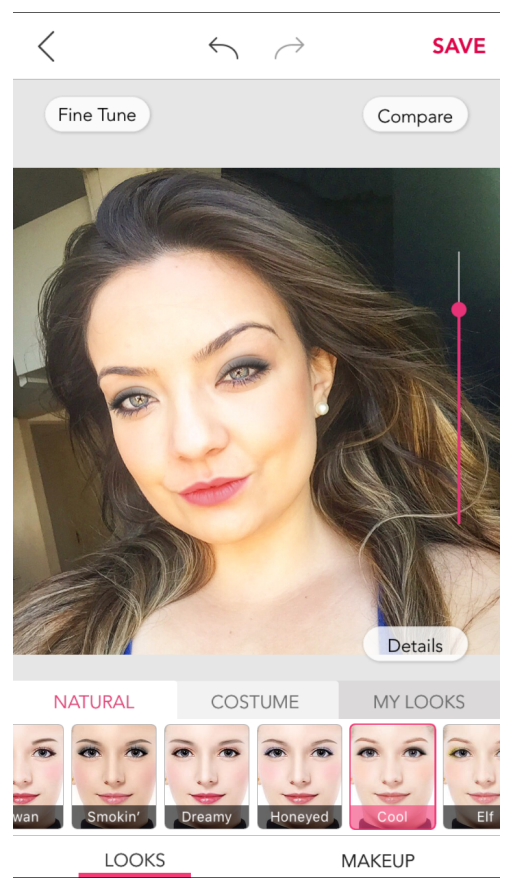

Figura 2.18: Interface Gráfica de Usuário do aplicativo YouCam Makeup obtida durante a utilização desse aplicativo.

A empresa Modiface, dando continuidade em um projeto que iniciou em 1999 na Universidade de Stanford, possui diversos aplicativos para dispositivos móveis e um site de simulação de maquiagem. Quanto aos aplicativos para dispositivos móveis destinados a simulação de maquiagem, a empresa conta com o Modiface Live, Web Makeover, Modiface, Modiface Photo Editor e Beautiful Me. Esses aplicativos possibilitam 
aplicação de estilos pré-definidos de maquiagem em uma foto do usuário ou em vídeo capturado em tempo real pela câmera do dispositivo móvel. Como funcionalidades, oferecem a possibilidade de escolha de combinações de cores e intensidades para sombras e batons. Todos os aplicativos possibilitam a interação com as funcionalidades por meio de toques na tela do dispositivo móvel. A interface de usuário do aplicativo Modiface Live é apresentada na Figura 2.19.

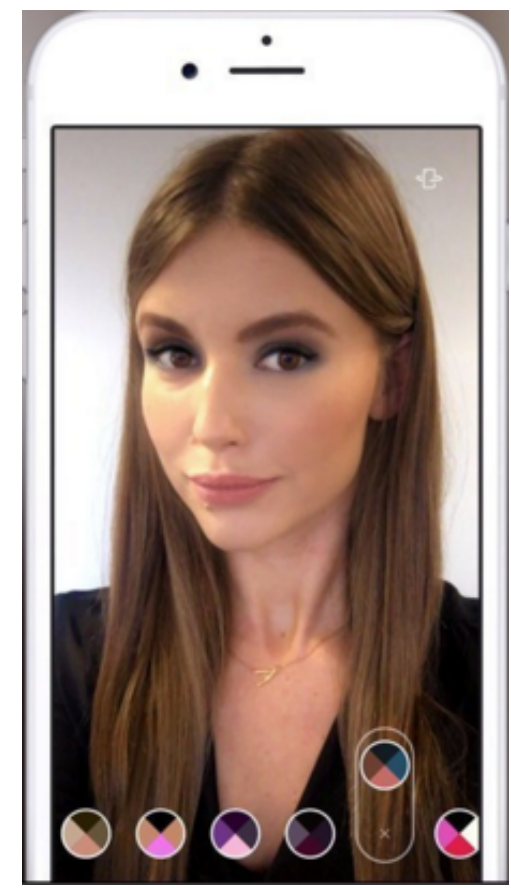

Figura 2.19: Imagem da Interface do aplicativo Modiface Live, composta pela imagem do usuário e pelas funcionalidades de cores a serem selecionadas de estilos pré-definidos de maquiagem a serem simulados. Essa imagem foi retirada do site http://modiface.com/.

O sistema disponibilizado no site permite a simulação da aplicação da maquiagem em fotos selecionadas pelo usuário ou em fotos de modelos disponibilizadas por esse sistema. Não é possível efetuar a simulação em vídeo da face do usuário capturado em tempo real e, mesmo para foto, requer que o usuário ajuste os pontos fiduciais do contorno da face, dos olhos e da boca. A Figura 2.20 apresenta a interface gráfica de usuário para ajustar os pontos do contorno da boca.

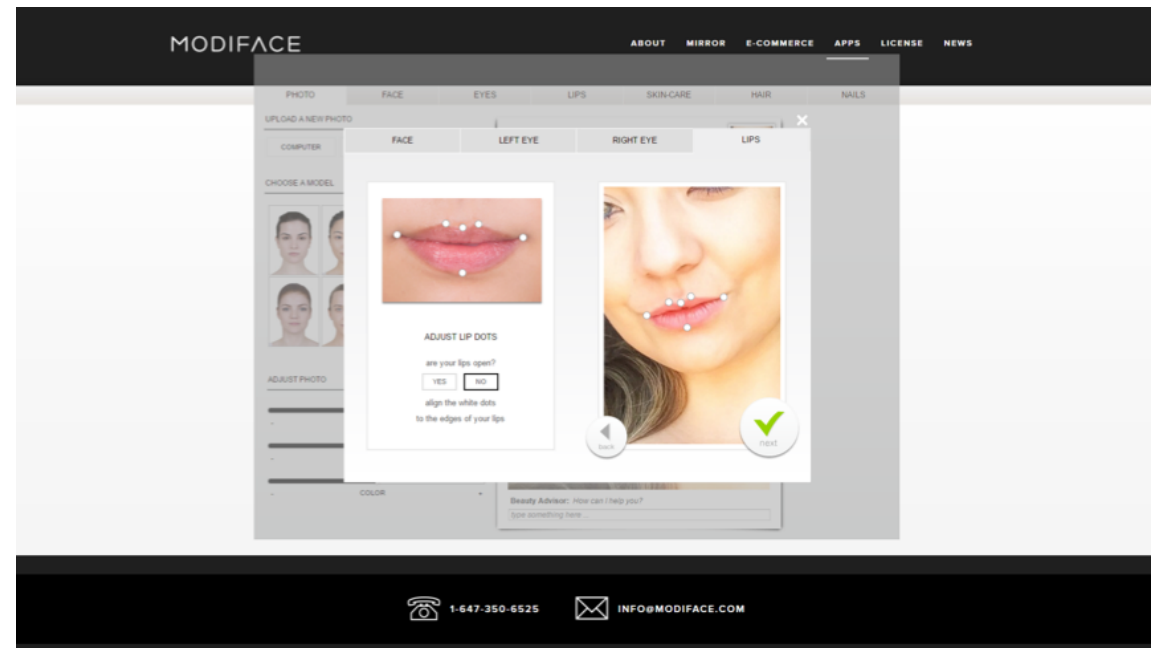

Figura 2.20: Interface Gráfica de Usuário disponibilizada pela Modiface em seu site. Essa imagem foi retirada do site http://modiface.com/. 
Depois de efetuar a calibração, o sistema da Modiface permite a simulação de maquiagem com estilos pré-definidos para sombra, batom, brilho labial, contorno labial, blush, base, iluminador, pó, pó de contorno, máscara e delineador. Entretanto, ainda que tenha sido realizada a calibração, o sistema possui baixa acurácia para a simulação de produtos nos olhos quando a face está inclinada, como pode ser visualizado na Figura 2.21 .

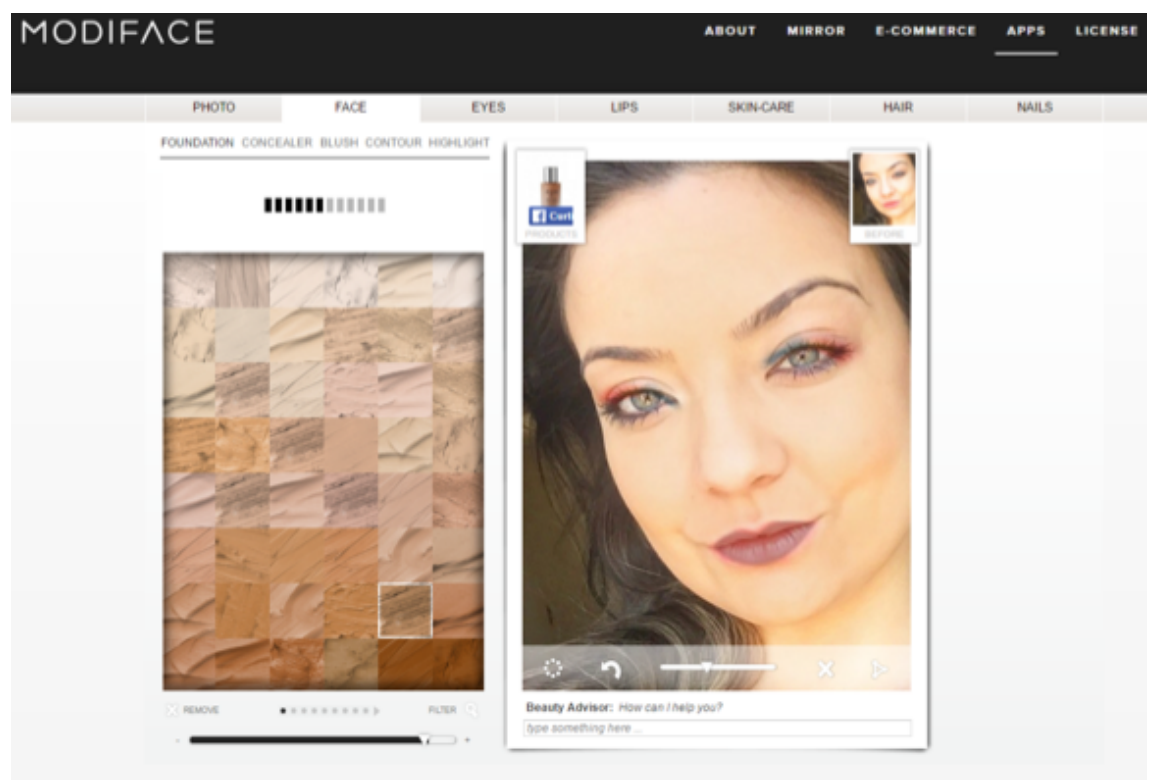

Figura 2.21: Resultado da simulação de aplicação de maquiagem obtida durante a utilização do sistema de simulação do site da Modiface. Essa imagem foi retirada do site http://modiface.com/.

Além disso, é possível compartilhar o resultado no facebook ou encontrar produtos semelhantes ao utilizado na simulação como apresentado na Figura 2.22.

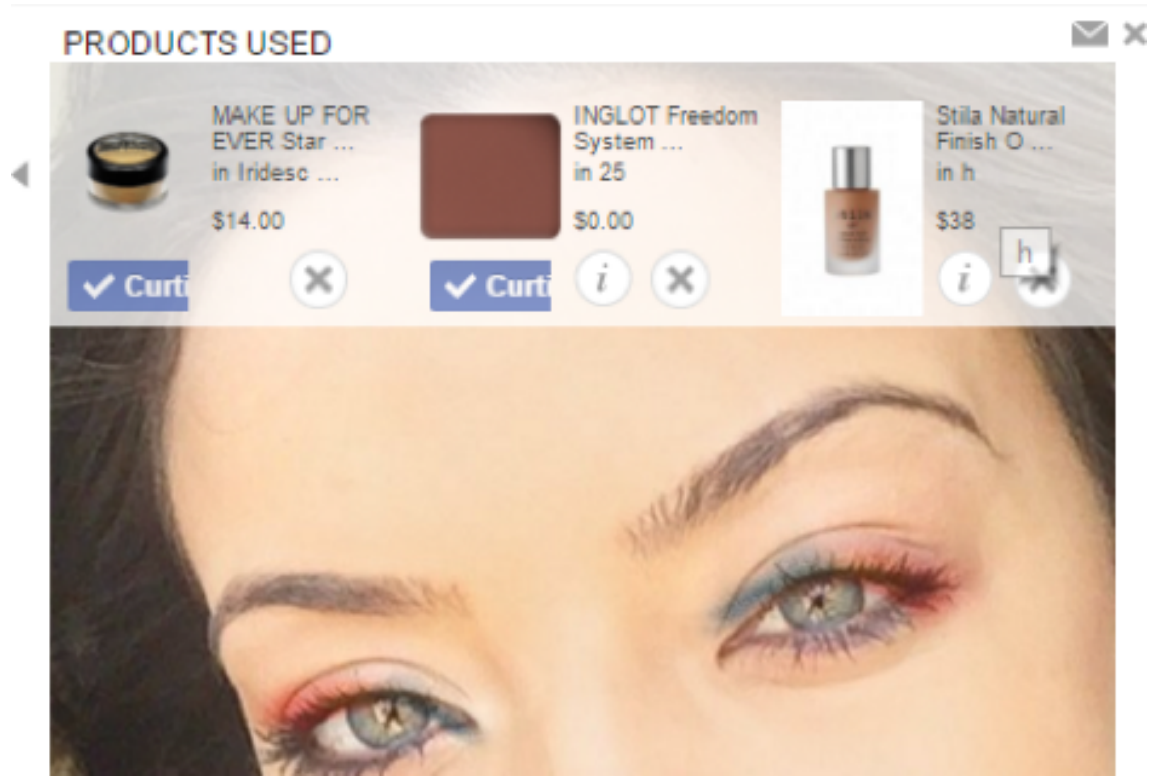

Figura 2.22: Interface Gráfica de Usuário do sistema de simulação de maquiagem do site da Modiface contendo a apresentação das funcionalidades de visualização dos produtos semelhantes aos utilizados na simulação. Essa imagem foi retirada do site http://modiface.com/.

A interface de usuário também permite a remoção da visualização de cada produto simulado. Além de maquiagem, permite ajustar a cor da imagem, o brilho e o contrate, além de possibilitar simular estilos de 
cabelo e cor de esmalte.

Em 2014, a empresa Sephora, em parceria com a Modiface, lançou um espelho de realidade aumentada pra que os usuários pudessem experimentar todos os tons de cores de sombra que a companhia vende, como pode ser observado na Figura 2.23. Por meio de um monitor sensível a toque, o usuário pode escolher o estilo da sombra, a cor e a intensidade, além de visualizar o resultado da simulação em vídeo de sua imagem facial em tempo real. O vídeo http://modiface.com/news.php?story=540 apresenta a interação de um usuário durante a utilização desse sistema.

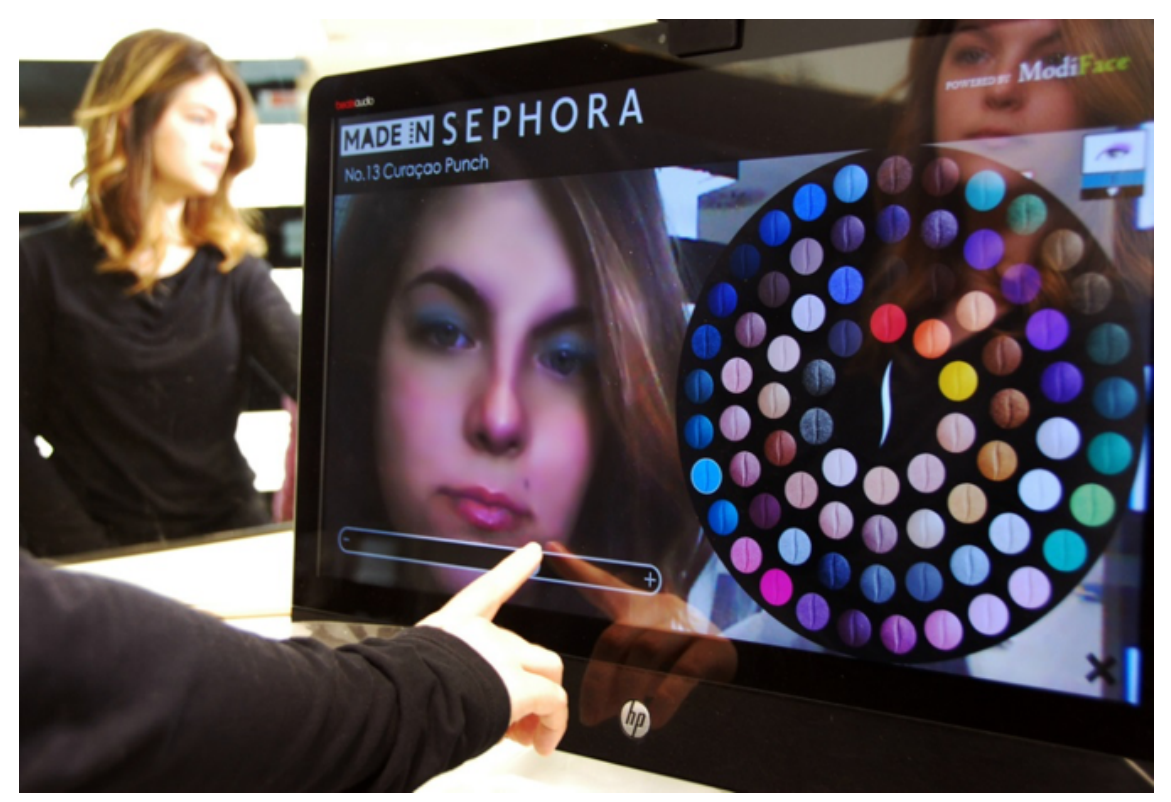

Figura 2.23: Imagem obtida no vídeo http://modiface.com/news.php?story=540 da Interface Gráfica de Usuário do sistema da Sephora.

A Panasonic lançou no Consumer Electronics Show, em 2015, um espelho aumentado que captura a imagem do usuário em tempo real, analisa a imagem capturada da face e efetua sugestões de acordo com essa análise. O sistema sugere ingestão de alimentos que melhorem as características da pele, estilos de maquiagem e cabelo. Em relação aos estilos de maquiagem, indica estilos de base, sobrancelha, sombra, blush e batom e possibilita ajustar características do pincel aplicador. A interação com o sistema é feita com um controle remoto. A imagem do usuário e o resultado do estilo sugerido são apresentados em um espelho aumentado, como pode ser observado na Figura 2.24.

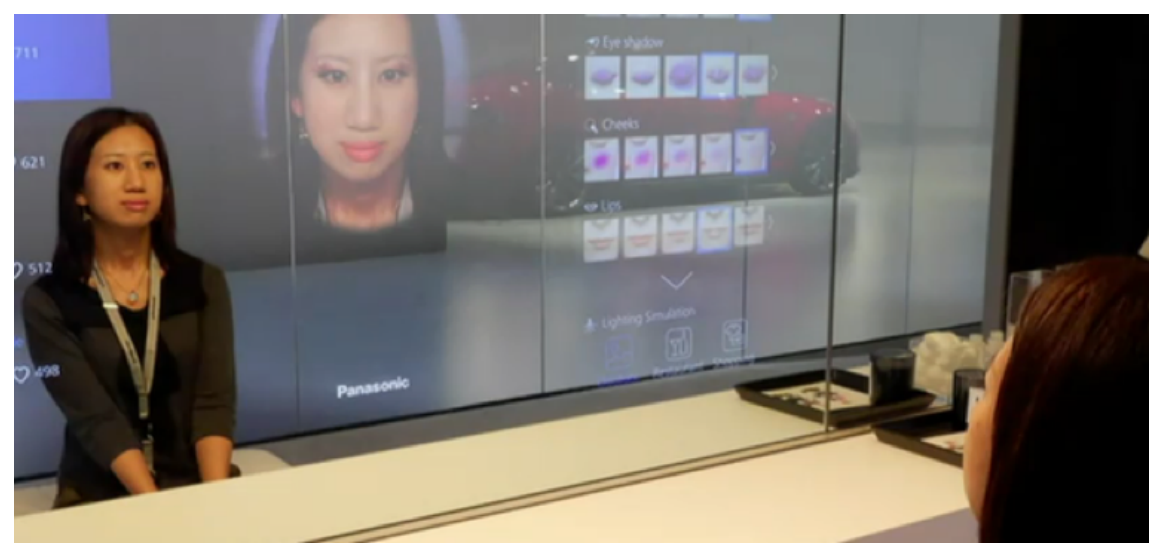

Figura 2.24: Interface do sistema de espelho aumentado para sugestão de maquiagem proposto pela Panasonic retirada do vídeo https://www.youtube.com/watch?v=pJubKcmsFQ4. 
Já na Consumer Electronics Show de 2016, a Panasonic apresentou um espelho aumentado com funcionalidades parecidas com o proposto em 2015, mas com a possibilidade de interagir com o sistema por meio de toques no espelho e também, pela simulação da aplicação de maquiagem em um tablet, como ilustrado na figura 2.25 .

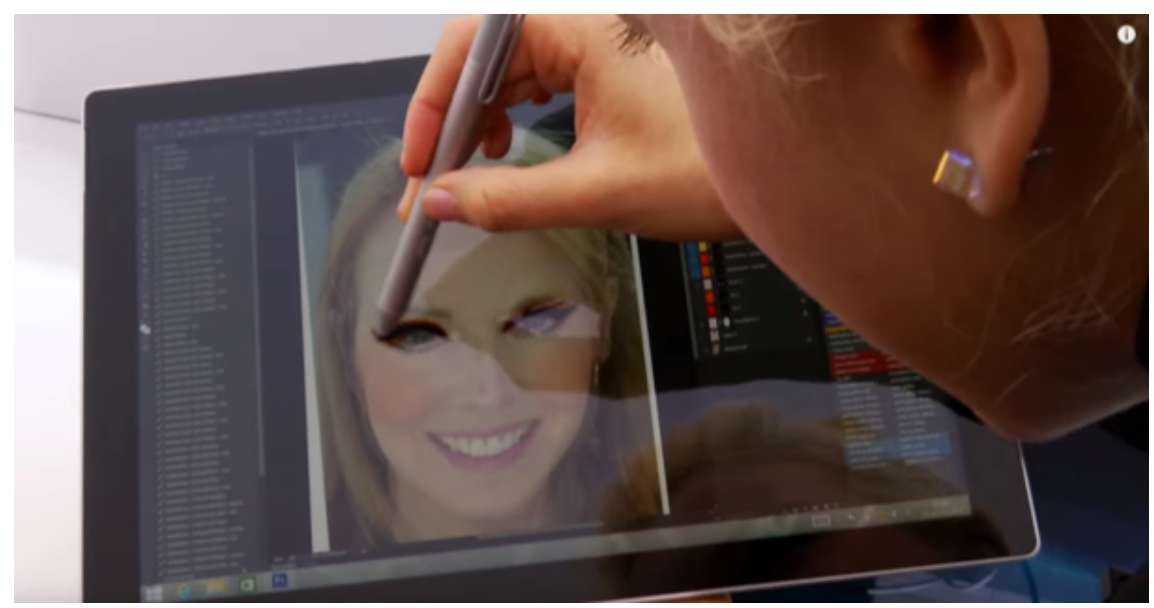

Figura 2.25: Imagem da interação do usuário com o sistema da Panasonic por meio de um tablet retirada do vídeo https://www.youtube.com/watch?v=pJubKcmsFQ4.

O resultado da simulação é mostrado no espelho aumentado como explicitado na Figura 2.26.

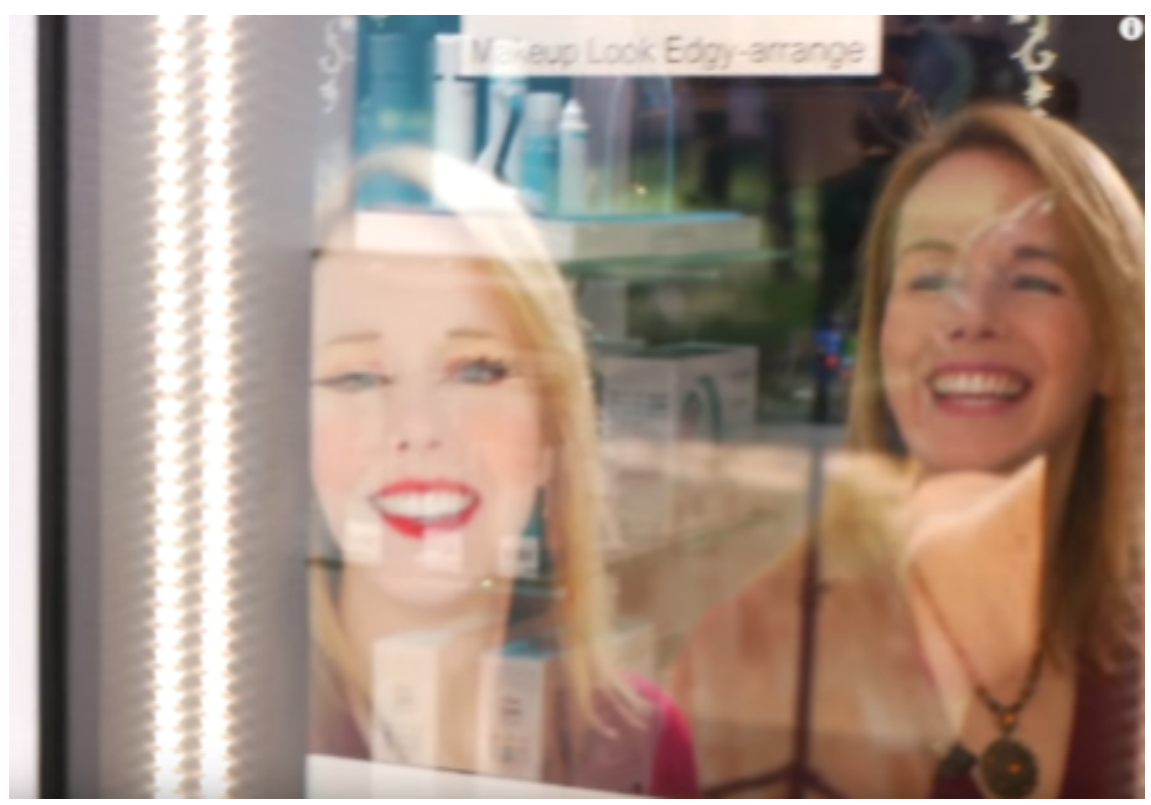

Figura 2.26: Imagem do espelho aumentado que exibe o resultado da simulação de aplicação de maquiagem obtida no vídeo https://www.youtube.com/watch?v=pJubKcmsFQ4.

$\mathrm{Na}$ internet existem vários sites para simulação de maquiagem, mas todos eles simulam a maquiagem a partir de imagens selecionadas pelo usuário ou de imagens de modelos que podem ser escolhidas no próprio site. Depois de escolher uma imagem, o usuário precisa ajustar manualmente os pontos fiduciais da face, como no site da modiface, explicitado anteriormente. Em seguida, o usuário pode escolher estilos pré-definidos para a simulação de sombras, máscaras para cílios, batons, base, blush e delineador, além de poder ajustar as cores e intensidades. Algumas empresas de cosméticos como Avon e Mary Kay possuem em seu site um simulador como esse e apresentam como possibilidade de escolha os produtos de maquiagem vendidos por elas. 
Entretanto, como pode ser observado nas Figuras 2.27 e 2.28, ainda que os marcadores fiduciais da face tenham sido ajustados, a simulação nos sites da Avon (http://www.avon.com.br/novidades/destaques/avonsimulador-de-maquiagem) e Mary Kay (https://www.marykay.com.br/pt-br/tips-and-trends/makeover-andbeauty-tools/virtual-makeover) é de baixa qualidade e fica aplicada em regiões que não seguem os contornos dos olhos e da boca.

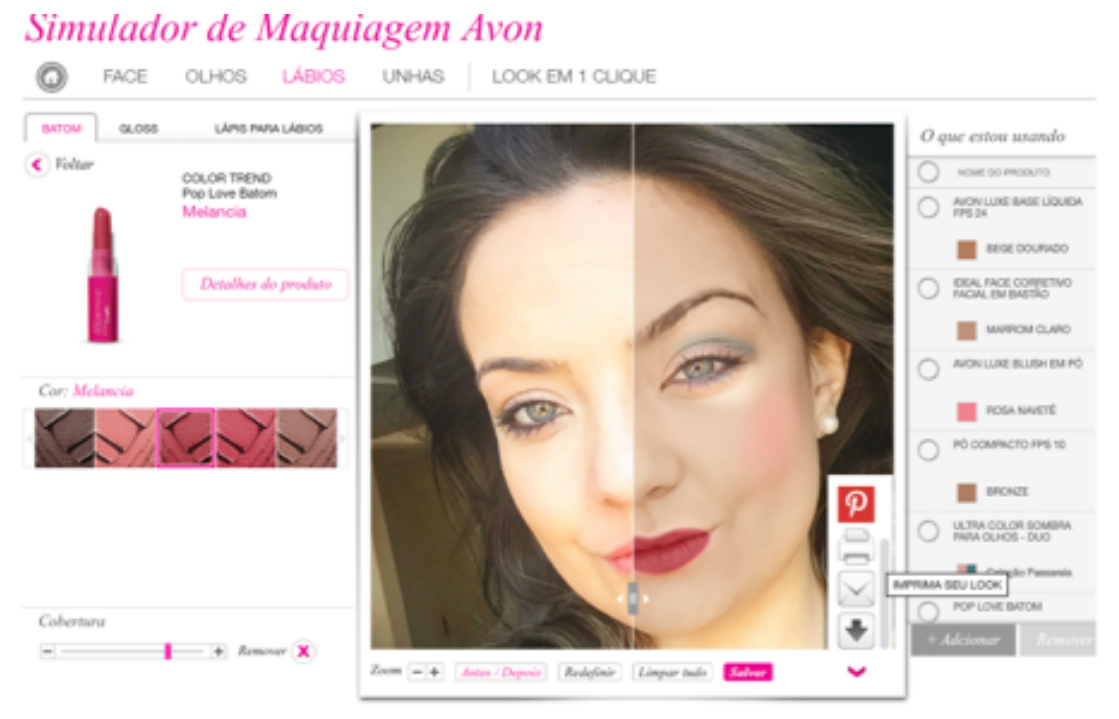

Figura 2.27: Imagem obtida durante a simulação de maquiagem no site da Avon e que apresenta a interface desse sistema de simulação disponível em: http://www.br.avon.com/PRSuite/avon_simulador_de_maquiagem.page.

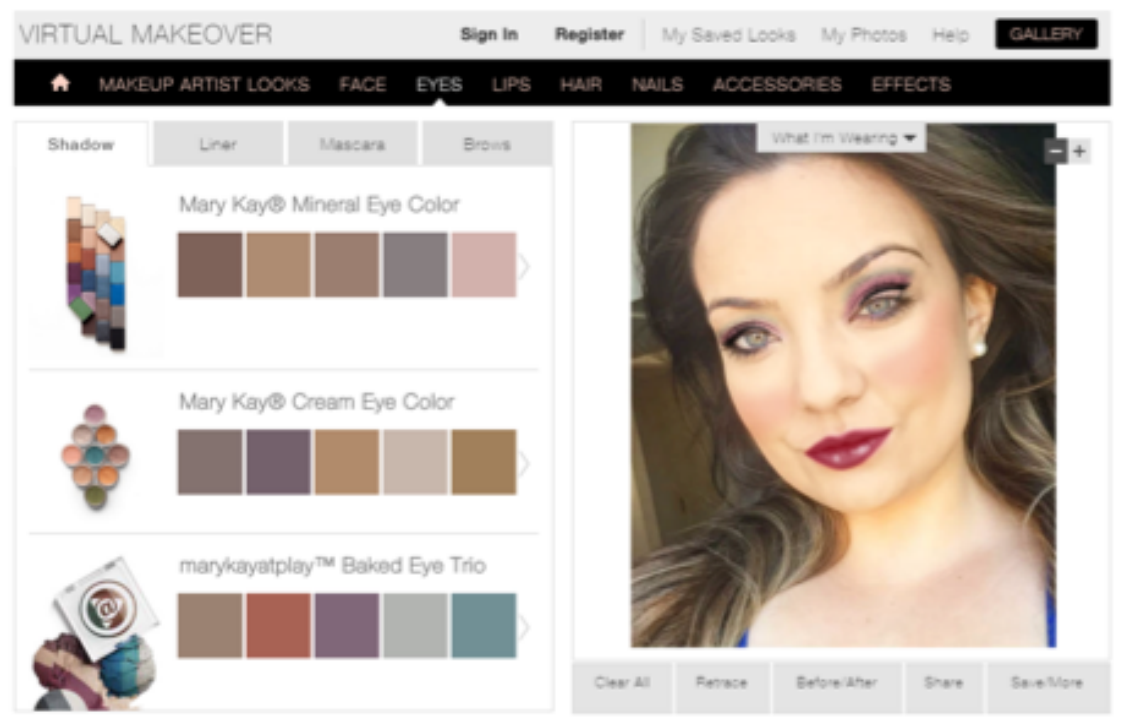

Figura 2.28: Sistema de simulação de maquiagem da Mary Kay contido em seu site: http://www.marykay.com.br/ pt-br/tips-and-trends/makeover-and-beauty-tools/virtual-makeover. Imagem obtida durante a utilização do sistema.

\subsection{Estimativa da posição das mãos e superfícies interativas}

Diversos métodos já foram propostos para resolver o problema de estimar a posição da mão em tempo real. Algumas abordagens propõem a utilização de duas câmeras RGB para capturar a imagem das mãos, 
como os estudos de Rehg e Kanade (1994) e Stenger et al. (2001), que apresentam propostas para rastrear, em tempo real, os movimentos das mãos com base em modelos previamente treinados. Utilizando imagens RGB adquiridas pelas câmeras, propõem um processo de extração de características que requer forte contraste entre o cenário de fundo e contorno das mãos. Mais tarde, Stenger et al. (2006) utilizou uma estrutura de árvore treinada para evitar poses improváveis da mão, que ofereceu ao modelo parâmetros que, por meio de otimização, possibilitam o rastreamento da pele até mesmo para cenários de fundo coloridos. de La Gorce et al. (2011), por sua vez, propôs uma abordagem que removeu a necessidade de treinamento, utilizando modelagem generativa de textura e iluminação. Essas abordagens baseadas no processamento de imagens RGB das mãos, possuem como limitação a necessidade de forte contraste entre a mão e o cenário de fundo, o que impossibilita a utilização em diversos contextos, inclusive para os cenários de autoaplicação de maquiagem. Para solucionar essa limitação, alguns estudos demonstram o emprego de marcadores e luvas usando cores para a estimativa da posição das mãos baseada em aparência. Nessa direção, Aristidou e Lasenby (2010) apresentaram, em sua investigação, uma abordagem utilizando marcadores em LED fixados nas mãos, realizando a captura dos movimentos com cinemática inversa. Mas, essa proposta de Aristidou e Lasenby (2010) necessita de um hardware específico, com certa complexidade para ser construído. Assim, já Wang e Popović (2009) explicitaram, em seu estudo, um método usando uma luva colorida para rastrear as mãos. Apesar da construção da luva não ter a complexidade da engenharia envolvida no hardware necessário para o sistema de Aristidou e Lasenby (2010), requer um padrão de cores específico, difícil de ser reproduzida utilizando as informações disponibilizada pelos autores.

Idealmente, a estimativa da posição da mão deve contemplar a interação natural e livre, visando a adoção generalizável. Pensando nisso, Hamer et al. (2009) foram pioneiros ao propor uma abordagem introduzindo o processamento da imagem de profundidade para a estimativa da pose da mão. Combinando a informação de profundidade com a de aparência, o método de Hamer et al. (2009) é capaz de lidar com forte oclusão por objetos capturados. No entanto, apesar dos resultados interessantes, a complexidade da otimização resulta em um tempo de processamento de vários segundos para um quadro. Utilizando também a informação de profundidade, o estudo de Oikonomidis et al. (2011) apresenta uma abordagem de otimização para resolver a estimativa da pose da mão usando Particle Swarm Optimization - PSO, com desempenho quase em tempo real. Em outro estudo, Oikonomidis et al. (2014) abordaram sobre a utilização de múltiplas câmeras para rastrear a manipulação de objetos. A pesquisa de Sridhar et al. (2013) também apresenta sobre o emprego de diversas câmeras em um método que combina otimização sobre a informação de profundidade de cinco câmeras RGB, mas possui como limitação o tempo que leva para calibrar todas as câmeras, limitando seu uso.

O maior desafio enfrentado na arquitetura de abordagens generalizáveis é que acarretam em uma sobrecarga na apresentação de uma pose candidata, o que influencia no desempenho do método. Considerando esse fator, Qian et al. (2014) reduziram esta complexidade por meio da subamostragem da observação e utilizando esferas para modelar a mão. Melax et al. (2013) propuseram a utilização de heurísticas para guiar a otimização em um processo similar ao do algoritmo Iterative Closest Point - ICP. O estudo de Schmidt et al. (2015), em vez disso, explicitou sobre a utilização de Signed Distance Function para a otimização de um modelo generalizável para o rastreamento do corpo e mãos. Já o trabalho de Sharp et al. (2015) explicita sobre um método que utiliza aprendizagem discriminativa para fornecer vários parâmetros dos modelos candidatos e incorpora informações temporais usando um modelo otimizado com PSO. Entretanto, essas abordagens ainda não oferecem desempenho suficiente para aplicação nesta pesquisa.

Com o intuito de fazer a estimativa da pose em menor tempo que os métodos descritos anteriormente, 
a investigação de Keskin et al. (2013) introduziu uma abordagem que utiliza Random Forests - RDFs para segmentar e estimar a pose da mão, usando imagens sintéticas para o treinamento. Entretanto, além da dificuldade relacionada à criação das imagens sintéticas, dados sintéticos não possuem ruído, que é característico de imagens de profundidade e portanto, esse método não possui acurácia suficiente para utilização em cenários que utilizam imagens capturadas em tempo real. A síntese de ruído foi introduzida por Xu e Cheng (2013), como forma de melhorar o treinamento. Já o trabalho de Tang et al. (2013), explicitou uma abordagem que utiliza dados sintéticos e dados reais para o treinamento das RFDs. Tang et al. (2014) propôs a utilização de RDFs para regressão das articulações das mãos usando uma abordagem hierárquica, regredindo todas as articulações em uma única passagem pela floresta por quadro. No entanto, essa abordagem é vulnerável à propagação de erro, o que leva a estimativas de poses inválidas.

Além de RDFs, outros métodos de aprendizado de máquina podem ser empregados no processo de estimar a pose das mãos. O estudo de Neverova et al. (2014) propõe a utilização de Redes Neurais Convolucionais (CNNs) para para particionar as regiões da mão, enquanto Tompson et al. (2014) as utilizou para estimar a localização das juntas das mãos. Entretanto, os métodos que utilizam CNNs têm desempenho mais lento que as propostas que empregam RDFs. Alternativamente, o uso de Regressão Linear em cascada foi proposto pelo estudo de Sun et al. (2015) para estimar a posição das juntas diretamente da imagem de profundidade. Entretanto, apenas as posições da juntas não são suficientes para estimar a posição de toque da ponta do dedo na face, conforme necessário para esta investigação.

Técnicas estruturais usando a forma e contorno também têm sido utilizadas para estimar a pose das mãos. Nesse contexto, Krejov e Bowden (2013) e Liang et al. (2012) propõem uma abordagem que utiliza informações de profundidade par segmentar as mãos e a geodésica máxima para identificar a pose das mãos em tempo real. Porém, assim como os demais trabalhos analisados, essas abordagens possuem características que não possibilitam o uso em cenários nos quais a mão está muito próxima da face.

Foram investigados ainda, os métodos que são correlatos à perspectiva de transformar a face em uma superfície computacionalmente interativa. Segundo de Sousa e Morimoto (2015), superfícies interativas são superfícies com computação e interação embutidas. Exemplos de superfícies interativas são as paredes mágicas, os quais são utilizados em diversos contextos como educação, arte, entretenimento, etc.

No contexto educacional, Lee (2008) propôs em seu estudo a transformação de uma superfície plana, como uma mesa ou parede, em um quadro interativo. Como equipamentos, o sistema de Lee (2008) necessita de um controle Wiimote, que é um dispositivo dotado de um sensor infra-vermelho, um projetor, um computador e uma caneta LED. Para o funcionamento desse sistema, o sensor sensor infra-vermelho do Wiimote é posicionado em direção a superfície interativa. A superfície é calibrada por meio de matrizes de homografia de modo que qualquer ponto luminoso detectado pela câmera do Wiimote seja mapeado para um pixel correspondente na projeção da superfície. Utilizando a caneta LED o usuário pode interagir com a superfície. Entretanto, esse sistema apresenta como limitações a influência da luz do ambiente na sensibilidade da caneta LED e oclusão da caneta pelo posicionamento do usuário em relação ao sensor.

Ainda no contexto da educação, (Avancini, 2011) demonstrou em seu trabalho de mestrado o uso de um sensor Microsoft Kinect e um projetor para transformar uma parede comum em um quadro interativo. Em relação ao trabalho de Lee (2008), a investigação de (Avancini, 2011) apresenta como vantagem não necessitar de caneta LED para o funcionamento. O processo de calibração desse sistema é dividido em três etapas: detecção do usuário e remoção do cenário de fundo; mapeamento entre o sistema de coordenadas do Kinect e o sistema de coordenadas da projeção na parede; e, por último, detecção da ponta do dedo indicador do usuário fazendo um deslocamento da palma da mão detectada na primeira etapa. Entretanto, 
esse processo de calibração fez com que o uso do sistema seja limitado em relação a interação pois não possibilita ao usuário mover a mão livremente e também não detecta o contato com a parede, necessitando de um mouse para efetuar um clique.

No intuito de transformar superfícies para que sejam sensíveis ao toque, Xiao et al. (2013) propuseram o sistema WorldKit, o qual permite ao usuário utilizar superfícies do dia-a-dia para interagir com aplicativos. Assim como o sistema de Avancini (2011), o funcionamento do WorldKit depende um projetor e um sensor Microsoft Kinect, mas ambos diferem no contexto de uso. A proposta de Xiao et al. (2013) é permitir ao usuário pintar, com a mão, controles denominados interectors, que se assemelham a widgets, além de possibilitar a interação com esses controles. A funcionalidade de toque depende de uma etapa inicial de calibração, na qual 50 quadros são capturados usando o Kinect. Então, as informações de profundidade desses quadros são processada de modo a criar o perfil do cenário de fundo, que nessa etapa de calibração não deve apresentar nenhuma atividade. Depois da calibração, os pixels que estão no limiar de 3 a 50 milímetros de distância dos pixels pertencentes ao cenário de fundo são considerados como pixels de contato. Esses pixels de contato são segmentados e, então, é feita a detecção dos blobs.

Utilizando os fundamentos da abordagem de (Xiao et al., 2013) para calibração e detecção de objetos em contato com uma superfície, de Sousa e Morimoto (2015) apresentaram em seu estudo uma Superficie Mágica, que consiste em um sistema que transforma uma superfície comum em um espaço interativo multi-toque. Nesse sistema, a classificação de objetos é realizada com base em sua cor e a normalização das coordenadas é efetuada por meio de matrizes de homografia. Além disso, (de Sousa e Morimoto, 2015) propuseram em seu trabalho uma "varinha mágica", que se trata de um dispositivo de apontamento para interação 3D construído com materiais de baixo custo com um design fácil de ser reproduzido.

\subsection{Discussão}

Estabelecido o cenário atual dos métodos existentes para transferência e aplicação de maquiagem virtual, foi feita uma análise com foco nas principais características desses métodos em relação ao objetivo desta pesquisa. Essas características são explicitadas na Tabela 2.1. A coluna "Tipo" indica se o algoritmo é para transferência ou aplicação de maquiagem. A coluna "Utiliza Estilo Pré Definido" explicita se o algoritmo permite a aplicação de maquiagem virtual a partir da interação do usuário para escolher livremente as regiões nas quais serão aplicados os produtos virtuais. Sobre o tipo de renderização do resultado da simulação pode ser na forma da renderização do modelo facial 3D ou na própria imagem do usuário e é mostrado na coluna "Renderização do Modelo 3D". Ainda em relação a renderização, a coluna "Tempo Real" refere ao tempo de processamento da imagem do usuário e renderização do resultado da simulação.

Analisando as principais características dos métodos de simulação de maquiagem, foi possível perceber que os artigos que tratam de transferência de maquiagem de Tong et al. (2007), Guo e Sim (2009) e Scherbaum et al. (2011) não são, por si só, suficientes para a implementação do método de aplicação de maquiagem virtual deste estudo, pois necessitam de imagens modelo com maquiagem aplicada na face $\mathrm{e}$ requerem que a pose da face da imagem alvo seja o mais parecida possível com a pose da imagem modelo. Além desses requisitos indesejáveis, não apresentam uma forma generalizável para simular o efeito da maquiagem com produtos físicos na imagem da face de uma pessoa.

Em relação aos métodos apresentados para aplicação de maquiagem, os trabalhos de Dhall et al. (2009) e Kim e Choi (2008) são limitados em calcular uma média ponderada para simular os efeitos da maquiagem na pele e não levam em consideração características faciais, o que implica em um resultado pouco realista. 


\begin{tabular}{|c|c|c|c|c|}
\hline Estudo & Tipo & $\begin{array}{c}\text { Utiliza Estilo } \\
\text { Pré-definido }\end{array}$ & $\begin{array}{c}\text { Renderização } \\
\text { do Modelo 3D }\end{array}$ & Tempo Real \\
\hline Tong et al. $(2007)$ & Transferência & Sim & Não & Possivelmente Não \\
\hline Kim e Choi $(2008)$ & Aplicação & Não & Sim & Sim \\
\hline Guo e Sim $(2009)$ & Transferência & Sim & Não & Possivelmente Não \\
\hline Scherbaum et al. $(2011)$ & Transferência & Sim & Sim & Possivelmente Não \\
\hline Dhall et al. $(2009)$ & Aplicação & Sim & Não & Sim \\
\hline Huang et al. $(2013)$ & Aplicação & Sim & Sim & Sim \\
\hline Jang et al. (2013) & Aplicação & Sim & Sim & Possivelmente Não \\
\hline Campos $(2014)$ & Aplicação & Não & Não & Sim \\
\hline
\end{tabular}

Tabela 2.1: Comparativo dos métodos de simulação de transferência e aplicação de maquiagem.

Quanto aos métodos propostos por Huang et al. (2013) e Jang et al. (2013), apesar de apresentarem resultados interessantes para a renderização da maquiagem virtual, utilizam equipamentos especiais para escanear a pele e os produtos de maquiagem para obter as propriedades ópticas, o que impossibilita seu uso em tempo real em um sistema interativo para aplicação de maquiagem virtual.

A pesquisa de Campos (2014) apresenta aspectos desejáveis para o presente trabalho como aplicação sem estilos pré-definidos, renderização da imagem da face do usuário e ser em tempo real. Entretanto, Campos (2014) não trata os efeitos de sombreamento e destaque causados pela maquiagem virtual. Dessa forma, esses trabalhos que abordam sobre aplicação de maquiagem virtual também não possuem características suficientes para a implementação do método para aplicação de maquiagem virtual desta pesquisa.

A análise dos trabalhos acadêmicos e sistemas investigados foi realizada com foco nas principais características de interação com o usuário adequadas ao propósito desta investigação. Essa análise possibilitou averiguar que diferentes tipos de interação são usados pelos sistemas existentes. Além disso, foi verificado que alguns sistemas não possuem como finalidade a aplicação da maquiagem virtual.

A tabela 2.2 apresenta os sistemas estudados juntamente com suas respectivas características relevantes para esta pesquisa, quais sejam: "Maquiagem Virtual" que se refere à funcionalidade de aplicação de maquiagem virtual; "Interface" que se trata do tipo de dispositivo utilizado para aplicar a maquiagem; "Marcadores" que é relativa a utilização de marcadores nos aplicadores físicos utilizados; "Simulação em vídeo" que está relacionada à simulação em tempo real; e "Disponível para uso" que indica se o sistema está disponível no mercado para utilização.

Como explicitado na Tabela 2.2, apesar de alguns trabalhos estudados possuírem uma interface de interação 3D e possibilitarem que o usuário empregue movimentos semelhantes aos utilizados para a automaquiagem com produtos físicos, somente o de (Rahman et al., 2010) e o da Natura (2012) permitem que o usuário toque na própria face para autoaplicar maquiagem virtual. Entretanto, o protótipo de (Rahman et al. , 2010) possui restrições de uso pois necessita de leitores RFID, emissores e câmera IR, pincéis ou aplicadores com marcadores fixados e precisa ser calibrado. Em relação à experiência do usuário, os resultados experimentais indicaram que os usuários não se sentiram satisfeitos com a qualidade da imagem resultante da aplicação da maquiagem virtual. Assim, apenas o sistema proposto pela Natura (2012) tem características semelhantes às propostas neste estudo, mas, como explicitado anteriormente, esse sistema possui limitações como baixa resolução da imagem, erros na região de aplicação da maquiagem, apresentação por vezes, da figura geométrica que delimita as regiões faciais e não possui a funcionalidade de zoom. Além disso, a Natura não realizou experimentos para investigar sobre a experiência do usuário na interação com o sistema e 


\begin{tabular}{|c|c|c|c|c|c|}
\hline $\begin{array}{l}\text { Autor ou } \\
\text { Empresa }\end{array}$ & $\begin{array}{l}\text { Maquiagem } \\
\text { virtual }\end{array}$ & Interface & Marcadores & $\begin{array}{l}\text { Simulação } \\
\text { em vídeo }\end{array}$ & $\begin{array}{l}\text { Disponível } \\
\text { para uso }\end{array}$ \\
\hline Kim e Choi (2007) & $\mathrm{Sim}$ & $\begin{array}{l}\text { Dispositivo } \\
\text { Háptico }\end{array}$ & Não & Não & Não \\
\hline Kim e Choi (2008) & Sim & $\begin{array}{l}\text { Dispositivo } \\
\text { Háptico }\end{array}$ & Não & Não & Não \\
\hline Iwabuchi et al. (2009) & Não & $\begin{array}{l}\text { Próprio } \\
\text { Produto }\end{array}$ & Não & Sim & Não \\
\hline Rahman et al. (2010) & Sim & $\begin{array}{c}\text { Mockup } \\
\text { do produto }\end{array}$ & Sim & Sim & Não \\
\hline Shiseido (2010) & Sim & $\begin{array}{l}\text { Toques } \\
\text { na tela }\end{array}$ & Não & Sim & Sim \\
\hline Hanafusa et al. (2010) & Não & $\begin{array}{l}\text { Próprio } \\
\text { produto }\end{array}$ & Não & Sim & Não \\
\hline Nakagawa et al. (2011) & Não & $\begin{array}{l}\text { Próprio } \\
\text { produto }\end{array}$ & Não & Sim & Não \\
\hline Natura (2012) & Sim & $\begin{array}{l}\text { Toques } \\
\text { na face }\end{array}$ & Não & Sim & Não \\
\hline Campos (2014) & Sim & $\begin{array}{l}\text { Toques } \\
\text { na tela }\end{array}$ & Não & Sim & Não \\
\hline Modiface (2014) & Sim & $\begin{array}{l}\text { Toques } \\
\text { na tela }\end{array}$ & Não & Sim & Não \\
\hline $\begin{array}{c}\text { Sephora em parceria } \\
\text { com a Modiface (2014) }\end{array}$ & Sim & $\begin{array}{l}\text { Toques } \\
\text { na tela }\end{array}$ & Não & Sim & Sim \\
\hline YouCam Makeup (2015) & Sim & $\begin{array}{l}\text { Toques } \\
\text { na tela }\end{array}$ & Não & Sim & Sim \\
\hline Panasonic (2015) & Sim & $\begin{array}{l}\text { Toques } \\
\text { na tela }\end{array}$ & Não & Sim & Sim \\
\hline Panasonic (2016) & Sim & $\begin{array}{l}\text { Toques } \\
\text { na tela }\end{array}$ & Não & Sim & Sim \\
\hline $\begin{array}{c}\text { Sites como Avon } \\
\text { e Mary Kay (2016) }\end{array}$ & Sim & Mouse & Não & Sim & Sim \\
\hline Site Modiface (2016) & Sim & Mouse & Não & Sim & Sim \\
\hline
\end{tabular}

Tabela 2.2: Comparativo das características dos trabalhos e sistemas investigados.

não o disponibilizou para uso, o que impossibilita sua utilização como ferramenta para verificar a hipótese considerada por esta pesquisa.

Ao analisar os sistemas de simulação de maquiagem que estão disponíveis para utilização, o que se pôde perceber é que todos possuem estilos pré-definidos de maquiagens a serem simuladas e não disponibilizam uma interface 3D para que o usuário interaja de forma mais realista. Desse modo, considerando a nossa hipótese de pesquisa apresentada na sessão introdutória, essas características não se encaixam nos objetivos propostos neste trabalho.

Em relação aos trabalhos encontrados na revisão de literatura com foco no toque facial, as abordagens que efetuam a estimativa da posição da mão não são adequadas para os cenários de autoaplicação de maquiagem, e ao analisar as características das abordagens apresentadas para a transformação de superfícies para se tornarem computacionalmente interativas, o que se pode perceber é que nenhuma delas é adequada para os propósitos desta pesquisa, pois todas elas consideram que a superfície não pode mudar de posição depois da 
etapa de calibração, e portanto, não podem ser aplicadas à face, que vai estar em movimento nos cenários de autoaplicação de maquiagem. 


\section{Capítulo 3}

\section{Design do SelfMakeup}

Ao estabelecer o cenário atual sobre as investigações acadêmicas e sistemas existentes no mercado voltados para o tema desta pesquisa, foi constatado que, embora existam diversas iniciativas para proporcionar ao usuário a experimentação de maquiagem virtual, a autoaplicação de maquiagem virtual tocando diretamente na face foi pouco explorada.

Uma questão em interação humano-computador é naturalismo na interação. Estudos mostram que altos graus de naturalismo podem melhorar a experiência do usuário no geral e que técnicas de interação tradicionais, as quais não envolvem interação 3D, são limitadas no potencial do naturalismo. Por outro lado, interfaces 3D são únicas em sua capacidade de alcançar níveis elevados de fidelidade na interação e que esse naturalismo pode ser uma vantagem significativa (Bowman et al., 2012).

Considerando esse contexto e a forma com que o processo de automaquiagem com produtos físicos é realizado, nós acreditamos que, permitir que o usuário autoaplique maquiagem virtual tocando em sua própria face é mais natural que usando toques na tela. Mais especificamente, acreditamos que é possível melhorar a experiência do usuário ao proporcionar fidelidade na interação com um sistema de realidade aumentada para autoaplicação de maquiagem virtual. Entretanto, como mostrado no Capítulo 2, nenhum estudo ou sistema encontrado possui as características adequadas para subsidiar a investigação sobre a nossa hipótese de pesquisa. Desse modo, como forma de viabilizar essa investigação, foi necessário arquitetar e construir um sistema de realidade aumentada, denominado SelfMakeup, que possibilita ao usuário a autoaplicação de maquiagem virtual por meio de toques na face. Assim, este capítulo apresenta as características do design de interação do SelfMakeup.

O primeiro passo do design de interação do SelfMakeup foi o estabelecimento dos requistos, que levaram à definição de um caso de uso essencial. Como pode ser observado na tabela 3.1, esse caso de uso essencial apresenta uma abstração dos cenários de automaquiagem e foi estruturado em três partes: um nome que representa a intenção geral do usuário, uma descrição que representa as ações do usuário e uma descrição em passos que corresponde às responsabilidades do sistema.

A divisão entre as ações do usuário e as responsabilidades do sistema nesse caso de uso essencial foram utilizadas como subsídios para a construção do modelo conceitual do SelfMakeup. Assim, para projetar a interface de interação do SelfMakeup foi estabelecido um modelo conceitual com base nos aspectos fundamentais da experiência das pessoas no processo de automaquiagem com produtos físicos. Como componente central do modelo conceitual foi utilizada a metáfora de interface espelho, com o intuito de fornecer uma entidade familiar, a qual permite ao usuário compreender o modelo conceitual subjacente e saber como interagir com o sistema. Ainda, para compor o modelo conceitual, foi determinada a utilização de uma interface natural para possibilitar ao usuário autoaplicar maquiagem virtual tocando em sua própria face. 
aplicarMaquiagemVirtual

\begin{tabular}{ll}
\hline INTENÇÃO DO USUÁRIO & RESPONSABILIDADES DO SISTEMA \\
\hline Selecionar um produto de maquiagem. & $\begin{array}{l}\text { Apresentar produtos de maquiagem virtual } \\
\text { na Interface Gráfica. }\end{array}$ \\
$\begin{array}{l}\text { Tocar o aplicador físico na face para aplicar } \\
\text { o produto virtual. }\end{array}$ & $\begin{array}{l}\text { Reconhecer a posição na face tocada pelo } \\
\text { usuário. }\end{array}$ \\
$\begin{array}{l}\text { Visualizar o resultado da aplicação do pro- } \\
\text { duto de maquiagem virtual, em tempo real, } \\
\text { na imagem de sua própria face. }\end{array}$ & $\begin{array}{l}\text { Capturar a imagem da face do usuário em } \\
\text { tempo real e renderizar os resultados da } \\
\text { aplicação da maquiagem virtual. }\end{array}$
\end{tabular}

Tabela 3.1: Caso de uso essencial para a autoaplicação de maquiagem virtual por meio de toques na face

O modelo conceitual estabelecido possibilitou a definição da arquitetura do SelfMakeup, que é explicitada na figura 3.1.

Depois de construir um modelo conceitual do sistema e planejar as características arquiteturais, partiu-se para a expansão desse modelo conceitual. Essa etapa englobou a análise de cada módulo e o levantamento de características mais específicas do design da solução.

\subsection{Componentes da interface}

Considerando o modelo conceitual estabelecido para o SelfMakeup, o sistema possui um monitor, um mouse e um sensor RGBD como componentes de interface.

Visto que as pessoas utilizam um espelho físico para visualizar o resultado da aplicação de um produto de maquiagem na face, o monitor efetua a renderização da imagem do usuário contendo o resultado da aplicação da maquiagem virtual em tempo real, comportando-se como um espelho virtual. Além da imagem do usuário, esse monitor apresenta ao usuário as funcionalidades do sistema, que podem ser selecionadas usando o mouse.

Com o intuito de permitir ao usuário do sistema de realidade aumentada autoaplicar a maquiagem virtual tocando em sua própria face, foi idealizada a utilização de um sensor RGBD que seja capaz de capturar a imagem do usuário em alta resolução e a profundidade dos componentes presentes na imagem.

\subsubsection{Sensor RGBD}

Dos sistemas apresentados no Capítulo 2, os que mais se assemelham ao proposto pelo presente estudo utilizaram um sensor Microsoft Kinect para a captura das imagens RGBD. Desse modo, inicialmente, foram levantadas algumas características do Kinect importantes para a sua utilização nesta pesquisa. Depois disso, foi realizada uma busca sobre as características do sensor Intel RealSense, por ele ser capaz de rastrear mãos e dedos, além de fazer análise facial. Desse modo, foi possível estabelecer as principais diferenças entre esses dois sensores, as quais podem ser visualizadas na Tabela 3.2.

Considerando os dados comparativos dos dois sensores, foi possível perceber que o Intel RealSense oferece mais vantagens, principalmente pelo fato de possuir uma câmera RGB com maior resolução. Ainda, como pode ser observado na Tabela 3.2, o RealSense possui como vantagem em relação ao Kinect, o intervalo de rastreamento da face ter limite inferior menor, pois isso possibilita que a câmera RGB capture a imagem 


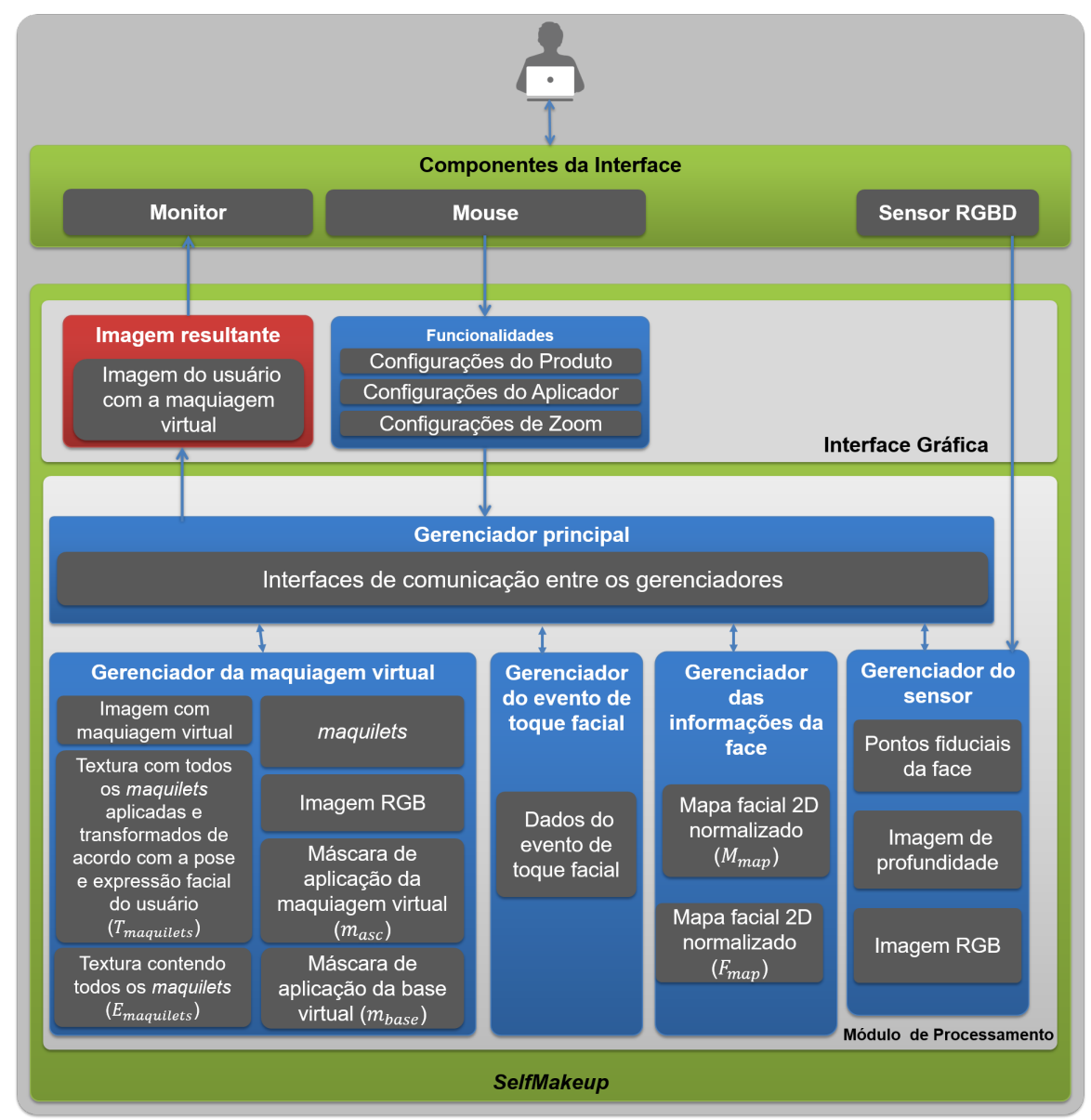

Figura 3.1: Arquitetura do SelfMakeup, composta por componentes da interface, interface Gráfica e módulo de processamento.

da face do usuário mais aproximada e, portanto, são capturados mais detalhes da face do usuário, os quais são de grande importância para a aplicação da maquiagem virtual.

De acordo com Intel (2014), o rastreamento dos pontos fiduciais da face é suportado para usuários com pelos faciais e com óculos de grau e funciona melhor quando a cabeça do usuário está inclinada até $30^{\circ}$ de yaw e pitch. Entretanto, o fabricante informa que se pontos fiduciais da face ou das mãos estiverem oclusos, não é garantido que o SDK forneça as posições desses pontos com acurácia alta. Além disso, quanto a sugestão da Intel (2014) para o uso do sensor para rastrear a posição de pontos nas mãos, foi possível averiguar que não é garantida a acurácia das informações em ocasiões na quais um dedo oclui do campo de captura da câmera grande parte de outro dedo, ou quando as mãos estão tocando partes do corpo ou segurando objetos.

Dessa forma, foram realizados alguns testes utilizando aplicações exemplo que acompanham o SDK do RealSense com o intuito de averiguar as informações obtidas na documentação da Intel e verificar a adequação do uso do RealSense como sensor RGBD para alguns cenários de autoaplicação de maquiagem. Analisando qualitativamente os resultados inciais obtidos a partir dos testes com o RealSense utilizando cenários de automaquiagem, foi possível constatar empiricamente que o sensor Intel RealSense é adequado aos objetivos deste estudo, pois, além de capturar a imagem RGB do usuário em alta resolução, é capaz de fornecer informações sobre o rastreamento da face sob condições como movimentação da face do usuário em relação ao sensor, utilização de óculos, expressões faciais e oclusão de regiões faciais pelo aplicador. Entretanto, foi identificado que os dados sobre o rastreamento da mão fornecidos pelo RealSense não são suficientes para utilização no âmbito desta pesquisa. 


\begin{tabular}{|c|c|c|}
\hline Característica & Kinect & RealSense \\
\hline Rastreamento Facial & Sim & Sim \\
\hline Número de pontos na face $3 \mathrm{D}$ & 36 & 78 \\
\hline Rastreamento das mãos & Não & Sim \\
\hline Número de pontos das mãos & 0 & 22 \\
\hline $\begin{array}{l}\text { Resolução em pixels da Câmera } \\
\text { de Profundidade }\end{array}$ & $640 \times 480$ & $640 \times 480$ \\
\hline $\begin{array}{l}\text { Resolução em pixels da Câmera } \\
\text { RGB }\end{array}$ & $1280 \times 960$ & $1920 \times 1080(2 \mathrm{M})$ \\
\hline $\begin{array}{l}\text { Ângulo de Visão da Câmera de } \\
\text { Profundidade }\end{array}$ & $43^{\circ}$ vertical por $57^{\circ}$ horizontal & $90^{\circ} \times 59^{\circ} \times 73^{\circ}($ Cone $)$ \\
\hline $\begin{array}{l}\text { Ângulo de Visão da Câmera } \\
\text { RGB }\end{array}$ & $43^{\circ}$ vertical por $57^{\circ}$ horizontal & $77^{\circ} \times 43^{\circ} \times 70^{\circ}($ Cone $)$ \\
\hline $\begin{array}{l}\text { Frame rate (Câmera de Profundi- } \\
\text { dade) }\end{array}$ & 30 frames por segundo (FPS) & 30/60/120FPS \\
\hline Frame rate (Câmera RGB) & 30 frames por segundo (FPS) & 30/60/120FPS* \\
\hline $\begin{array}{l}\text { Intervalo para rastreamento da } \\
\text { face }\end{array}$ & $80 \mathrm{~cm} \mathrm{a} 400 \mathrm{~cm}$ & 2D: $35-120 \mathrm{~cm} 3 \mathrm{D}: 35-70 \mathrm{~cm}$ \\
\hline $\begin{array}{l}\text { Intervalo Reconhecimento de } \\
\text { gestos }\end{array}$ & Não Contém & $\begin{array}{l}\text { HVGA mode: } 20-55 \mathrm{cmVGA} \\
\text { mode: } 20-60 \mathrm{~cm}\end{array}$ \\
\hline
\end{tabular}

Tabela 3.2: Comparativo das principais características dos sensores Microsof Kinect e Intel RealSense. As informações foram retiradas do site dos respectivos fabricantes: https://msdn.microsoft.com/en-us/library/jj131033.aspx e https://software.intel.com/en-us/realsense/devkit.

\subsection{Interface gráfica}

A interface gráfica permite ao usuário acessar as funcionalidades do sistema, além de conter imagem do usuário com o resultado da aplicação da maquiagem virtual.

Como funcionalidades, o SelfMakeup possibilita que o usuário escolha o tipo de produto virtual que deseja aplicar e sua cor, além de permitir que configure o aplicador de maquiagem virtual, ajustando o tipo de borda, tamanho e intensidade. Propicia ainda, que o usuário utilize o removedor para retirar produtos aplicados em uma região da face, volte a última aplicação, remova o último ou todos os produtos. Além disso, possui também como funcionalidade a opção de o usuário ampliar sua imagem.

Como opções de produtos de maquiagem, o SelfMakeup disponibiliza: base, blush, sombra, batom e removedor.

Considerando essas funcionalidades, o SelfMakeup permite que o usuário escolha as características do aplicador e do produto virtual para então aplicar esse produto virtual na região facial desejada. Ainda, possibilita ao usuário a comparação ou combinação da aplicação de um ou mais produto virtual, além de permitir que o usuário desfaça aplicações de produtos virtuais indesejados.

\subsection{Módulo de processamento}

O Módulo de processamento, processa essas imagens RGBD com o intuito de identificar a posição da face do usuário na imagem, juntamente com os marcadores faciais correspondentes ao contorno da face, do nariz, dos olhos e dos lábios. Além disso, detecta a posição na imagem correspondente ao aplicador que será utilizado para tocar a face e aplicar a maquiagem virtual. Esse módulo contém o modelo da face do 
usuário construído com base nos marcadores faciais e os maquilets correspondentes aos produtos virtuais disponibilizados na GUI, além de detectar a região facial que o aplicador está tocando.

O Módulo de processamento é responsável ainda por fornecer, para a interface gráfica, a imagem resultante do processo de aplicação de um ou mais produtos de maquiagem virtual.

Os detalhes sobre o gerenciamento das informações da face são apresentados a seguir e servem de subsídio para o entendimento do método que efetua a estimativa da posição do toque facial e do algoritmo para aplicação da maquiagem virtual na imagem facial do usuário.

\subsubsection{Gerenciador das informações da face}

Um passo importante para o módulo de processamento do SelfMakeup é a detecção e rastreamento da face. Mais especificamente, para aplicar a maquiagem virtual na imagem da face do usuário, é preciso, primeiro, obter os pontos fiduciais da face com o intuito de utilizá-los como referenciais. Esses pontos fiduciais são pontos localizados nos contornos de regiões faciais, como boca, nariz, olhos, sobrancelhas, queixo e testa, e são necessários para fazer o mapeamento da posição da aplicação da maquiagem virtual em todos os quadros capturados em tempo real. Isso porque, considerando os cenários do processo de automaquiagem com produtos físicos e as ações tomadas por um indivíduo nesse processo, durante a utilização do sistema para autoaplicação de maquiagem virtual, é preciso permitir que o usuário mova a cabeça e mude de expressão facial.

Apesar de existirem alternativas da implementação da Intel para recuperar as informações da posição da face e dos seus pontos fiduciais como as bibliotecas Dlib e Viola Jones, foi decidido usar os dados fornecidos pelo SDK do Real Sense, uma vez que apresentou resultados satisfatórios na detecção e rastreamento da face mesmo em cenários nos quais uma parte de face é ocultada pelo aplicador. O SDK do RealSense fornece 78 pontos fiduciais da face que indicam a localização da boca, sobrancelhas, olhos, nariz e contorno do rosto, como apresentado na Figura 3.2.

Como o SDK do RealSense não fornece os pontos fiduciais de contorno da testa e do nariz, nós calculamos quinze pontos adicionais, com base em proporções faciais. Esses novos pontos, calculados com as equações explicitadas no Apêndice A, são apresentados na cor verde na Figura 3.3, enquanto os pontos em azul são os pontos fornecidos pelo SDK do RealSense. Os dois pontos correspondentes às pupilas não são utilizados.

Considerando a localização desses pontos e proporções da face humana, antes de iniciar o processo iterativo do gerenciador das informações da face, é criado um mapa facial 2D em um espaço normalizado com coordenadas $(u, v)$. Esse mapa facial $M_{m a p}$ é subdividido em oito regiões $R_{\text {face }}$ que correspondem a: bochecha direita; bochecha esquerda; testa; nariz; lábios inferiores da boca e queixo; lábios superiores e região entre a boca e o nariz; pálpebra direita; pálpebra esquerda. De acordo com a topologia da face, cada $r_{i} \in R_{\text {face }}$ é subdividida em um número de triângulos que possuem como vértices os prontos fiduciais da face. Ao final, $M_{\text {map }}$ contém 124 triângulos em um espaço normalizado que vai de 0 a 0,5 no eixo vertical (eixo v) e de 0 a 1 no eixo horizontal (eixo u), como apresentado na Figura 3.3. Essa etapa de criação de $M_{\text {map }}$ elimina a necessidade de calibração do sistema para construção do modelo 3D da face do usuário.

Uma vez que $M_{\text {map }}$ é criado no espaço normalizado, é gerado um mapa facial 2D $F_{\text {map }}$ contendo a mesma estrutura de pontos, triângulos e regiões faciais que $M_{m a p}$. Isto é, para cada ponto $p_{i}(u, v) \in M_{\text {map }}$ existe um ponto $p_{i}^{\prime}(x, y) \in F_{\text {map }}$ correspondente, para cada triângulo $t_{i}^{\prime} \in M_{\text {map }}$ existe um triângulo $t_{i} \in F_{\text {map }}$ correspondente e para cada região facial $r_{i} \in M_{\text {map }}$ existe uma região correspondente $r_{i}^{\prime} \in F_{\text {map }}$. Tendo $F_{\text {map }}$ construído, a cada quadro do processo iterativo, as coordenadas $(x, y)$ de cada $p_{i}^{\prime} \in F_{\text {map }}$ são atualizadas com 


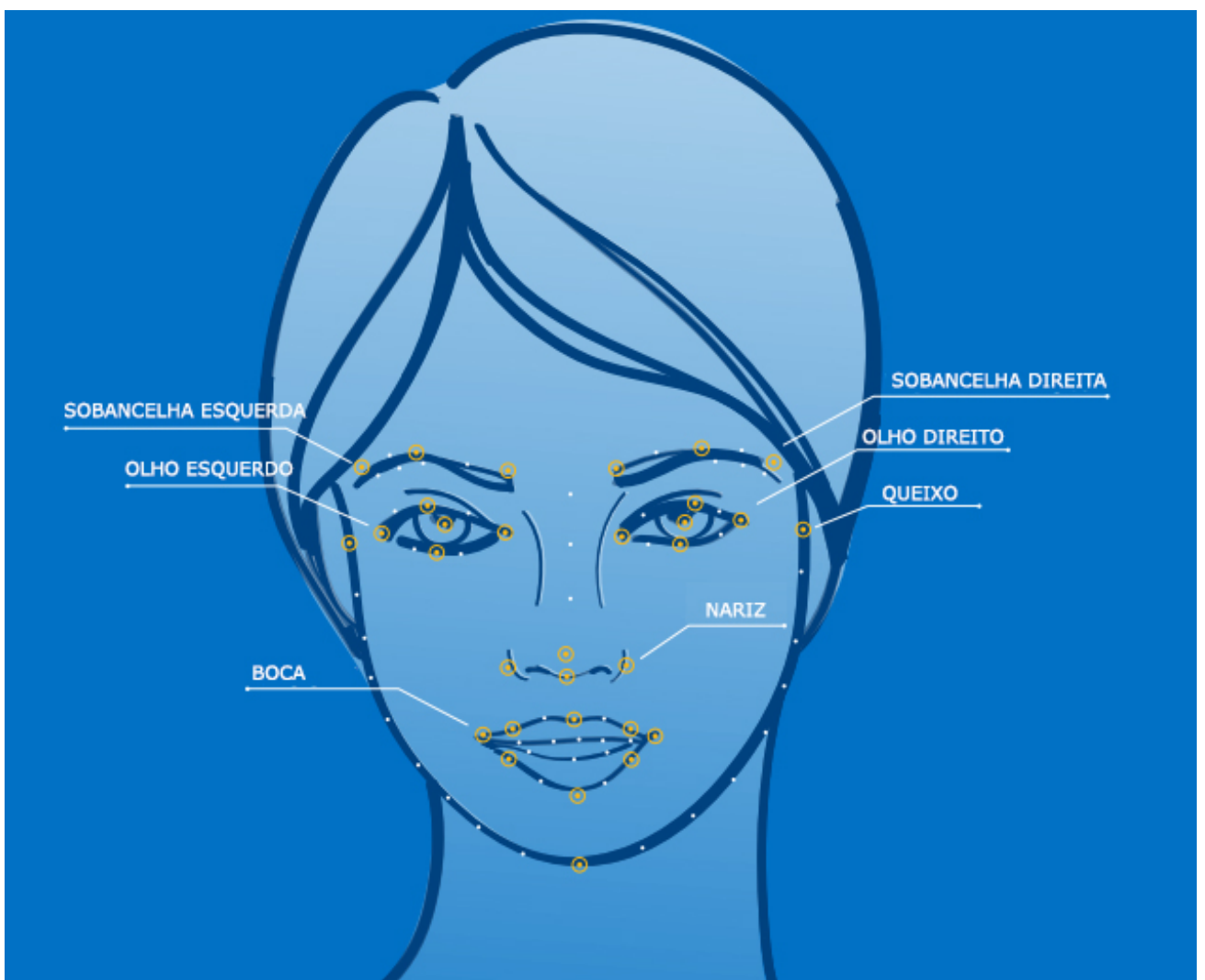

Figura 3.2: Pontos fiduciais da face fornecidos pelo módulo de rastreamento da face do SDK do RealSense. Imagem retirada de RealSense (2016).

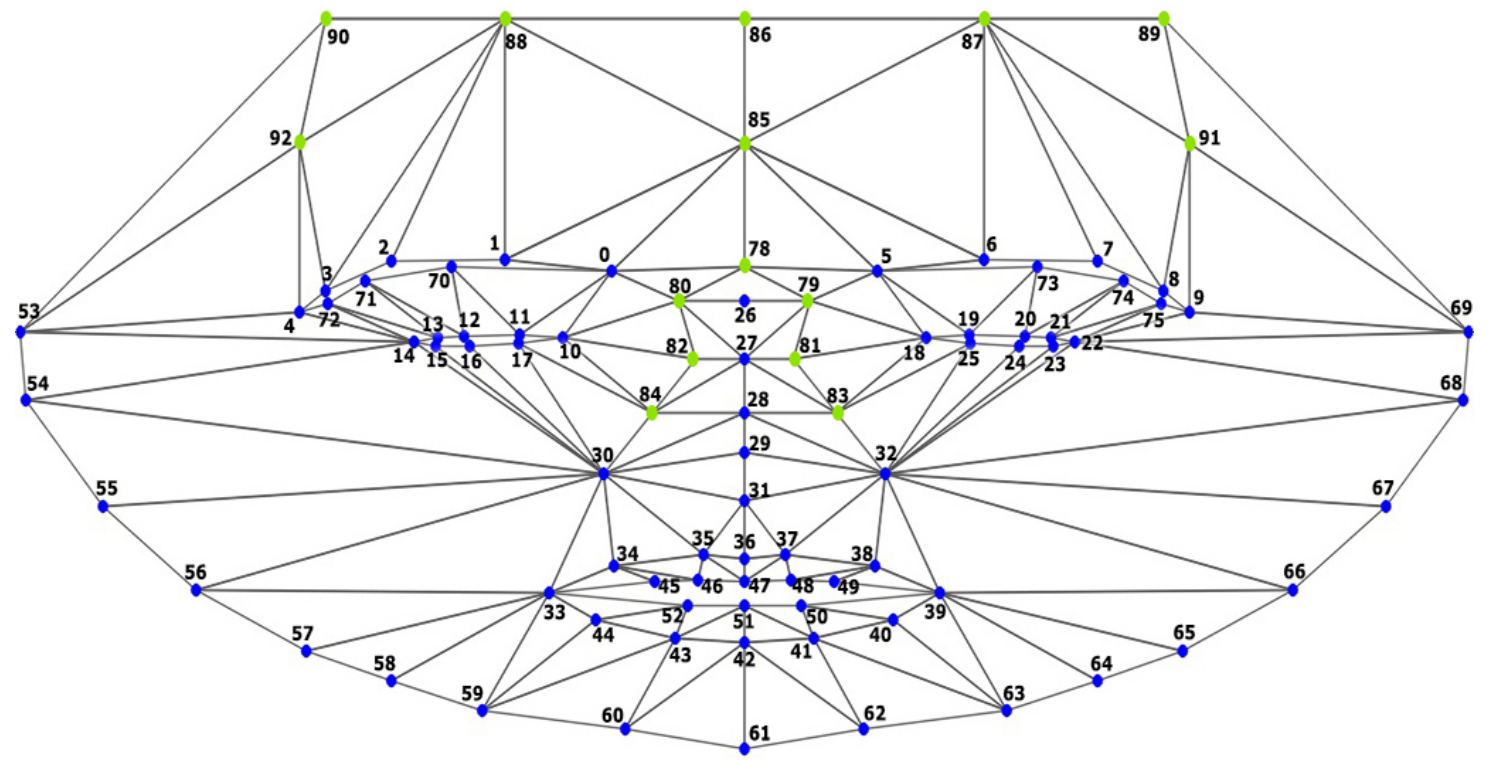

Figura 3.3: Mapa do modelo facial $M_{\text {map }}$ contendo 124 triângulos no espaço facial normalizado 2D. Os pontos fiduciais da face em azul são os pontos fornecidos pelo SDK do RealSense. Os pontos em verde são pontos calculados.

os valores das coordenadas dos pontos faciais fornecidas pelo SDK do RealSense. As coordenadas $(x, y)$ são posições da imagem RGB do usuário capturada pelo RealSense.

Além de atualizar as posições dos pontos de $F_{\text {map }}$ de acordo com a pose e a expressão facial do usuário em cada quadro, o módulo de gerenciamento de informações da face possui outras duas funções: fazer a transformação de coordenadas $(x, y)$ de $F_{\text {map }}$ para coordenadas $(u, v)$ de $M_{m a p}$ e vice-versa. A primeira, é 
necessária para detectar a posição do toque na face no espaço normalizado, que será detalhado na subseção 3.3.2. A segunda é imprescindível para efetuar o mapeamento da textura da maquiagem virtual na imagem facial do usuário, etapa que será apresentada na subseção 3.3.3. Essas transformações são realizadas utilizando a correspondência das regiões faciais e triângulos dos mapas modelos $M_{\text {map }}$ e $F_{\text {map }}$.

A função que efetua a transformação de uma coordenada $(x, y)$ de $F_{\text {map }}$ para uma coordenada $(u, v)$ de $M_{\text {map }}$ recebe como entrada um ponto $p_{i n}$ com coordenadas $(x, y)$ e verifica, primeiro, a qual região facial $r_{i}^{\prime} \in F_{\text {map }}$ esse ponto pertence. Encontrada $r_{i}^{\prime}$, essa função identifica em qual triângulo $t_{i}^{\prime} \in r^{\prime}$ de $F_{\text {map }}, p_{\text {in }}$ está posicionado. Depois de detectar $t_{i}^{\prime}$, para obter a transformação afim necessária para que $t_{i}^{\prime}$ assuma a posição de $t_{i}$, as coordenadas $\left(u_{k}, v_{k}\right)$ dos três vértices de $t_{i}$ e as coordenadas $\left(x_{k}, y_{k}\right)$ dos três vértices de $t_{k}^{\prime}$ são submetidas à equação 3.1 .

$$
\left[\begin{array}{l}
u_{k} \\
v_{k}
\end{array}\right]=\left[\begin{array}{lll}
m_{11} & m_{12} & x_{t k} \\
m_{21} & m_{22} & y_{t k}
\end{array}\right]\left[\begin{array}{l}
x_{k} \\
y_{k}
\end{array}\right]
$$

Uma vez que os pontos internos de $t_{i}^{\prime}$ deverão passar pelas mesmas transformações geométricas que $t_{i}^{\prime}$, a transformação afim obtida com a equação 3.1 deve ser aplicada a $p_{\text {in }}(x, y)$ para obter o ponto $p_{\text {out }}(u, v)$, que indica a posição do toque facial em coordenadas $(u, v)$ de $M_{\text {map }}$ ao final desse processo, que pode ser observado pela figura 3.4 .

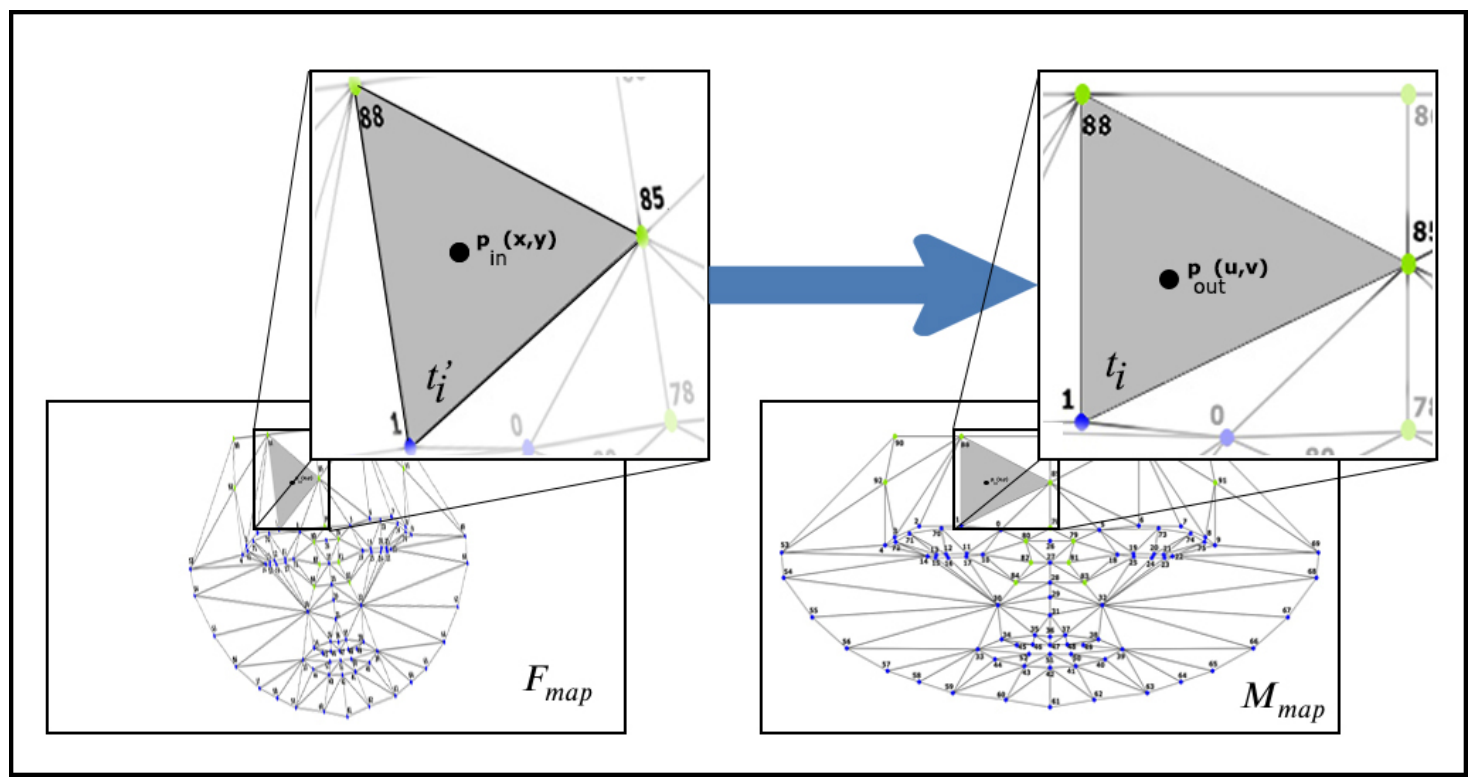

Figura 3.4: Imagem que representa o processo de transformação das coordenadas de um ponto $p_{\text {in }}(x, y)$ de $F_{\text {map }}$ para

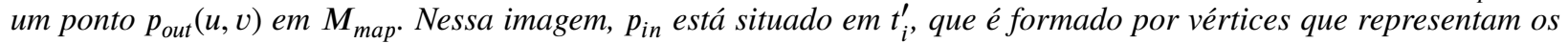
pontos fiduciais 1, 88 e 85 e possui como correspondente $t_{i}$. Assim, as coordenadas dos vértices 1, 88 e 85 de $F_{\text {map }} e$ de $M_{\text {map }}$ são utilizadas para obter a transformação afim que será aplicada a $p_{i n}(x, y)$ para encontrar as coordenadas de $p_{\text {out }}(u, v)$.

Já a função que efetua o cálculo das transformações afins de todos os triângulos $t_{i} \in M_{\text {map }}$ que contêm maquiagem virtual aplicada para os seus correspondentes $t_{i}^{\prime} \in F_{\text {map }}$, recebe como entrada uma textura $T_{i n}$ contendo a maquiagem virtual aplicada. Como essa textura é construída com base em $M_{m a p}$ e possui pontos com coordenadas $(u, v)$, a cada quadro, precisa ser mapeada para $F_{\text {map }}$. Para tanto, utilizando a correspondência de triângulos entre $M_{\text {map }}$ e $f_{\text {map }}$, os vértices de cada triângulo $t_{i}$ e de seu correspondente $t_{i}^{\prime}$ são 
submetidos à matriz da equação 3.2 para encontrar a transformação afim necessária.

$$
\left[\begin{array}{l}
x_{k} \\
y_{k}
\end{array}\right]=\left[\begin{array}{lll}
m_{11} & m_{12} & u_{t k} \\
m_{21} & m_{22} & v_{t k}
\end{array}\right]\left[\begin{array}{l}
u_{k} \\
v_{k}
\end{array}\right]
$$

Depois de obter a transformação de um $t_{i} \in M_{\text {map }}$ para o triângulo correspondente $t_{i}^{\prime} \in F_{\text {map }}$, essa transformação é aplicada a todos os pontos internos a $t_{i}$ e esse processo se repete para todo $t_{i}$ que tem maquiagem virtual aplicada. Ao final, $T_{\text {in }}$ é transformada em $T_{\text {out }}$, que é a textura da maquiagem virtual correspondente a pose e expressão facial do usuário no quadro atual. A Figura 3.5 apresenta esse processo.

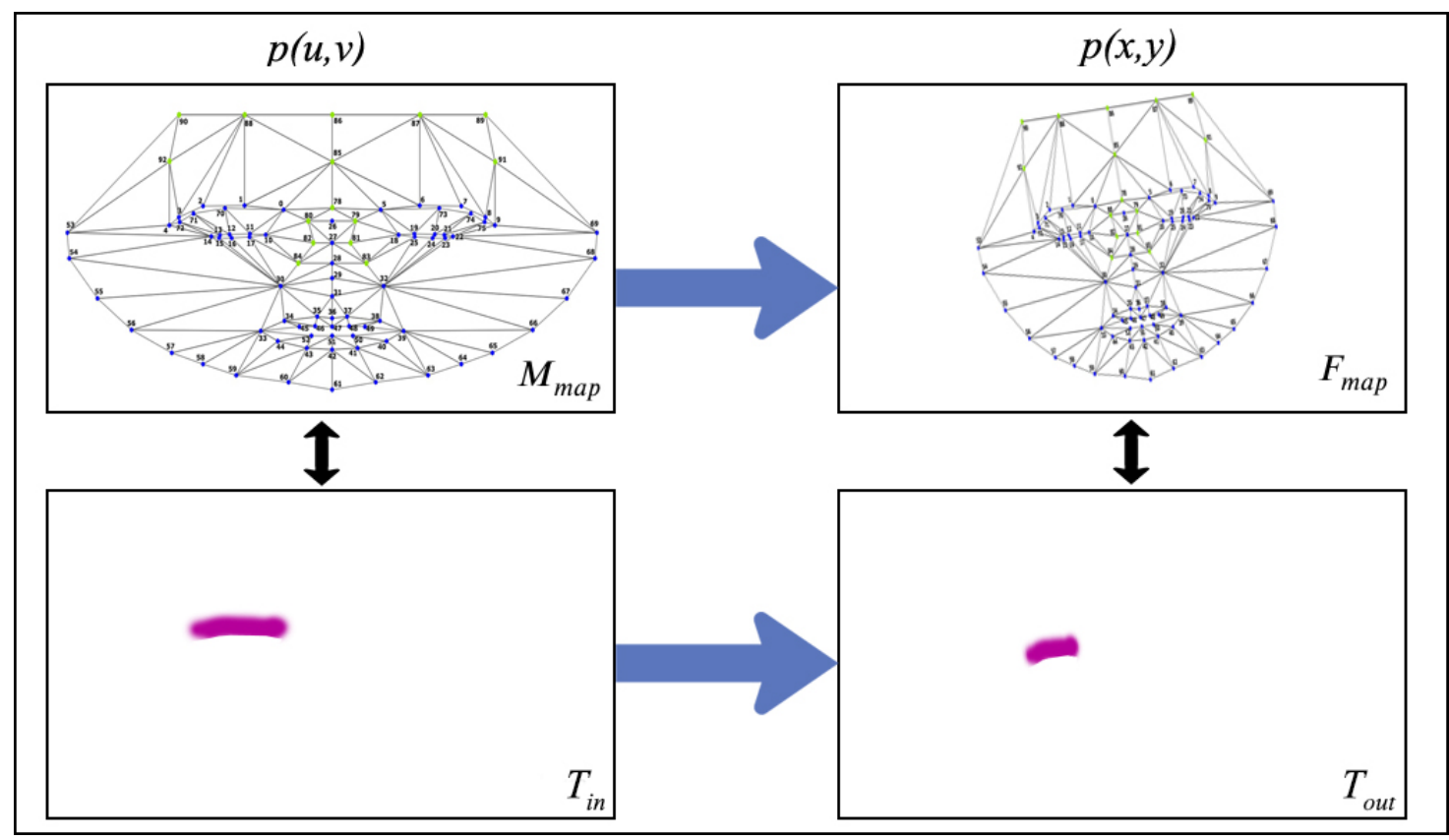

Figura 3.5: Imagem que representa o processo de transformação de uma textura com coordenadas $(u, v)$ para uma textura com coordenadas $(x, y)$ de acordo com a pose e expressão facial do usuário, utilizando as informações das transformações de $M_{\text {map }}$ para $F_{\text {map }}$.

\subsubsection{Gerenciador do evento de toque facial}

Para possibilitar a autoaplicação de maquiagem virtual em tempo real permitindo os mesmos movimentos empregados para a automaquiagem no mundo real, é necessário disponibilizar uma interface natural que detecta toques de um aplicador físico na própria face do usuário. Entretanto, considerando os cenários de automaquiagem, esse aplicador físico pode possuir diferentes tamanhos, formas e cores. Assim, idealmente a solução para detectar eventos de toque deveria ser capaz de adaptar-se a uma grande variedade de tipos de aplicadores enquanto mantém a acurácia para uma interação precisa. Além dessa diversidade de tipos, o aplicador oclui uma parte da face para aplicar a maquiagem virtual; então, detectar a posição de um toque com precisão também é um problema.

Para simplificar a interação e resolver parte do problema de detectar a posição do toque, nós estabelecemos que esse aplicador deve ser um dedo da mão do usuário ou um bastão, com forma semelhante a pincéis de maquiagem, segurado pela mão do usuário. Desse modo, foram consideradas duas perspectivas para a investigar sobre a solução de detectar o toque de um aplicador na face. A primeira, a de efetuar o rastreamento de um objeto altamente articulado como a mão em tempo real e a outra, a de transformar a superfície facial em uma superfície sensível ao toque. Entretanto, como visto na seção 2.4, os métodos que efetuam o rastre- 
amento e a estimativa da posição da mão e abordagens que transformam superfícies comuns em superfícies interativas encontrados na revisão da literatura não são adequados para cenários de automaquiagem. Assim, é apresentada, na sequência, a solução proposta para detectar o toque facial e os resultados de experimentos realizados.

\section{Método para detecção de toque facial}

Considerando que os trabalhos encontrados na literatura não são adequados para reconhecer um aplicador desconhecido tocando uma superfície que está em movimento ou para serem utilizados em cenários nos quais a mão está muito próxima do rosto, conforme exigido pelos sistemas de autoaplicação de maquiagem virtual, desenvolvemos uma solução para estimar a posição de um toque facial. Assim, esta seção apresenta detalhadamente as características dessa solução proposta para estimar a posição de toque da ponta de um aplicador físico sobre a face em tempo real, combinando técnicas de detecção e rastreamento, usando informações das imagens de cor e de profundidade.

Capturando os streams de cor e de profundidade em tempo real, a estimativa da posição do toque da ponta do aplicador na face é feita detectando e rastreando a face e a ponta do aplicador na imagem de cor, e o toque facial processando a imagem de profundidade. O processo de detecção auxilia na inicialização e recuperação de falhas do rastreamento, que por sua vez, possibilita a estimativa da posição da ponta de um aplicador quando está tocando a face.

O processo iterativo inicia usando uma câmera RGBD para capturar a imagem de cor $I_{c}$ e a de profundidade $I_{d}$. Essas imagens são utilizadas para construir uma pirâmide de imagens com dois níveis de resolução. Assim, usando as imagens com menor resolução, $I_{c}^{\prime}$ e $I_{d}^{\prime}$, é iniciado o processo de detecção e rastreamento da face e do aplicador. A imagem de profundidade $I_{d}^{\prime}$ é mapeada para $I_{c}^{\prime}$ usando os parâmetros intrínsecos do sensor, de modo que a profundidade em milímitros de um pixel $p(x, y) \in I_{c}^{\prime}$ pode ser acessada usando $I_{d}^{\prime}(x, y)$.

Como detalhado na seção 3.3.1, 91 pontos fiduciais são detectados usando as informações do SDK do RealSense. Como a face pode assumir uma diversidade de poses em relação ao sensor, são construídos dois mapas faciais em 2D, $M_{\text {map }}$ e $F_{\text {map }}$, usando os pontos fiduciais e as características de topologia da face. Ambos os mapas contêm oito regiões faciais e 124 triângulos que são correspondentes. A diferença de $M_{\text {map }}$ e $F_{\text {map }}$ é que, a cada quadro, as coordenadas $(x, y)$ dos vértices de $F_{\text {map }}$ são atualizadas de acordo com as coordenadas $(x, y)$ dos 91 pontos fiduciais. Assim, $F_{\text {map }}$ possui um número de linhas e colunas igual à largura e comprimento de $I_{c}^{\prime}$ e permite realizar a transformação das coordenadas de qualquer quadro capturado para as coordenadas de $M_{\text {map }} . M_{\text {map }}$ por sua vez, possui coordenadas $(u, v)$ do espaço normalizado. A cada quadro do processo iterativo, a posição da face é identificada em $I_{d}^{\prime}$ e, usando a equação (3.3), é calculada a distância média $\theta_{f}$ entre a face e o sensor usando a média da distância dos pontos fiduciais da face, representados por $d_{i}(x, y) \in I_{d}^{\prime}$.

$$
\theta_{f}=\left(\sum_{i=1}^{N} d_{i}\right) / N
$$

Em seguida, é realizado o processamento dos dados de $I_{d}^{\prime}$ para verificar se o aplicador está sobre a face e se a ponta dele está em contato com a face. Usando $I_{d}^{\prime}$ e as informações inerentes à posição da face, é assumido que o aplicador é o objeto mais próximo da câmera e, portanto, sua profundidade $\theta_{a}$ é definida como sendo $\theta_{a}<\left(\theta_{f}-50\right)$. O valor 50 foi estabelecido empiricamente, e é empregado com o objetivo de eliminar um grande número de pixels que pertencem à cabeça e torso do usuário e ao cenário de fundo. 
Então os pixels correspondentes ao aplicador formam uma imagem de profundidade $I_{d a}^{\prime}$, que é estimada usando o filtro da equação 3.4 .

$$
I_{d a}^{\prime}=\left\{p(x, y) \in I_{d}^{\prime} \mid p(x, y)<\left(\theta_{f}-50\right)\right\}
$$

Em seguida, os pixels restantes são refinados usando uma operação morfológica de erosão seguida por uma dilatação, para eliminar o ruído produzido pela câmera de profundidade. A equação 3.5 é utilizada para a erosão, enquanto a 3.5 é empregada para a dilatação.

$$
\begin{aligned}
& I_{d a}^{\prime} \ominus H=\left\{p \mid H_{p} \subseteq I_{d a}^{\prime}\right\} \\
& I_{d a}^{\prime} \oplus H=\left\{p \mid H_{p} \subseteq I_{d a}^{\prime}\right\}
\end{aligned}
$$

onde $H$ é um elemento estrutural circular com tamanho $3 \times 3$ sem deslocamento utilizado para fazer uma convolução com $I_{d a}^{\prime}$.

Depois da operação de erosão, $I_{d a}^{\prime}$ é submetida à uma operação de dilatação, para assumido que o ponto máximo de $I_{d a}^{\prime}$ é o ponto $p_{t a}$ situado na ponta do aplicador. Essa etapa permite iniciar o rastreamento da ponta do aplicador. Para tanto, a maior parte das abordagens utilizam modelos de aparência discriminativa, que consiste no treinamento online do classificador, para predizer a existência ou não da parte a ser rastreada na imagem da janela de busca. Certos classificadores podem predizer diretamente a posição do alvo, enquanto alguns estudos propõem a utilização de regressão para essa tarefa (F. Henriques et al., 2014). Dado que existem diversos algoritmos na literatura que podem ser utilizados para o rastreamento, foi buscado um algoritmo que possuísse as características desejadas para esta investigação, que é o treinamento online, para eliminar uma etapa de inicialização que tomasse muito tempo do usuário, e desempenho em tempo real. Desso modo, optou-se pela utilização do algoritmo Kernelized Correlation Filters - KCF para o rastreamento.

O KCF é uma abordagem que utiliza o domínio da frequência da imagem pra criar filtros de correlação, que filtram frequências de partes consistentes da imagens de treinamento e oferecem invariância ao deslocamento. Essas características possibilitam o desempenho em tempo real, fazendo com que o rastreamento seja mais rápido do que utilizando Tracking, learning and detection (TLD) ou Multiple Instance Learning (MIL) (F. Henriques et al., 2014).

Para iniciar o rastreador é preciso um núcleo, que é construído com a imagem do alvo, e de uma imagem que servirá de janela de busca. Considerando que o aplicador é cilíndrico, possui aproximadamente $1.5 \mathrm{~cm}$ de diâmetro e está a aproximadamente $30 \mathrm{~cm}$ do sensor, a largura $l$ da região no topo formado pelo blob em $I_{d a}^{\prime}$ é calculada em acordo com o tamanho selecionado pelo usuário. Então, considerando o tamanho do núcleo do rastreador $t_{n}(l, l)$ como sendo em função da largura do aplicador $l$, núcleo do rastreador $N_{a p}$ é criado usando a equação 3.7 .

$$
\begin{array}{r}
N_{a p}=\left\{p(x, y) \in I_{c}^{\prime} \mid\left(x_{p_{a p}}-l / 2\right)<x<\left(x_{p_{a p}}+l / 2\right)\right. \\
\left.\cap\left(y_{p_{a p}}\right)<y<\left(y_{p_{a p}}+l\right)\right\}
\end{array}
$$

A janela de busca para rastrear o aplicador é definida em $I_{c}^{\prime}$ com tamanho $t_{j}(2 * l, 2 * l)$ duas vezes o tamanho de $t_{n}(w, w)$, para garantir que contenha toda a região de $I_{c}^{\prime}$ correspondente à ponta do aplicador. Essa janela de busca é estabelecida de acordo com a seguinte equação: 


$$
\begin{array}{r}
J_{a p}=\left\{p(x, y) \in I_{c}^{\prime} \mid\left(x_{p_{t a}}-l\right)<x<\left(x_{p_{t a}}+l\right)\right. \\
\left.\cap\left(y_{p_{t a}}\right)<y<\left(y_{p_{t a}}+l * 2\right)\right\}
\end{array}
$$

Depois de construir $N_{a p}$ e $J_{a p}$, é iniciado o rastreamento da ponta do aplicador. Quando o rastreador atualiza a posição da ponta do aplicador $N_{a p}$, a cada quadro, é verificado se está sobre a face.

Se a ponta do aplicador não estiver sobre a face, como forma de recuperar de possíveis falhas ou em cenários em que o usuário está movendo o aplicador mas não deseja utilizá-lo, a cada dez quadros é feita uma verificação se $N_{a p}$ contém o blob da ponta do aplicador, computando $I_{d a}^{\prime}$.

Quando a ponta do aplicador está sobre a face, é calculada a profundidade máxima $p_{f}=\max \left(N_{a p}\right)$, contida na região correspondente à ponta do aplicador, a qual é considerada como pertencente à face. A profundidade do aplicador $p_{a p}$ é considerada como sendo a distância do ponto central de $N_{a p}$. Então o toque facial é detectado se $p_{f}-p_{a p}<20 \mathrm{~mm}$. Uma vez que o aplicador está tocando a face, o próximo passo é estimar a posição facial no espaço normalizado correspondente a posição em que a face do usuário foi tocada.

Para verificar a posição facial na qual o a ponta do aplicador tocou, é utilizada a função de transformação do gerenciador das informações da face, detalhada na seção 3.3.1. Essa função efetua a transformação das coordenadas de $p_{a p}(X, Y)$ para $p_{\text {touch }}(u, v)$, onde $(u, v)$ são coordenadas do mapa facial 2D no espaço normalizado. Salvar a posição do toque facial no mapa da face normalizado permite a estimativa da posição do toque facial independente da pose ou expressão facial e também possibilita que essa informação do toque facial seja combinada e usada em conjunto com outros toques faciais, como ocorre no contexto da autoaplicação de maquiagem.

\section{Experimentos}

Para avaliar o método apresentado para estimar a posição de toque da ponta de um aplicador na face, foi realizado um experimento, com o intuito de verificar a adequação desse método ao seu uso em sistemas para autoaplicação de maquiagem.

O experimento foi conduzido com cinco participantes (três do sexo feminino) com idades entre 27 e 34 anos, sendo que três têm visão normal e dois usam óculos de grau. Três indivíduos já haviam participado de estudos similares envolvendo aplicações com interação 3D. Todos os indivíduos são destros.

Para capturar os streams de cor e profundidade foi usada uma câmera RGB Intel RealSense RS300 conectada a um notebook (2.4GHz Intel I7 CPU, 12GB RAM). Em vez de usar a tela do notebook, foi usado um monitor com tela de LED de 23", com resolução de $1920 \times 1080$ pixels, posicionado a aproximadamente $45 \mathrm{~cm}$ da face do participante. $\mathrm{O}$ experimento foi conduzido em uma sala com iluminação artificial sem incidência de luz solar. O método foi implementado em um sistema utilizando C++ com OpenCV. Os experimentos foram realizados capturando um stream de cor de $1280 \times 720$ pixels de resolução e um stream de profundidade com $640 \times 480$ pixels de resolução, ambos a 30 quadros por segundo.

Antes de iniciar a sessão experimental, foi explicado aos participantes sobre o propósito do experimento. Em seguida, os participantes assinaram um termo de consentimento livre e esclarecido em anuência à participação e responderam questões demográficas. Na sequência da introdução, nove círculos amarelos com raio de $3 \mathrm{~mm}$ foram fixados como alvos na face dos participantes, sendo dois na bochecha direta, dois na bochecha esquerda, um no queixo, um no nariz e três na testa. Foi estabelecido como aplicador do experimento o dedo indicador. Os participantes realizaram uma sessão de treinamento interagindo com o sistema para 


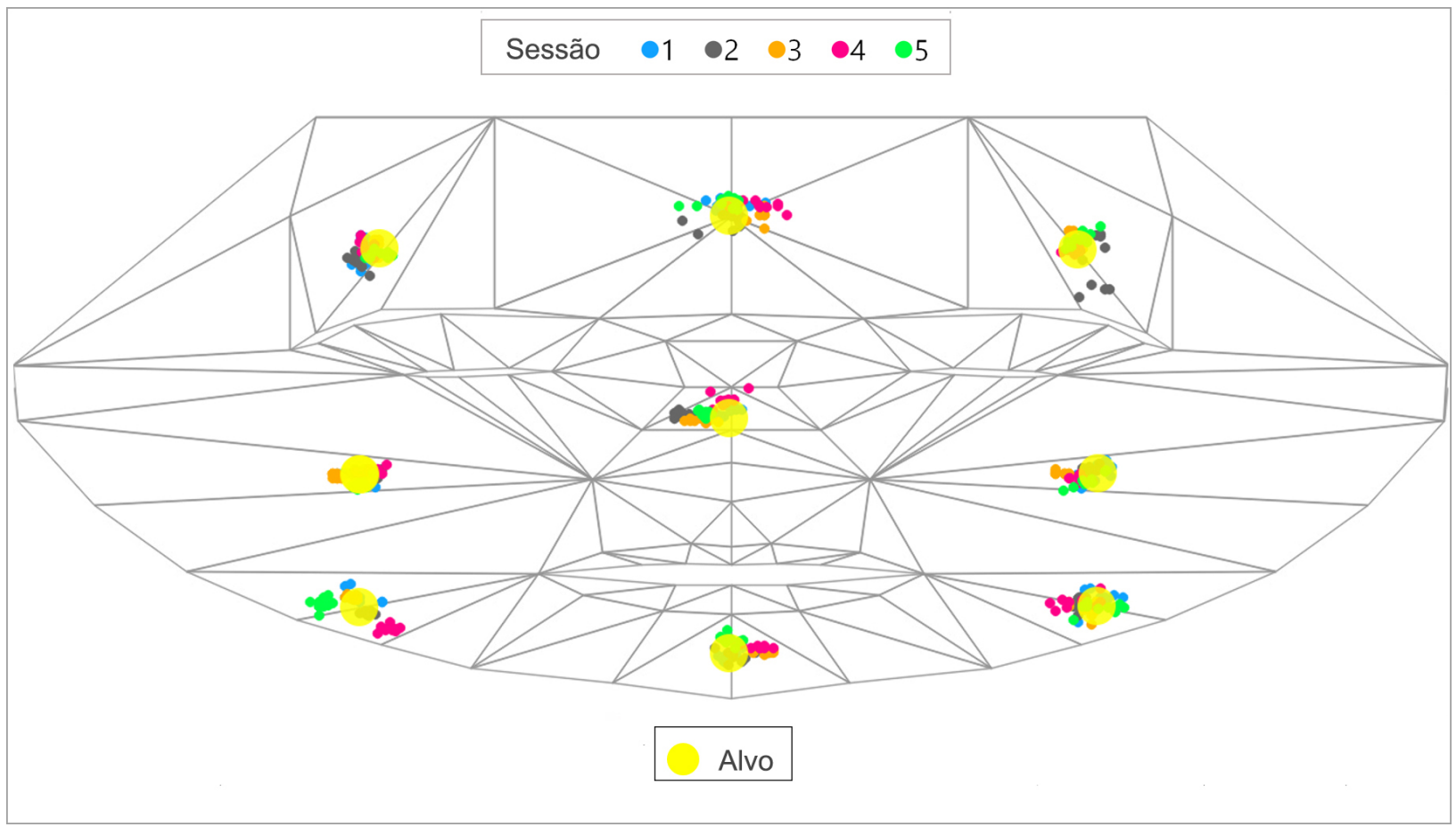

Figura 3.6: Imagem que apresenta a dispersão da posição estimada para cada toque facial, em cada uma das cinco sessões. Os círculos amarelos representam a posição dos alvos fixados na face.

familiarizar com a inicialização do sistema. Os dados da sessão de treinamento não foram considerados na análise dos dados. Durante os experimentos, os participantes não utilizaram descanso de queixo e puderam mexer a cabeça livremente. Cada sessão começou com a etapa de inicialização do sistema para detectar a face do usuário e a ponta do dedo indicador da mão direita (aplicador). Em seguida, os participantes foram instruídos a tocar dez vezes cada alvo. A sessão teve duração aproximada de dez minutos.

Em cada sessão, foram gravadas as posições dos nove alvos e as posições dos eventos de toque facial, todas em coordenadas $(u, v)$ do espaço facial. Os eventos de toque foram considerados de acordo com explicitado na subseção 3.3.1.

Apesar de ter sido estabelecido o número de dez toques por alvo fixado na face, cada participante teve uma velocidade para tocar o alvo, o que acarretou em um número diferente de amostras coletadas para cada evento de toque. Dessa forma, para cada sessão, primeiramente foi calculada a posição média de cada evento de toque $p_{m t}$, considerando as posições $a(u, v)$ de todas as amostras, de acordo com a equação 3.9.

$$
p_{m t}(u, v)=\left(\sum_{i=1}^{N} a(u, v)_{i}\right) / N
$$

onde $N$ é o número de amostras. Esses valores de $p_{m t}(u, v)$ para cada toque facial podem ser visualizados na Figura 3.6, que apresenta a dispersão desses valores para cada sessão.

Para investigar a acurácia da nosso método para estimar a posição da face que foi tocada pela ponta do aplicador, primeiro foi efetuado o cálculo do erro para cada uma das coordenadas do evento de toque $e_{t}(u)$ e $e_{t}(v)$ considerando a estimativa da posição do toque facial $p_{m t}(u, v)$ e a posição do alvo $p_{a}(u, v)$, usando a seguinte equação:

$$
e_{t}(c)=p_{m t}(u)-p_{a}(c)
$$




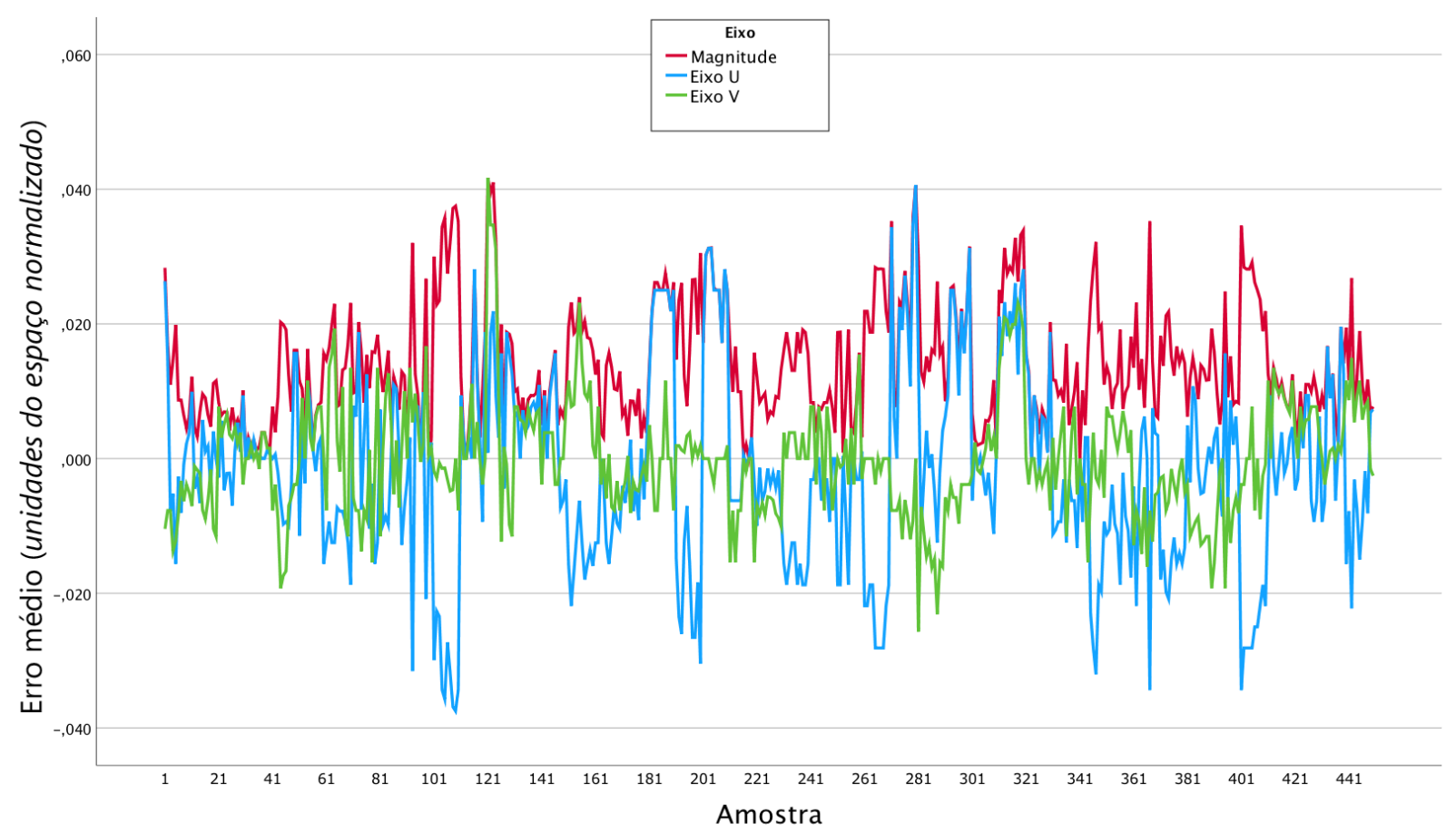

Figura 3.7: Erro médio do eixo U, do eixo Y e a magnitude do erro por evento de toque, em coordenadas do espaço facial normalizado.

onde $c$ representa uma coordenada $u$ ou $v$. A Figura 3.7 mostra os resultados do erro para essas coordenadas, para cada evento de toque. A magnitude máxima do erro sobre todas as amostras referentes aos 450 eventos de toque facial foi de 0.041 unidades do espaço normalizado e a menor magnitude foi 0 unidades do espaço normalizado.

A acurácia da nossa abordagem para cada coordenada, calculada usando a equação 3.11 , foi de $-0.0019 \pm$ 0.0141 unidades do espaço normalizado no eixo $\mathrm{U}$ e $-0.0003 \pm 0.0085$ unidades do espaço normalizado em V. Assim nosso método possui a acurácia de $0.0186 \pm 0.0091$ unidades do espaço normalizado. Esses valores podem ser visualizados na figura 3.8.

$$
a(c)=\left(\sum_{t=1}^{450} e_{t}(c)\right) / 450
$$

Para investigar se a acurácia tem relação com a posição do alvo, primeiro foi estimado o erro para cada alvo $a$, calculando as médias dos erros em cada coordenada $e_{a}(u)$ e $e_{a}(v)(3.12)$ para todas as sessões. A magnitude máxima do erro sobre todas as sessões e alvos foi de 0.0186 unidades do espaço normalizado e a mínima foi de 0.87 unidades do espaço normalizado. Esses valores podem ser observados na figura 3.9.

$$
e_{a}(c)=\left(\sum_{t=1}^{50} e_{t}(c)\right) / 50
$$

Depois de calculados os erros para cada eixo, inicialmente, foi aplicado um teste de normalidade utilizando Shapiro-Wilk, o qual indicou que os valores dos erros obtidos para os alvos, não são se encaixam no critério de normalidade, pois $p<0.05$ para ambos os eixos. Assim, foi aplicado um teste Kruskal-Wallis, o qual indicou que a posição do alvo fixado na face tem efeito significativo sobre a acurácia na estimativa da posição de toque facial no eixo $\mathrm{U}(\mathrm{H}(7)=103.23, \mathrm{p}=0.00)$ e no eixo $\mathrm{V}(\mathrm{H}(59.59)=103.23$, $\mathrm{p}=0.00)$. Um 


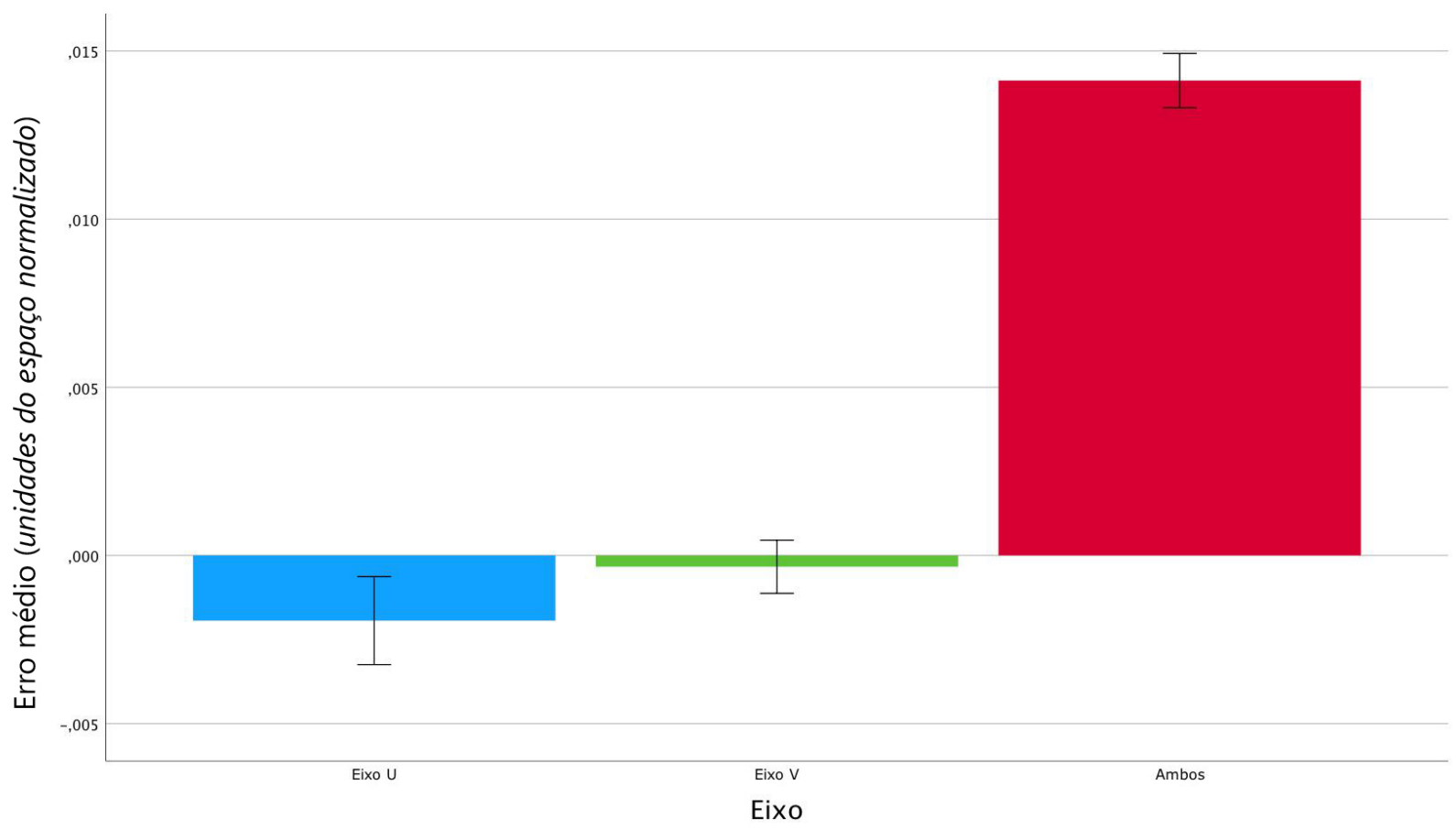

Figura 3.8: Erro médio do eixo $U$, do eixo $Y$ e de ambos os eixos.

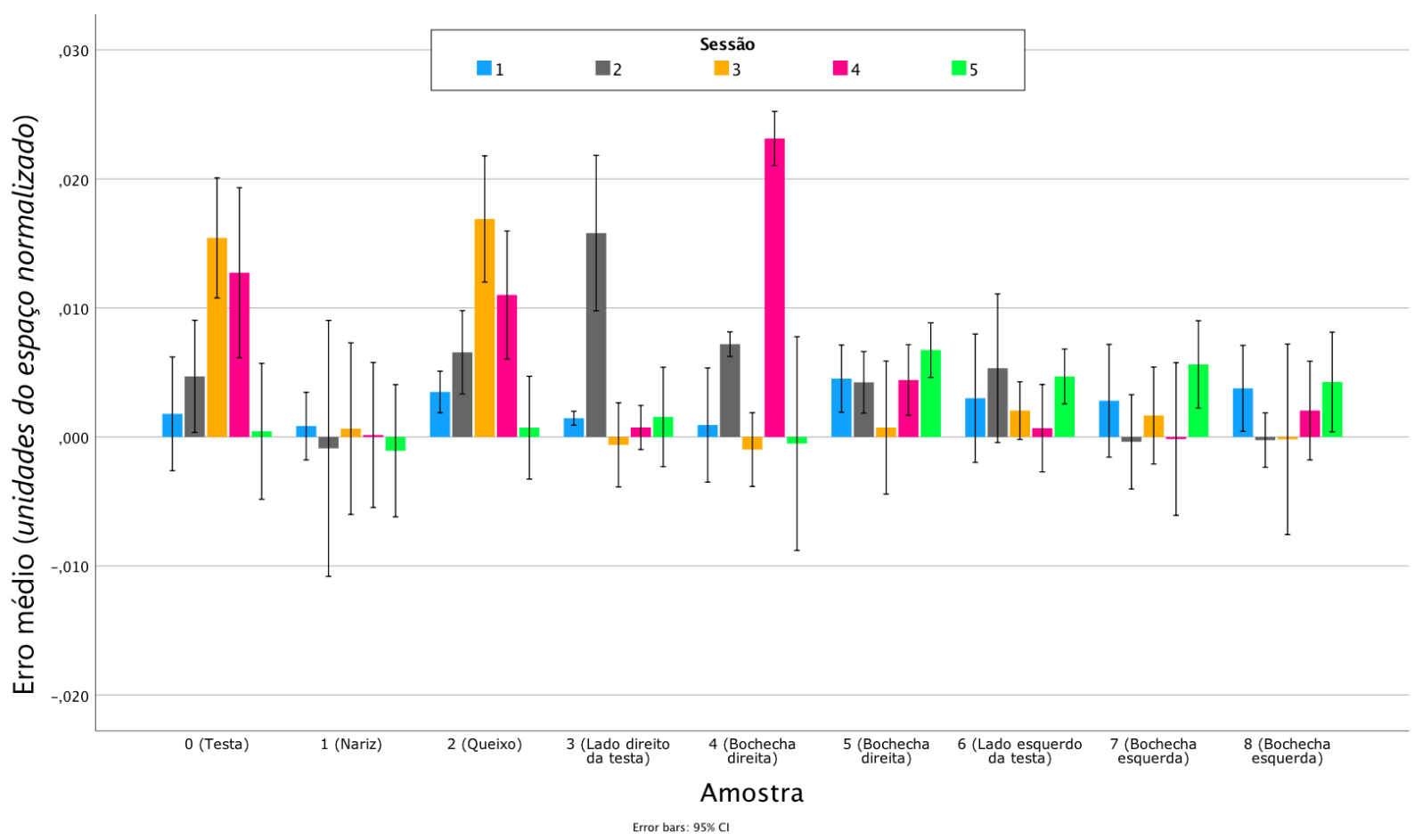

Figura 3.9: Erro médio em cada uma das sessões considerando cada um dos alvos. 


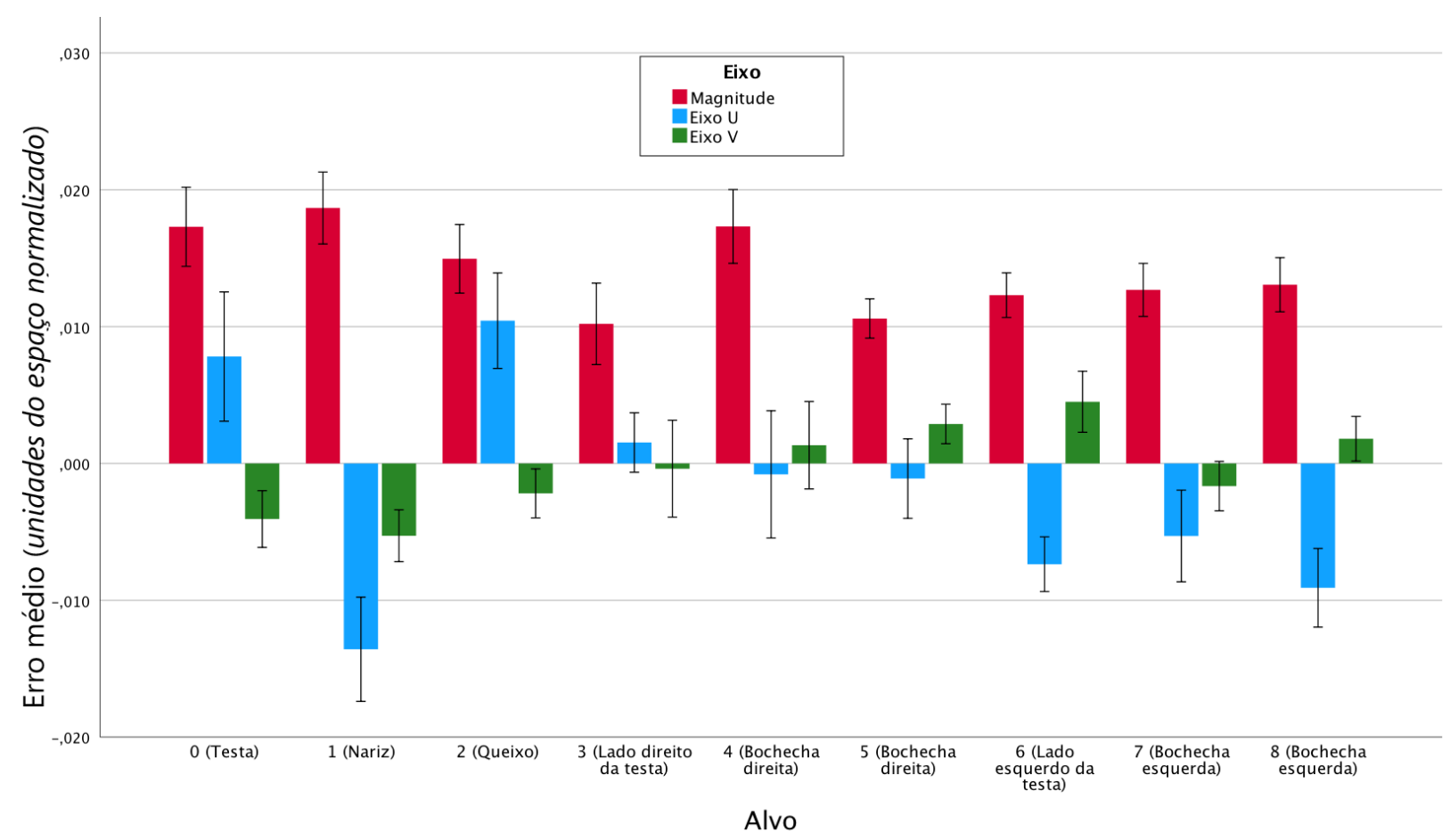

Figura 3.10: Erro médio em para cada um dos alvos.

teste pós-hoc mostrou que existem diferenças significativas entre o alvo 1 (Nariz) e os alvos 4(Bochecha Direita) $(\mathrm{p}=0.006), 0$ (Testa) $(\mathrm{p}=0.003)$ e 2(Queixo) $(\mathrm{p}=0.000)$. Além disso, foram encontradas diferenças significativas entre o alvo 2(queixo) e os alvos 7 (Bochecha esquerda) $(p=0.018)$ e 8 (Bochecha esquerda) $(\mathrm{p}=0.033)$. Essas diferenças podem ser visualizadas na figura 3.10.

Para explicitar os resultados do nosso método em milímetros, que é uma unidade que fornece uma ideia real do erro em relação a uma face humana, utilizamos as medidas faciais adotadas por (Burstone, 1967), as quais indicam que a face de um indivíduo do sexo feminino tem, no geral, altura de $137.1 \pm 4.3 \mathrm{~mm}$ e largura de $129,9 \pm 5.3 \mathrm{~mm}$, enquanto uma face de um indivíduo do sexo masculino tem altura de $187.0 \pm 8.1 \mathrm{~mm} \mathrm{e}$ largura de $172,5 \pm 7.5 \mathrm{~mm}^{1}$. Dessa forma, foi encontrado um erro médio de $-0,251852646 \pm 1,834239563 \mathrm{~mm}$ no eixo $\mathrm{U}$ e de $-0,046166103 \pm 1,168731222 \mathrm{~mm}$ no eixo $\mathrm{V}$ para indivíduos do sexo feminino. Enquanto para indivíduos do sexo masculino o erro obtido foi de $-0,334446354 \pm 2,435768473 \mathrm{~mm}$ no eixo $\mathrm{U}$ e de $-0,062969083 \pm 1,594111878 \mathrm{~mm}$. Esses valores podem ser visualizados na figura 3.11 .

Apesar das diferenças significativas encontradas para os erros médios entre alguns alvos, os resultados obtidos com os experimentos mostram que nossa abordagem é capaz de estimar, com acurácia e precisão, a posição facial tocada pela ponta de um aplicador com aproximadamente $15 \mathrm{~mm}$ de diâmetro. Os valores obtidos dessas diferenças significativas entre alguns alvos sugerem que o erro varia quando a mão do usuário causa oclusão em relação ao sensor de regiões da face que contêm pontos fiduciais, como o caso da oclusão da boca para tocar no nariz. Ainda, sugerem que a pose do usuário também pode influenciar no erro, como no caso das diferenças significativas encontradas entre o alvo do queixo e os da bochecha esquerda.

Para o cenário de autoaplicação de maquiagem, o método proposto consiste no estado da arte para estimativa da posição de um toque sobre a face, permitindo interação natural do usuário com um sistema para maquiagem virtual. Além disso, esse método tem desempenho em tempo real com recursos computacionais limitados, o que mostra seu potencial uso em aplicações sem requerer recursos de hardware de alto custo.

${ }^{1}$ Essas medidas correspondem a medições realizadas em um ângulo frontal à face 


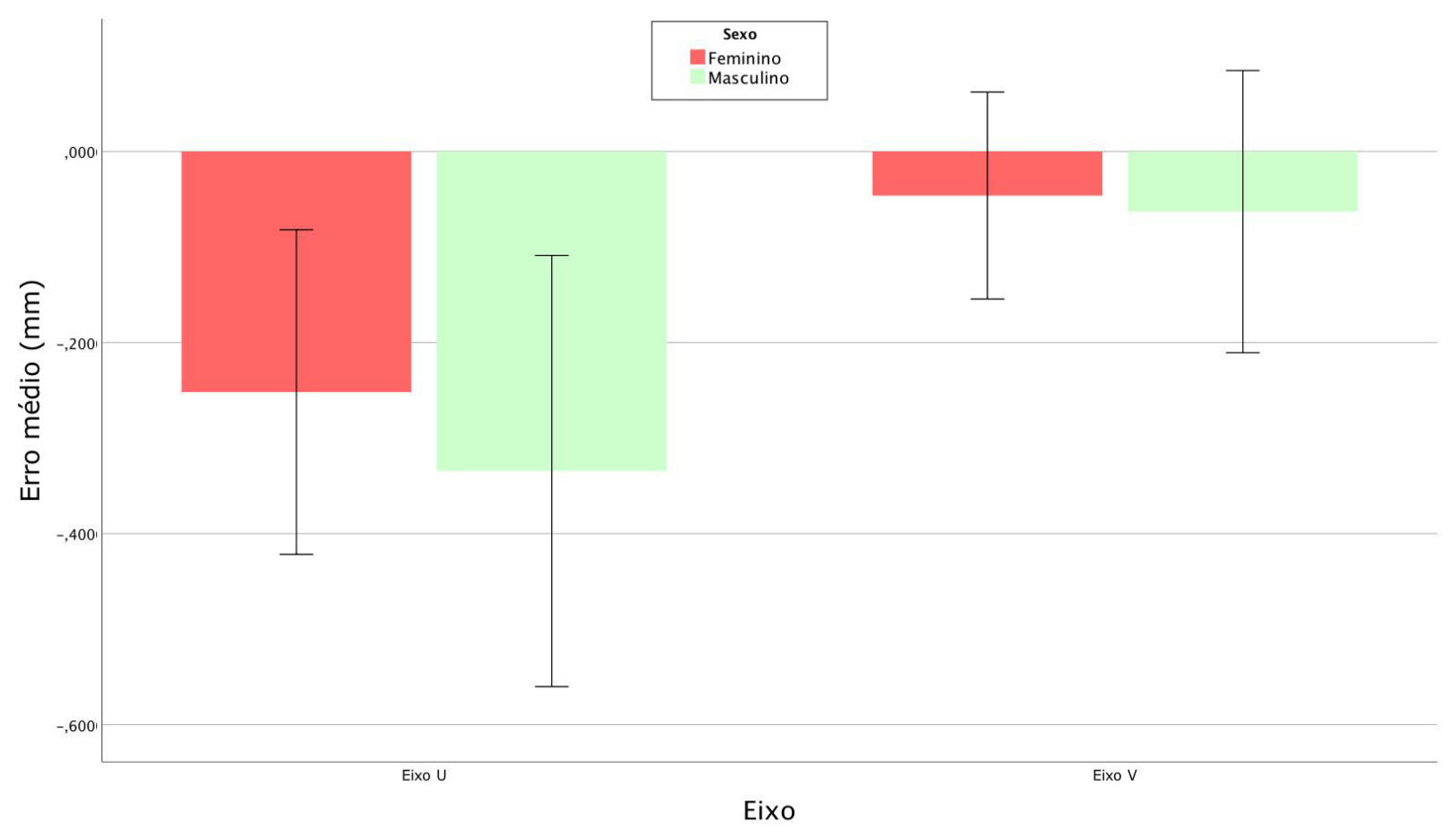

Figura 3.11: Erro médio em cada eixo para cada um dos sexos.

\subsubsection{Maquiagem virtual}

No contexto deste estudo, aplicar um produto de maquiagem virtual significa alterar as propriedades óticas e de textura da imagem da pele da face do usuário, modificando a forma com que a imagem facial pode ser percebida (Campos, 2014).

Depois de investigar sobre os métodos de transferência e aplicação de maquiagem virtual, foi constatado que a proposta de Campos (2014) apresenta realismo suficiente para nossa investigação e que, a deficiência desse método proposto por ele em relação aos efeitos de sombreamento e destaque da maquiagem virtual poderiam ser sanados com algumas características da abordagem de Guo e Sim (2009) para o tratamento da camada de luminosidade da imagem facial. Dessa forma, nossa proposta para a aplicação de maquiagem virtual combina alguns fundamentos do algoritmo de Campos (2014), para aplicação de maquiagem virtual, e certos aspectos do método de Guo e Sim (2009), para transferência de maquiagem.

Assim como na maquiagem física, para cada um dos produtos de maquiagem virtual, existe uma textura denominada maquilet, que consiste em uma imagem com canais RGBA contendo informações sobre as variações de tonalidade desse produto. Uma vez que existe um produto selecionado e o usuário toca na sua face, é criada uma máscara $m_{\text {asc }}$, inicialmente preenchida com o valor 0 , que conterá a informação das regiões faciais de aplicação desse produto e está em coordenadas do espaço facial.

O preenchimento de $m_{\text {asc }}$ depende do tipo de evento disparado pelo aplicador físico, ou seja, se o usuário acaba de tocar a ponta do aplicador físico na face, se já estava tocando na face mas mudou de posição ou se a ponta do aplicador foi distanciada da face, como detalhado na subseção 3.3.2. Para os dois primeiros eventos, nos quais o aplicador físico está em contato com a face, são consideradas as seguintes informações relacionadas ao aplicador virtual: o raio $r_{\text {aplicador }}$ devido ao formato circular e a intensidade $\alpha_{\text {aplicador }}$, que são configurados pelo usuário na interface gráfica e o ponto $p_{\text {aplicador }}$ com coordenadas $\left(u_{c}, v_{c}\right)$, que indicam a posição do centro desse aplicador virtual no espaço facial normalizado. A posição do centro do aplicador virtual $p_{\text {aplicador }}$ no momento do toque facial é armazenada em $p_{0}$ caso não tenha nenhum valor associado a 
$p_{0}$, do contrário, é armazenado em $p_{1}$. Então, o preenchimento de $m_{\text {asc }}$ é feito utilizando a equação 3.13.

$$
m_{\text {asc }}(u, v)= \begin{cases}255 * \alpha_{\text {aplicador }} & \left(u-u_{c}\right)^{2}+\left(v-v_{c}\right)^{2}=r_{\text {aplicador }}^{2} \\ m_{\text {asc }}(u, v) & \text { caso contrário }\end{cases}
$$

onde $(u, v)$ são as coordenadas de $m_{\text {asc }}$, que foi criada com base no espaço facial normalizado.

Se o usuário já estava tocando a ponta do aplicador na face e mudou de posição, $p_{0}$ e $p_{1}$ têm valores associados, então, além de preencher $m_{\text {asc }}$ usando a equação 3.13, a região de $m_{\text {asc }}$ compreendida entre $p_{0} \mathrm{e}$ $p_{1}$ também é preenchida. Para tanto, primeiro é criado um paralelogramo $P$ usando $p_{0}, p_{1}$ e $r_{\text {aplicador }}$, como explicitado na Figura 3.12. E $m_{a s c}$ é complementada de acordo com a equação 3.14.

$$
m_{\text {asc }}(u, v)= \begin{cases}255 * \alpha_{\text {aplicador }} & p(u, v) \text { está situado no interior de } P \\ m_{\text {asc }}(u, v) & \text { caso contrário }\end{cases}
$$

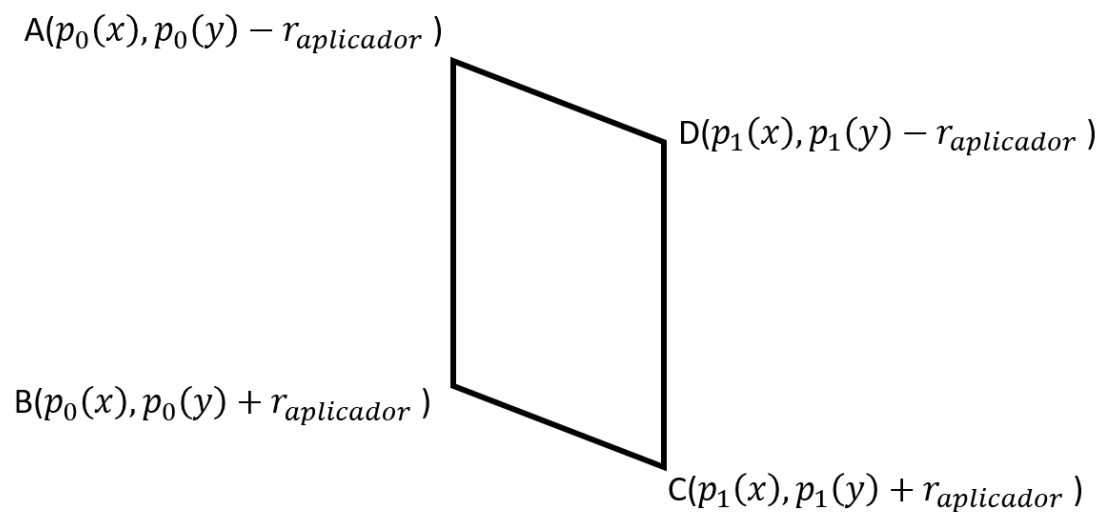

Figura 3.12: Paralelogramo $P$ criado para preencher $m_{\text {asc }}$ na região da máscara compreendida entre $p_{0}$ e $p_{1}$.

Caso o usuário retire a ponta do aplicador físico da face, é detectado que esse aplicador não está mais tocando na face e então $p_{0}$ e $p_{1}$ recebem valores nulos.

Depois de adicionar as informações da aplicação à máscara do produto virtual selecionado, para suavizar as bordas de $m_{a s c}$, é aplicado um filtro gaussiano da equação 3.15 .

$$
G_{m}(u, v)=A e^{-\frac{u^{2}+v^{2}}{2 \sigma^{2}}}
$$

onde $A$ é o coeficiente de amplitude da gaussiana e $\sigma$ a variância para cada valor de $u$ e $v$. Se o tipo de borda escolhido for suave, $A=a_{r}$ e $\sigma=a_{r}$. Ao passo que se for definida, $A=a_{r}$ e $\sigma=2$. Esse valores foram definidos de forma empírica considerando o efeito de espalhamento da maquiagem virtual produzido pelo tamanho do aplicador virtual, assim como acontece com produtos e aplicadores de maquiagem física.

Em seguida, $m_{\text {asc }}$ é usada para adicionar o maquilet a textura $E_{\text {maquilets }}$, que contém todos os maquilets já aplicados em coordenadas do espaço facial normalizado, de acordo com a equação 3.16.

$$
E_{\text {maquilets }}(u, v)=E_{\text {maquilets }}(u, v) *\left(1-m_{\text {asc }}(u, v) / 255\right)+\operatorname{maquilet}(u, v) * m_{\text {asc }}(u, v) / 255
$$


onde $E_{\text {maquilets }}$, maquilet e $m_{\text {asc }}$ são imagens criadas usando o espaço facial normalizado e possuem dimensões iguais. Como $m_{\text {asc }}$ possui valores de 0 a 255, para atribuir a contribuição que o maquilet terá em $E_{\text {maquilets }}$, é preciso dividir o valor de cada pixel por 255 na equação 3.16 com o intuito de obter valores de 0 a 1 , sendo que 0 representa ausência de maquiagem virtual e 1, intensidade máxima.

Para a base virtual, $m_{\text {asc }}$ é adicionado a uma máscara $m_{\text {asc Base }}$, como apresentado na equação 3.17 que é utilizada na etapa de suavização da imagem do usuário na região de aplicação da base virtual.

$$
m_{\text {base }}(u, v)= \begin{cases}m_{\text {asc }}(u, v) & m_{\text {asc }}(u, v)>0 \\ m_{\text {base }}(u, v) & \text { caso contrário }\end{cases}
$$

Uma vez que $E_{\text {maquilets }}$ contém as informações de todos os produtos já aplicados, é necessário realizar o mapeamento da maquiagem virtual, que possui coordenadas $(u, v)$ do espaço facial normalizado, para coordenadas $(x, y)$ da imagem do usuário de acordo com a pose e expressão facial. Como $E_{\text {maquilets }}$ é construída a partir do espaço normalizado que possui um mapa 2D da face subdividido em triângulos, esse mapeamento é realizado usando cada um desses triângulos. Para tanto, como explicitado detalhadamente na subseção 3.3.1, é preciso usar funções do módulo que gerencia as informações da face para efetuar as transformações geométricas afins em cada triângulo de $E_{\text {maquilets }}$, de modo que as posições das aplicações da maquiagem virtual fiquem alinhadas com a pose e expressão da face do usuário no quadro do vídeo em questão. Essas transformações resultam na obtenção de $T_{\text {maquilets }}$

Depois de ajustar as posições das maquiagens virtuais aplicadas e obter $T_{\text {maquilets }}$, é iniciado o processo de aplicação da maquiagem virtual à imagem do usuário. Para tanto, a primeira etapa desse processo é realizada seguindo a ideia central do método proposto por Campos (2014) de decompor a imagem do usuário em cinco camadas, quais sejam:

- $C_{f b}=$ Camada de baixa frequência, que contém as características globais da face do usuário, como traços básicos;

- $C_{f 3}=$ Camada de frequência intermediária 3, a qual contempla os detalhes menos sutis da face do usuário, como variação do tom da cor da pele;

- $C_{f 2}=$ Camada de frequência intermediária 2, que é composta por detalhes faciais de intensidade intermediária e apresenta algumas características de textura da pele;

- $C_{f 1}=$ Camada de frequência intermediária 1 , que contém os detalhes faciais mais finos;

- $C_{f a}=$ Camada de alta frequência, a qual apresenta detalhes faciais como pelos, fios de cabelo e alguns contornos de regiões faciais;

A abordagem de utilização de camadas, segundo Campos (2014), permite que os contornos da face e suas características sejam preservados mesmo que a textura da pele seja alterada, com o intuito de não deformar a imagem da face do usuário. Além disso, possibilita o tratamento de componentes individuais da imagem do usuário de acordo com características faciais como cor e textura da pele, iluminação especularidade e pelos faciais (Campos, 2014). Assim, ao adquirir a imagem RGB original $I_{R G B}$ capturada pelo sensor RGBD e os dados sobre a posição facial, o módulo de processamento recorta $I_{R G B}$ de acordo com a posição da face, obtendo $I_{\text {faceRGB }}$. Então, $I_{\text {face } R G B}$ é dividida nas cinco camadas, aplicando filtros gaussianos que atuam como filtros passa baixa. Ao aplicar o filtro gaussiano em $I_{\text {face } R G B}$ usando a equação 3.15, obtém-se $G 1$. Em seguida, o filtro gaussiano é aplicado em G1, obtendo G2. Depois o filtro é aplicado em G2, resultando em G3. Por fim, ao aplicar o filtro gaussiano em G3, obtém-se G4. Utilizando essas imagens resultantes, as 
camadas de frequência são obtidas com as equações 3.18, 3.19,3.20,3.21,3.22.

$$
\begin{gathered}
C_{f a}(x, y)=I_{f a c e R G B}(x, y)-G 1(x, y) \\
C_{f 1}(x, y)=G 1(x, y)-G 2(x, y) \\
C_{f 2}(x, y)=G 2(x, y)-G 3(x, y) \\
C_{f 3}(x, y)=G 3(x, y)-G 4(x, y) \\
C_{f b}(x, y)=G 4(x, y)
\end{gathered}
$$

Depois de obter essas cinco camadas, caso o usuário tenha aplicado base virtual, é realizada uma suavização nas camadas intermediárias $C_{f 1}, C_{f 2}$ e $C_{f 3}$, que são camadas que contêm detalhes da pele, com o intuito de deixar a pele mais homogênea, produzindo um efeito parecido com a base física. As camadas $C_{f b}$ e $C_{f a}$ são mantidas intactas nesse processo, pois contém os detalhes globais que caracterizam a estrutura da face do usuário. Para suavizar $C_{f 1}$ é aplicado, em cada um dos canais RGB, um filtro gaussiano (equação 3.15) com valores de $A=5$ e $\sigma=5$. Em cada canal de $C_{f 2}$, esse filtro é aplicado usando $A=9$ e $\sigma=9$. Enquanto em cada canal RGB de $C_{f 3}$, é aplicado o filtro gaussiano com $A=13 \mathrm{e} \sigma=13$. Esses valores para os parâmetros dos filtros gaussianos foram obtidos de forma empírica considerando o custo computacional da aplicação de cada filtro e o realismo do efeito resultante dessa aplicação. Em seguida, os resultados da aplicação dos filtros $C_{f 2 G}, C_{f 1 G}$ e $C_{f 1 G}$ são colocados em $C_{f 2}, C_{f 1}$ e $C_{f 1}$ apenas nas regiões de aplicação da base virtual utilizando $m_{\text {asc Base }}$, de acordo com as equações 3.23, 3.24,3.25.

$$
\begin{aligned}
& C_{f 1}(x, y)=C_{f 1}(x, y) *\left(1-m_{\text {asc Base }}(x, y) / 255\right)+C_{f 1 G}(x, y) * m_{\text {asc Base }}(x, y) / 255 \\
& C_{f 2}(x, y)=C_{f 2}(x, y) *\left(1-m_{\text {asc Base }}(x, y) / 255\right)+C_{f 2 G}(x, y) * m_{\text {asc Base }}(x, y) / 255 \\
& C_{f 3}(x, y)=C_{f 3}(x, y) *\left(1-m_{\text {asc Base }}(x, y) / 255\right)+C_{f 3 G}(x, y) * m_{\text {asc Base }}(x, y) / 255
\end{aligned}
$$

Se o usuário não aplicou base virtual, essa etapa de suavização das camadas de frequências intermediárias não é realizada.

Uma vez que as cinco camadas relacionadas às faixas de frequência de $I_{\text {face } R G B}$ foram obtidas, e a suavização das camadas de frequências intermediárias foi efetuada no caso de aplicação de base, a etapa de processamento da camada de luminosidade é realizada utilizando aspectos do método de Guo e Sim (2009). A camada de luminosidade, ao mesmo tempo que contém detalhes importantes da maquiagem, contempla detalhes de contorno essenciais para a caracterização da face, o que requer que processamento dessa camada seja feito de forma diferente das camadas de cor. Desse modo, para adicionar à imagem facial os detalhes de 
destaque e sombreamento da maquiagem, sem comprometer os detalhes importantes de contorno da face, é utilizada $C_{f 3}$, que é a camada que contém as características faciais menos sutis. Para isso, $C_{f 3}$, que está em RGB, é transformada para o espaço de cor CIELAB, por possibilitar uma melhor separação da luminosidade e da cor que os outros espaços de cor (Guo e Sim, 2009). Assim, é obtida $C_{f 3 L a * b *}$, que é separada em camadas de acordo com os canais $\mathrm{La}^{*} \mathrm{~b}^{*}$, obtendo uma imagem do canal de luminosidade $C_{f 3 L}$.

Depois de obter $C_{f 3 L}$, é necessário transformar $E_{\text {maquilets }}$, que está em RGBA, para o espaço de cor CIELAB. A imagem resultante dessa transformação, $E_{\text {maquilets } L a * b *}$, é dividida em camadas de acordo com os canais e, então, é obtida uma imagem $E_{\text {maquilets } L}$, a partir do canal L, que contém os efeitos de destaque e sombreamento da maquiagem virtual. Ainda, considerando $E_{\text {maquilets }}$ e seu canal com a informação de transparência A, é obtida uma máscara para aplicação da maquiagem virtual $m_{\text {asc Maquilets }}$ contendo as regiões faciais e intensidade de aplicação. Em seguida, esses efeitos da maquiagem virtual são aplicados à imagem do usuário usando a equação:

$$
C_{f 3 L}(x, y)=C_{f 3 L}(x, y) *\left(1-m_{\text {asc Maquilets }}(x, y) / 255\right)+E_{\text {maquilets } L}(x, y) * m_{\text {asc Maquilets }} / 255
$$

onde os valores de $m_{\text {asc Maquilets }}$ vão de 0 a 255 e precisam ser divididos por 255 para obter o peso da contribuição dos efeitos da maquiagem virtual na imagem da face do usuário. Depois de ter sido processada, a camada $C_{f 3 L}$ é então colocada em $C_{f 3 L a * b *}$, que é transformada novamente para RGB, resultando em $C_{f 3}$ com a contribuição da luminosidade da maquiagem virtual.

$\mathrm{Na}$ sequência, é realizada uma fusão das camadas $C_{f a}, C_{f 1}, C_{f 2}, C_{f 3}$ e $C_{f b}$, obtendo $I_{f a c e R G B}$, que agora contém a contribuição dos efeitos de sombreamento e destaque da maquiagem virtual e a suavização provocada pela base virtual, caso tenha sido aplicada.

Depois de modificar a imagem do usuário adicionando os efeitos relacionados a textura da pele, é realizada a adição da cor dos maquilets aplicados. Para tanto, é feita a transformação de $I_{\text {face } R G B}$, que está no espaço de cor RGB, para o espaço de cor CIELAB, obtendo $I_{L a * b *}$. Em seguida, é efetuada a divisão de $I_{L a * b *}$ em camadas de acordo com cada canal, resultando em $I_{L}, I_{a *}$ e $I_{b *}$. Assim, as informações sobre a cor da maquiagem virtual, que estão em $E_{\text {maquiletsa* }}$ e em $E_{\text {maquilets } * *}$, são aplicadas usando as equações:

$$
\begin{aligned}
& I_{a *}(x, y)=I_{a *}(x, y) *\left(1-m_{\text {ascMaquilets }}(x, y) / 255\right)+E_{\text {maquiletsa* }}(x, y) * m_{\text {asc Maquilets }} / 255 \\
& I_{b *}(x, y)=I_{b *}(x, y) *\left(1-m_{\text {ascMaquilets }}(x, y) / 255\right)+E_{\text {maquilets } b *}(x, y) * m_{\text {asc Maquilets }} / 255
\end{aligned}
$$

O processo de aplicação da maquiagem virtual segue para a fusão de $I_{L}, I_{a *}$ e $I_{b *}$ em $I_{L a * b *}$, que nessa etapa contém toda a informação da maquiagem virtual. Dessa forma, $I_{L a * b *}$ é transformada para RGB novamente, obtendo $I_{f a c e R G B}$ contendo o resultado da aplicação da maquiagem virtual. Por fim, $I_{\text {face } R G B}$ é colocado em $I_{R G B}$, encerrando o processamento do módulo de maquiagem virtual para esse quadro do vídeo.

A imagem contendo a aplicação da maquiagem virtual $I_{R G B}$ é então enviada para a interface gráfica, que a exibe para o usuário. 


\section{Capítulo 4}

\section{Protótipo do SelfMakeup}

Para avaliar o design foi implementado um protótipo de baixo custo, utilizando uma câmera Intel RealSense. O software foi desenvolvido em $\mathrm{C}++$, utilizando o SDK do RealSense e a biblioteca de Visão Computacional OpenCV.

\subsection{Interação}

O SelfMakeup é iniciado com valores definidos para o aplicador, com uma cor de batom selecionada e exibindo a imagem de cor capturada em tempo real. Para começar a interagir com esse sistema, o usuário deve posicionar sua face no intervalo de $30 \mathrm{~cm}$ a $80 \mathrm{~cm}$ em relação ao Intel RealSense SR300.

A interface do SelfMakeup possui um menu de produtos que possibilita ao usuário selecionar um produto virtual entre base, batom, blush e sombra. Para cada um desses produtos existem diversas cores que podem ser escolhidas. Além disso, o usuário pode selecionar as características de tamanho, intensidade e tipo de borda do aplicador que deseja usar. Depois de configurar o aplicador e escolher uma cor de produto, o usuário pode iniciar a aplicação. Para iniciar a aplicação de um produto, o usuário precisa posicionar o dedo da mão, ou qualquer outro bastão que se asemelhe a pinceis de maquiagem, entre sua face e o sensor. Quando o sistema detecta a ponta do aplicador, é exibido um círculo branco na posição da imagem correspondente, como pode ser observado na figura 4.1.

Uma vez que a ponta do aplicador é detectada, o usuário pode mover esse aplicador e tocar a face na posição que deseja aplicar a maquiagem virtual escolhida. Quando o sistema detecta o toque na face, o círculo do aplicador fica da mesma cor que a maquiagem selecionada, indicando que o produto está sendo aplicado. A figura 4.2 apresenta esse cenário no qual a ponta do aplicador está em contato com a face.

Para interromper a aplicação, basta que o usuário retire a ponta do aplicador do contato facial, fazendo com que o círculo renderizado na região da imagem correspondente ao aplicador digital fique branco novamente, como pode ser observado na figura 4.3.

Se o usuário desejar visualizar os resultados da maquiagem virtual, basta remover o aplicador da cena, como apresentado na figura 4.4. 


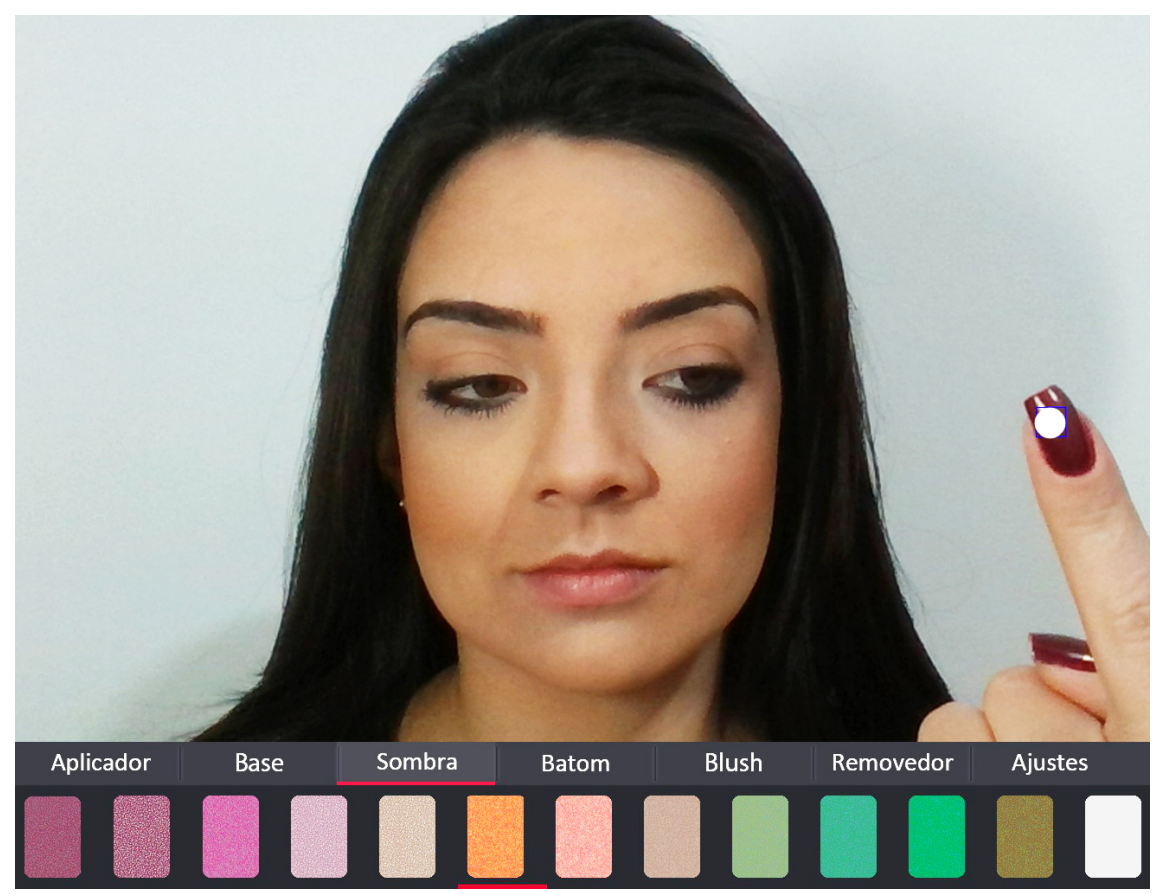

Figura 4.1: Cenário no qual o usuário vai iniciar a autoaplicação de maquiagem virtual.

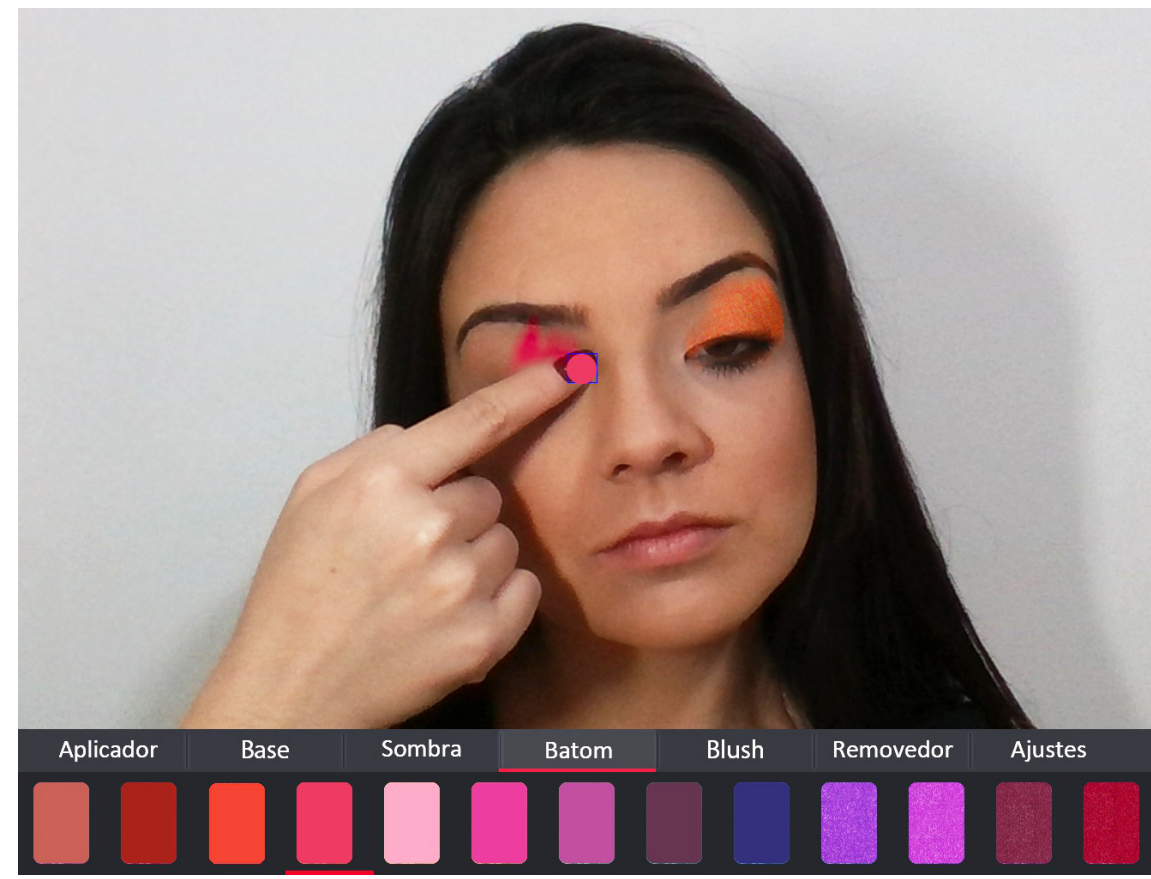

Figura 4.2: Cenário no qual o usuário está efetuando a autoaplicação de maquiagem virtual tocando em sua própria face. 


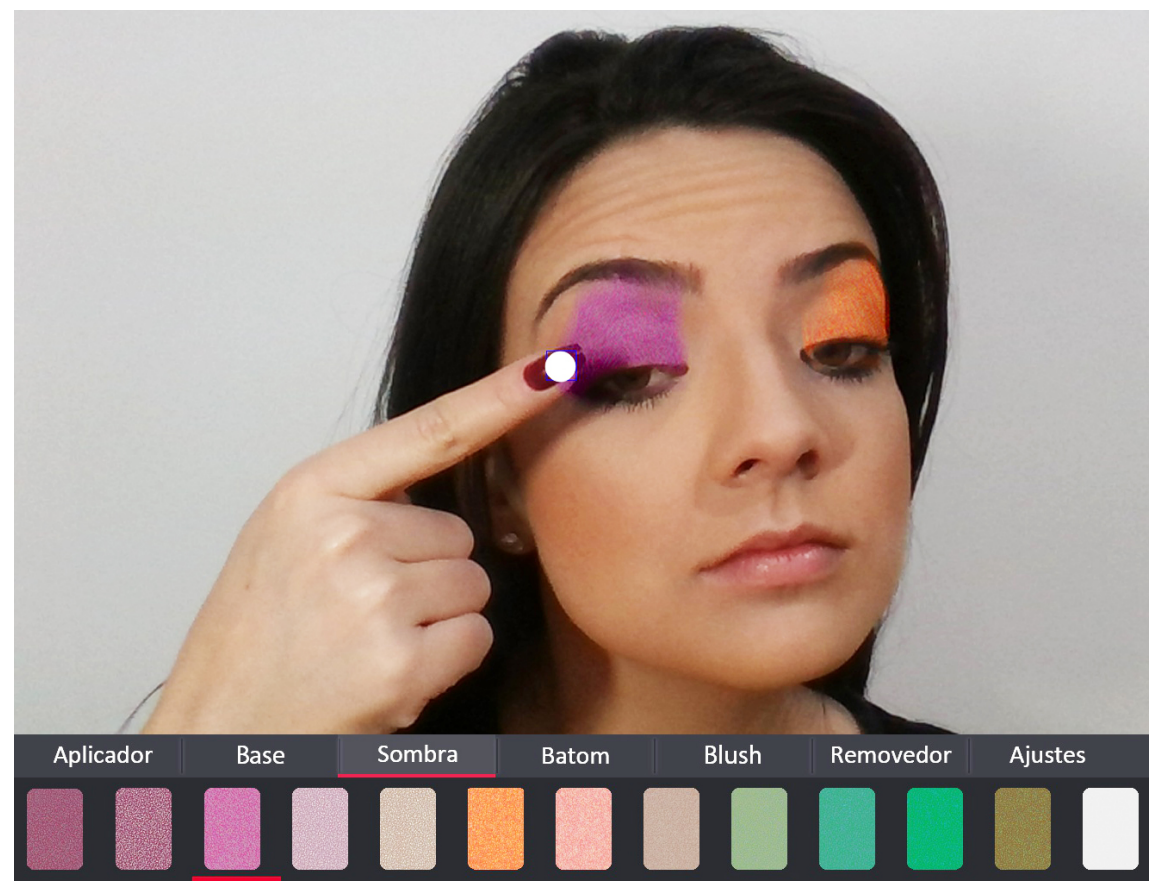

Figura 4.3: Cenário no qual o usuário parou de tocar em sua face com o aplicador, interrompendo o processo de aplicação de maquiagem virtal.

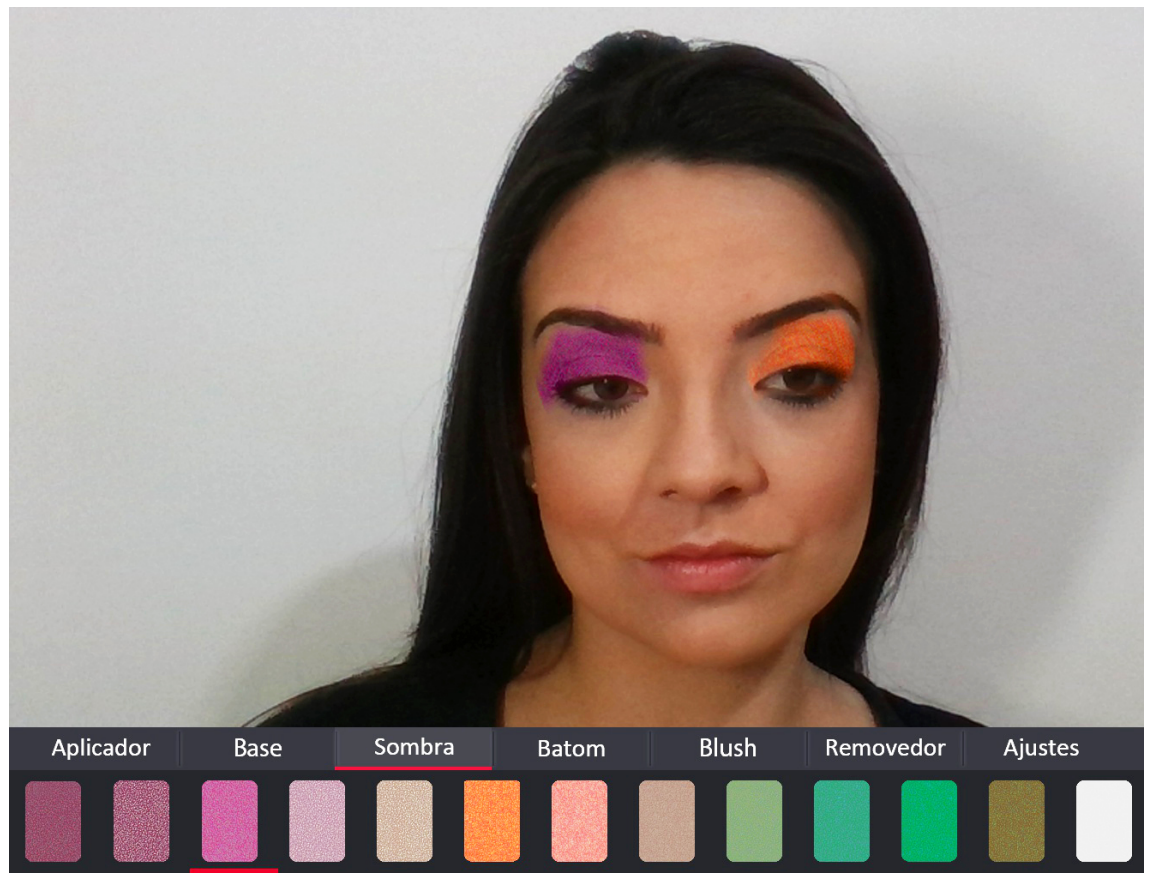

Figura 4.4: Cenário no qual o usuário está visualizando os resultados da aplicação de maquiagem virtual e comparando duas cores de semba. 


\section{Capítulo 5}

\section{Experimento piloto}

Antes de conduzir um estudo com usuários, decidimos realizar um experimento piloto com poucos usuários para identificar possíveis problemas com o design do sistema e limitações do protótipo que possam inviabilizar o experimento.

\subsection{Design do protocolo experimental}

O objetivo deste estudo é validar a implementação do SelfMakeup e investigar sobre a experiência do usuário na utilização desse sistema. Para tanto, deve ser realizado um experimento intra-sujeito (withinsubjects) com a variável independente modo de interação para autoaplicação de maquiagem virtual e com duas condições, toque na face e toque na tela. Antes de começar a sessão, cada participante é avisado que o objetivo do experimento é investigar sobre sua experiência na interação com o sistema de autoaplicação de maquiagem virtual utilizando dois modos: tocando na face e tocando na tela. Além disso, o participante é informado que não é ele que está sendo avaliado, que pode interromper o experimento a qualquer instante e que sua identidade será preservada. Em seguida, o participante assina o termo de consentimento livre e esclarecido em anuência a sua participação na pesquisa, antes de realizar um breve treinamento com os dois modos de interação. Depois do treinamento, a utilização do sistema pelo participante se dá em dois momentos, um aplicando a maquiagem virtual tocando na tela e o outro tocando na face. A ordem desses modos deve ser alternada para cada participante de forma que o tempo de aprendizagem do usuário não interfira na análise dos resultados.

Cada participante é orientado de acordo com as instruções descritas no Apêndice B para a realização das tarefas durante o experimento. Essas tarefas são fundamentadas em cenários reais de autoaplicação de maquiagem com os seguintes produtos físicos: base, blush, sombra e batom.

$\mathrm{Na}$ interface do SelfMakeup, cada participante é instruído a selecionar a mesma cor de cada um dos produtos virtuais a ser aplicado na seguinte ordem: base, blush, sombra e batom. Após concluir a aplicação da maquiagem virtual com os quatro produtos por meio de um dos modos de interação, o participante é orientado a remover a maquiagem virtual aplicada e mudar para o segundo modo. Assim, os participantes que iniciarem a sessão aplicando maquiagem virtual tocando em sua imagem na tela, trocam para o modo de autoaplicação de maquiagem virtual tocando na face e vice-versa.

Depois de experimentar os dois modos de interação com o sistema, o participante responde ao questionário (Apêndice C) contendo, em sua primeira parte, questões relacionadas a: idade, tempo (em anos) que se maquia, frequência mensal de automaquiagem com produtos físicos, uso de sistemas de maquiagem virtual e uma escala de Likert de 1 (descontente) a 5 (muito contente) em relação aos resultados da automa- 
quiagem com base em sua habilidade; e na segunda parte, questões sobre a experiência na autoaplicação de maquiagem virtual utilizando o SelfMakeup nos dois modos de interação. Também nesse questionário, os participantes informam uma escala de Likert de 1 (muito difícil) a 5 (muito fácil) sobre a facilidade do uso do sistema, de 1 (muito distante) a 5 (muito perto) em relação à precisão da posição da maquiagem virtual, de 1 (muito baixo) a 5 (muito alto) quanto ao nível em que foi natural e agradável de usar o SelfMakeup nos dois modos de interação. Na sequência, os participantes respondem no mesmo questionário suas preferências em relação a qual modo de interação foi mais fácil, qual permitiu resultados mais precisos, qual possibilitou maior satisfação com o resultado final, qual foi mais rápido, qual gostou mais, qual achou mais natural e qual escolheria.

Após responder ao questionário, o participante realiza uma sessão livre de autoaplicação de maquiagem virtual, na qual pode escolher produtos e cores, além do modo de interação com o SelfMakeup. Depois dessa sessão, cada participante responde oralmente duas perguntas: "O que você achou mais interessante em sua interação com o sistema?"e "Você gostaria de mudar algo no sistema?".

\subsubsection{Materiais e métodos}

Uma câmera Intel RealSense RS300 é conectada a um notebook com processador de $2.4 \mathrm{GHz}$ Intel I5, 12GB RAM, com tela sensível ao toque de resolução $1920 \times 1080$ pixels. A tela do notebook é posicionada a aproximadamente $45 \mathrm{~cm}$ da face do participante. Os experimentos foram conduzidos em uma sala com iluminação artificial, sem incidência direta da luz solar, para melhor funcionamento do Intel RealSense RS300.

Durante o experimento, o sensor fornece imagens coloridas com resolução de $1280 \times 720$ pixels e imagens de profundidade com resolução de $640 \times 480$ pixels, ambos a $30 \mathrm{fps}$.

\subsection{Análise dos resultados}

Utilizando o procotolo experimental, realizamos um experimento piloto e a apresentação dos resultados segue o padrão sugerido na 6a Edição do Manual da Associação Americana de Psicologia (APA, do inglês American Psychological Association), disponível em www.apastyle.com. Como o nosso foco era investigar sobre características subjetivas da experiência do usuário, não foram gravados logs referentes a eventos de interface ou tempo de execução das tarefas. A etapa da coleta de dados ocorreu como descrito no protoloco experimental utilizando uma triangulação metodológica.

Trinta e duas pessoas participaram do experimento em uma visita à empresa Mazzatech, organizada pela analista de RH Letícia Rodrigues, depois do diretor Leonardo Raposo permitir a realização do experimento na empresa. Cada sessão experimental durou aproximadamente 25 minutos ao todo e os participantes foram orientados de acordo com o protocolo experimental.

\subsubsection{Caracterização da amostra}

Em um primeiro momento, foram estabelecidas as características da amostra com base nas questões sobre idade do participante, tempo em anos que se maquia, frequência que se maquia com cada um dos produtos: batom, base, blush e sombra, nível de contentamento em relação a habilidade para se automaquiar e se já usou algum sistema ou aplicativo de maquiagem virtual. Como as alternativas de resposta $r$ da frequência 
$f_{p}$ em que o participante se maquia com cada produto físico foram: todos os dias; uma vez por semana; a cada quinze dias; e mensalmente; os resultados foram transformados de acordo com a seguinte função 5.1:

$$
f_{p}(r)= \begin{cases}30 & \mathrm{r}=\text { todos os dias } \\ 4 & \mathrm{r}=\text { uma vez por semana } \\ 2 & \mathrm{r}=\text { a cada quinze dias } \\ 1 & \mathrm{r}=\text { mensalmente }\end{cases}
$$

Considerando $f_{l}$ a frequência em que o participante se maquia com batom, $f_{f}$ a frequência em que o participante se maquia com base, $f_{b}$ a frequência em que o participante se maquia com blush, e $f_{e}$ a frequência em que o participante se maquia com sombra, a frequência $F$ em que o participantes se maquia com produtos de maquiagem reais, foi calculada como sendo:

$$
F=\frac{f_{l}+f_{f}+f_{b}+f_{e}}{4}
$$

Os participantes do experimento piloto têm idade de 18 a 54 anos com média de $30.84 \pm 8.7$. Todos os participantes são do sexo feminino sendo que a maioria (50\%) tem de 12 a 17 anos de experiência com automaquiagem, já usou um sistema de maquiagem virtual(65.6\%) e se sente contente ou muito contente em relação à habilidade na automaquiagem (81.3\%). A tabela 5.1 mostra detalhadamente essas características de todos os participantes.

\subsubsection{Fatores associados à experiência dos participantes na automaquiagem usando produ- tos físicos}

Muitos autores acreditam que a interação 3D deve ser tão natural quanto possível de modo a reproduzir interações do mundo real. Isso possibilita aos usuários aproveitar seus conhecimentos e habilidades para que suas ações para executar uma tarefa na UI sejam correspondentes as ações usadas no mundo real (Bowman et al., 2012). Dessa forma, nós consideramos a hipótese de que a experiência e habilidade dos participantes na automaquiagem com produtos físicos tem associação com a experiência do usuário na automaquiagem virtual. Para avaliar se existe a associação entre as respostas dos participantes sobre os níveis em que foi fácil, rápido, preciso e agradável de usar os dois modos de interação, utilizamos o teste Kruskal-Wallis, depois de verificar que os dados não obedeciam ao critério de normalidade por meio do teste Kolmogorov-Smirnov.

Verificamos que não existe associação entre a experiência dos participantes na automaquiagem com produtos físicos e os níveis em que foi fácil usar o SelfMakeup. Para o modo de interação tocando na face, $\mathrm{H}(3)=3.01$ e $\mathrm{p}>0.05$ para tempo (em anos) que se maquia, $\mathrm{H}(3)=2.43 \mathrm{e} \mathrm{p}>0.05$ para frequência em que se maquia e $\mathrm{H}(3)=3.65$ e p $>0.05$ para nível de contentamento baseado na sua habilidade de automaquiagem. Enquanto que, para o modo tocando na tela, $\mathrm{H}(4)=6.80 \mathrm{e} \mathrm{p}>0.05$ para tempo (em anos) que se maquia, $\mathrm{H}(4)=2.23$ e $\mathrm{p}>0.05$ para frequência em que se maquia e $\mathrm{H}(4)=2.53$ e $\mathrm{p}>0.05$ para nível de contentamento baseado na sua habilidade de automaquiagem.

Ao analisarmos a existência de associação entre a experiência dos participantes na automaquiagem com produtos físicos e os níveis em que foi natural interagir com o SelfMakeup tocando na face, constatamos que não existe associação, visto que $\mathrm{H}(4)=4.7$ e p $>0.05$ para tempo (em anos) que se maquia, $\mathrm{H}(4)=2.42 \mathrm{e}$ p $>0.05$ para frequência em que se maquia e $\mathrm{H}(4)=2.69$ e p $>0.05$ nível de contentamento baseado na sua 


\begin{tabular}{|c|c|}
\hline Variáveis & Total $(\mathrm{N}=32)$ \\
\hline \multicolumn{2}{|l|}{ Idade (anos) } \\
\hline Média \pm DP & $30.84 \pm 8.69$ \\
\hline Mediana [IIQ] & $28.50[26.00 ; 34.00]$ \\
\hline Idade (anos) & $\mathrm{n}(\%)$ \\
\hline 18 a 23 & $4(12.5)$ \\
\hline 24 a 29 & $16(50)$ \\
\hline 30 a 35 & $5(15.6)$ \\
\hline 36 a 41 & $4(12.5)$ \\
\hline 48 a 53 & $2(6.3)$ \\
\hline 54 a 59 & $1(3.1)$ \\
\hline \multicolumn{2}{|l|}{ Experiência (anos) na automaquiagem } \\
\hline Média \pm DP & $15.19 \pm 8.19$ \\
\hline Mediana [IIQ] & $13.00[10.00 ; 17.00]$ \\
\hline Experiência (anos) na automaquiagem & $\mathrm{n}(\%)$ \\
\hline 6 a 11 & $10(31.3)$ \\
\hline 12 a 17 & $16(50)$ \\
\hline 18 a 23 & $3(9.4)$ \\
\hline 30 a 35 & $1(3.1)$ \\
\hline 36 a 41 & $2(6.3)$ \\
\hline \multicolumn{2}{|l|}{ Frequência em que se maquia (dias por mês) } \\
\hline Média \pm DP & $21 \pm 7.9$ \\
\hline Mediana [IIQ] & $23[15.81 ; 28.37]$ \\
\hline Frequência em que se maquia (dias por mês) & $\mathrm{n}(\%)$ \\
\hline$<10$ & $5(15.6)$ \\
\hline 10 a 20 & $5(15.6)$ \\
\hline 21 a 30 & $22(68.7)$ \\
\hline \multicolumn{2}{|l|}{$\begin{array}{l}\text { Nível de contentamento com sua habilidade } \\
\text { com na automaquiagem (Escala Likert } 1 \text { a 5) }\end{array}$} \\
\hline Média $\pm \mathrm{DP}$ & $4.25 \pm 0.76$ \\
\hline Mediana [IIQ] & $4.00[4.00 ; 5.00]$ \\
\hline $\begin{array}{l}\text { Nível de contentamento com sua habilidade } \\
\text { com na automaquiagem (Escala Likert } 1 \text { a } 5 \text { ) }\end{array}$ & $\mathrm{n}(\%)$ \\
\hline 3 & $5(15.6)$ \\
\hline 4 & $5(15.6)$ \\
\hline 5 & $22(68.7)$ \\
\hline Já utilizou sistema de maquiagem virtual & $\mathrm{n}(\%)$ \\
\hline Sim & $21(65.6)$ \\
\hline Não & $11(34.4)$ \\
\hline
\end{tabular}

DP: desvio-padrão. IIQ: intervalo interquartil $\left(1^{\circ} ; 3^{\circ}\right.$ quartis $)$.

Tabela 5.1: Perfil dos participantes do experimento piloto 
habilidade de automaquiagem.

Em relação ao nível em que foi natural tocar na tela, não existe associação com a frequência em que se maquia , $\mathrm{H}(4)=7.31 \mathrm{e}$ p $>0.05$, e nível de contentamento baseado na sua habilidade de automaquiagem, visto que $\mathrm{H}(4)=5.48$ e p $>0.05$. Entretanto, existe associação do tempo (em anos) que se maquia com o nível e que foi natural tocar na tela, pois $\mathrm{H}(4)=11.11 \mathrm{e} \mathrm{p}=0.025$. Assim, uma análise post-hoc utilizando o teste de MannWhitney mostrou uma diferença significativa entre os níveis de naturalidade, $U=32.5$ e $p=0.01$, expressos pelos participantes que tem de 6 a 11 anos (31.25\%) e 12 a 17 anos (50\%) de experiência na automaquiagem. A figura 5.1 mostra os resultados desse efeito significativo para o modo de interação tocando na tela.

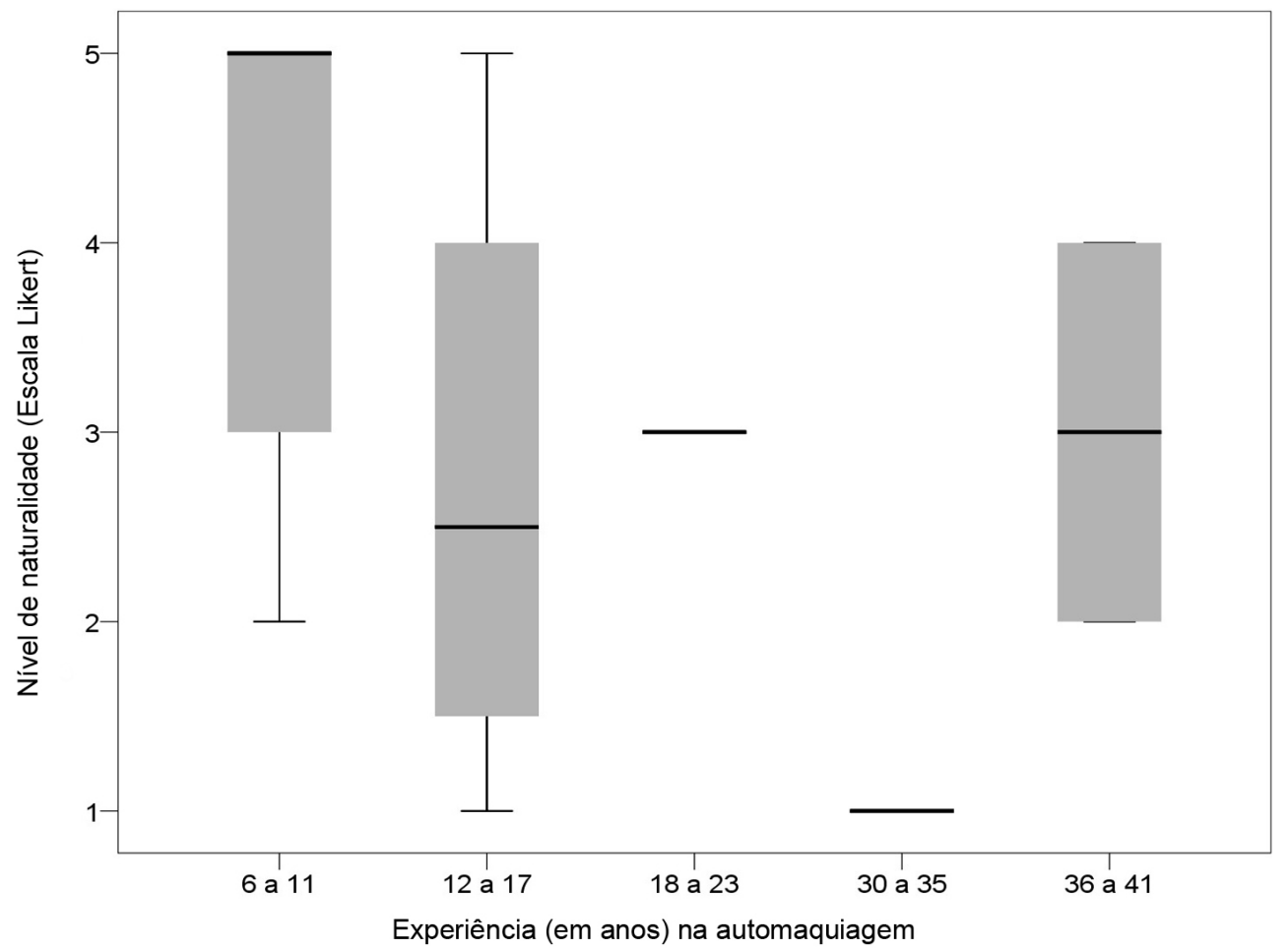

Figura 5.1: Resultado experimental para a relação entre a experiência em anos dos participantes e os níveis em que foi natural interagir com o SelfMakeup no modo tocando a tela expressados por meio de uma escala Likert. Para cada grupo é mostrado como extremos os níveis máximo e mínimo de naturalidade de interação, os quartis inferior e superior como sendo extremos da caixa sombreada e a mediana como uma linha dentro da caixa.

Ao relacionar a experiência dos participantes na automaquiagem com produtos físicos e os níveis de precisão que os modos de interação possibilitaram a autoaplicação de maquiagem virtual no local desejado, constatamos que, para o modo tocando na face, não existe efeito significativo da frequência em que se maquiam $(\mathrm{H}(2)=1.68, \mathrm{p}>0.05)$ e experiência em anos na automaquiagem $(\mathrm{H}(2)=4.02, \mathrm{p}>0.05)$. Para o modo tocando na tela, os níveis expressados pelos participantes em que foi natural a interação não têm influência da frequência em que se maquiam $(\mathrm{H}(4)=2.36, \mathrm{p}>0.05)$ e do nível de contentamento dos participantes em relação a sua habilidade na automaquiagem $(\mathrm{H}(4)=2.98$, $\mathrm{p}>0.05)$.

Entretanto, para o modo de interação tocando na face, o nível de contentamento dos participantes no que tange a sua habilidade na automaquiagem interfere nos níveis expressados pelos participantes em relação à precisão na autoaplicação de maquiagem virtual no local desejado, pois $\mathrm{H}(2)=6.33, \mathrm{p}=0.042$. Por meio de uma análise post-hoc utilizando o teste de Mann-Whitney verificamos uma diferença significativa ( $\mathrm{U}=41.00$, $\mathrm{p}=0.014)$ expressa pelos participantes que atribuíram 4 (15.6\%) ou 5(15.6\%) na escala de Likert para o nível de contentamento em relação a sua habilidade na automaquiagem. Essa diferença para o modo de interação tocando na face, pode ser observada na figura 5.2. 


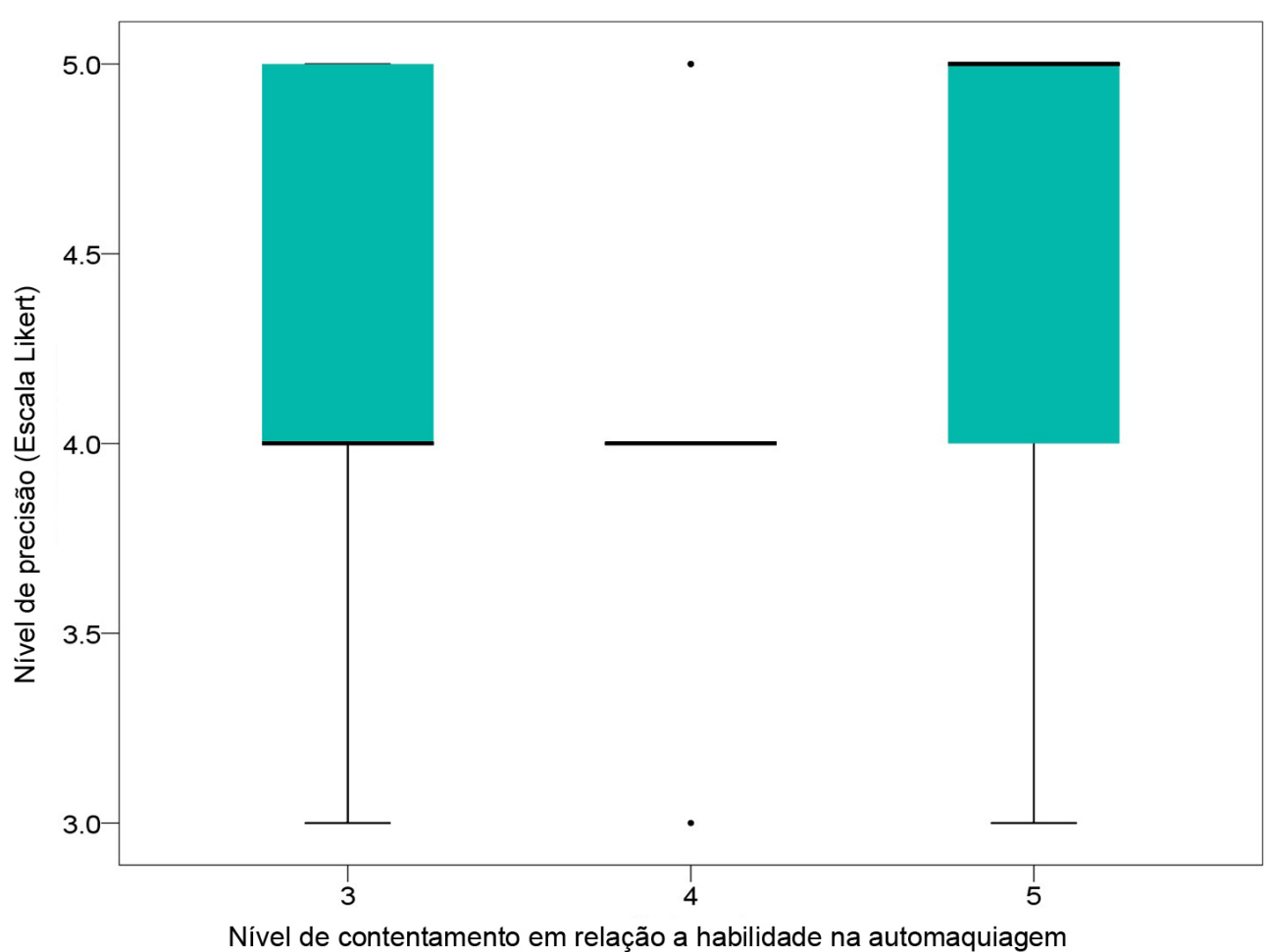

Figura 5.2: Resultado experimental do efeito significativo entre o nível de contentamento dos participantes em relação a habilidade na automaquiagem e a precisão na autoaplicação de maquiagem virtual no modo tocando na tela. Para cada grupo é mostrado como extremos os níveis máximo e mínimo de precisão expressados pelos participantes, os quartis inferior e superior como sendo extremos da caixa sombreada e a mediana como uma linha dentro da caixa.

No modo de interação tocando na tela, averiguamos que a experiência em anos dos participantes na automaquiagem teve associação com o nível de em que foi precisa a autoaplicação de maquiagem virtual pois $\mathrm{H}(4)=9.58, \mathrm{p}=0.048$. Uma análise post-hoc utilizando o teste de Mann-Whitney permitiu certificar que há uma diferença significativa exteriorizada pelos participantes que tem de 6 a 11 anos (31.25\%) e 12 a 17 anos $(50 \%)$ de experiência na automaquiagem, pois $U=39.00, p=0.025$. Essa diferença para o modo de interação tocando na tela é explicitada na figura 5.3.

Não encontramos associação entre os níveis em que foi agradável de usar o modo tocando na face e a experiência dos participantes na automaquiagem com produtos físicos, pois $\mathrm{H}(3)=2.37 \mathrm{e} p>0.05$ para tempo (em anos) que se maquia, $\mathrm{H}(3)=2.34$ e p $>0.05$ para frequência em que se maquia e $\mathrm{H}(3)=1.40$ e $\mathrm{p}>0.05$ para o nível de contentamento baseado na habilidade de automaquiagem. Também não houve essa associação para o modo tocando na tela, visto que $\mathrm{H}(4)=6.58 \mathrm{e} \mathrm{p}>0.05$ para tempo (em anos) que se maquia, $\mathrm{H}(4)=7.58$ e p $>0.05$ para frequência em que se maquia e $\mathrm{H}(4)=1.03$ e p $>0.05$ para o nível de contentamento baseado na habilidade de automaquiagem.

Para avaliar se há associação, para os dois modos de interação com o SelfMakeup, entre a experiência dos participantes no uso de sistemas de aplicação de maquiagem virtual e a indicação de qual gostaram mais; qual deles consideraram mais natural; qual acharam mais fácil de utilizar; qual foi mais preciso; qual trouxe mais satisfação; qual foi mais rápido; qual desses modos de interação escolheria usar; e qual realmente escolheu para realizar a sessão livre, foi utilizado o teste Exato de Fisher. Os resultados obtidos com o teste mostraram não haver associação, pois $\mathrm{p}>0.05$ para todas as variáveis. 


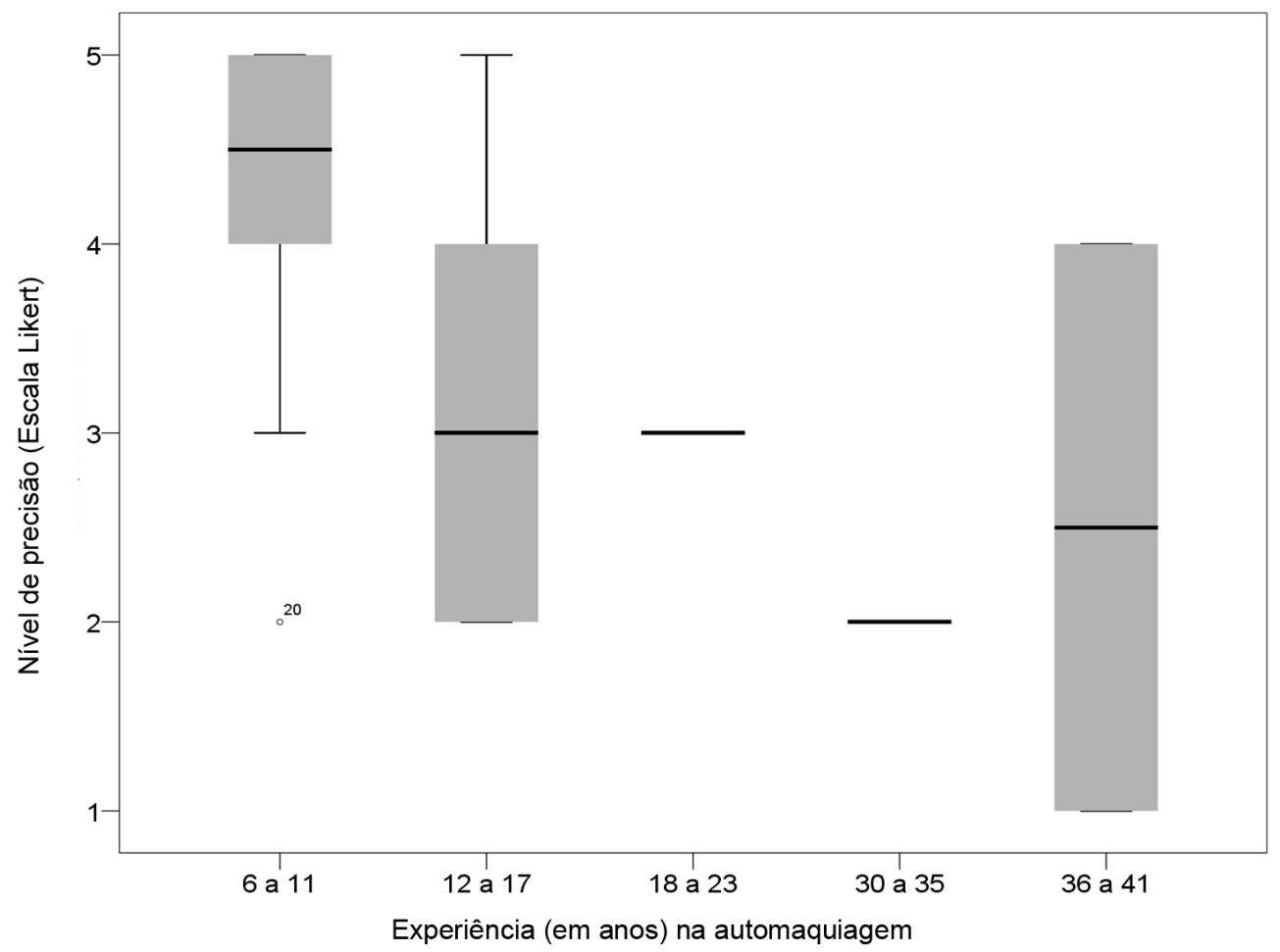

Figura 5.3: Resultado experimental do efeito significativo entre o tempo de experiência dos participantes na automaquiagem e a precisão na autoaplicação de maquiagem virtual no modo tocando na tela. Para cada grupo é mostrado como extremos os níveis máximo e mínimo de precisão expressados pelos participantes, os quartis inferior e superior como sendo extremos da caixa sombreada e a mediana como uma linha dentro da caixa.

\subsubsection{Fatores relacionados à ordem de utilização dos modos de interação com o SelfMakeup}

Além de averiguar a existência de associação entre as características dos participantes relacionadas à sua experiência no dia-a-dia com automaquiagem nas opiniões por eles expressadas, analisamos também se a ordem de utilização dos modos de interação influenciou nas respostas dos participantes ao questionário.

Um teste Mann-Whitney mostrou que a ordem dos modos utilizados na sessão orientada não teve efeito significativo em relação à expressão dos participantes nos níveis em que os modos de interação foram fáceis de usar, naturais e precisos, pois p>0.05 para todas as variáveis. Mas, evidenciou que, apesar de não ter influenciado no nível em que foi agradável usar o modo de interação tocando a tela, $p>0.05$, impactou no nível em que foi agradável aplicar maquiagem virtual tocando a face $U=77, p=0.018$. A figura 5.4 mostra essa influência.

Ao averiguar o impacto da ordem de utilização dos modos de interação na sessão orientada nas respostas dos participantes de qual gostaram mais; qual deles consideraram mais natural; qual acharam mais fácil de utilizar; qual foi mais preciso; qual trouxe mais satisfação; qual foi mais rápido; qual desses modos de interação escolheria usar; e qual realmente escolheu para realizar a sessão livre, usamos o teste Exato de Fisher. Os resultados mostraram que o modo de interação no qual o participante terminou a sessão orientada não influenciou nas suas respostas, pois p $>0.05$ para todas as variáveis.

\subsubsection{Comparando os dois modos de interação}

Além de investigar acerca do efeito do conhecimento e habilidade dos usuários na automaquiagem com produtos físicos na experiência de utilizar o SelfMakeup nos dois modos de interação, analisamos as respostas dos participantes ao questionário com o objetivo de comparar os dois modos de interação propostos para 


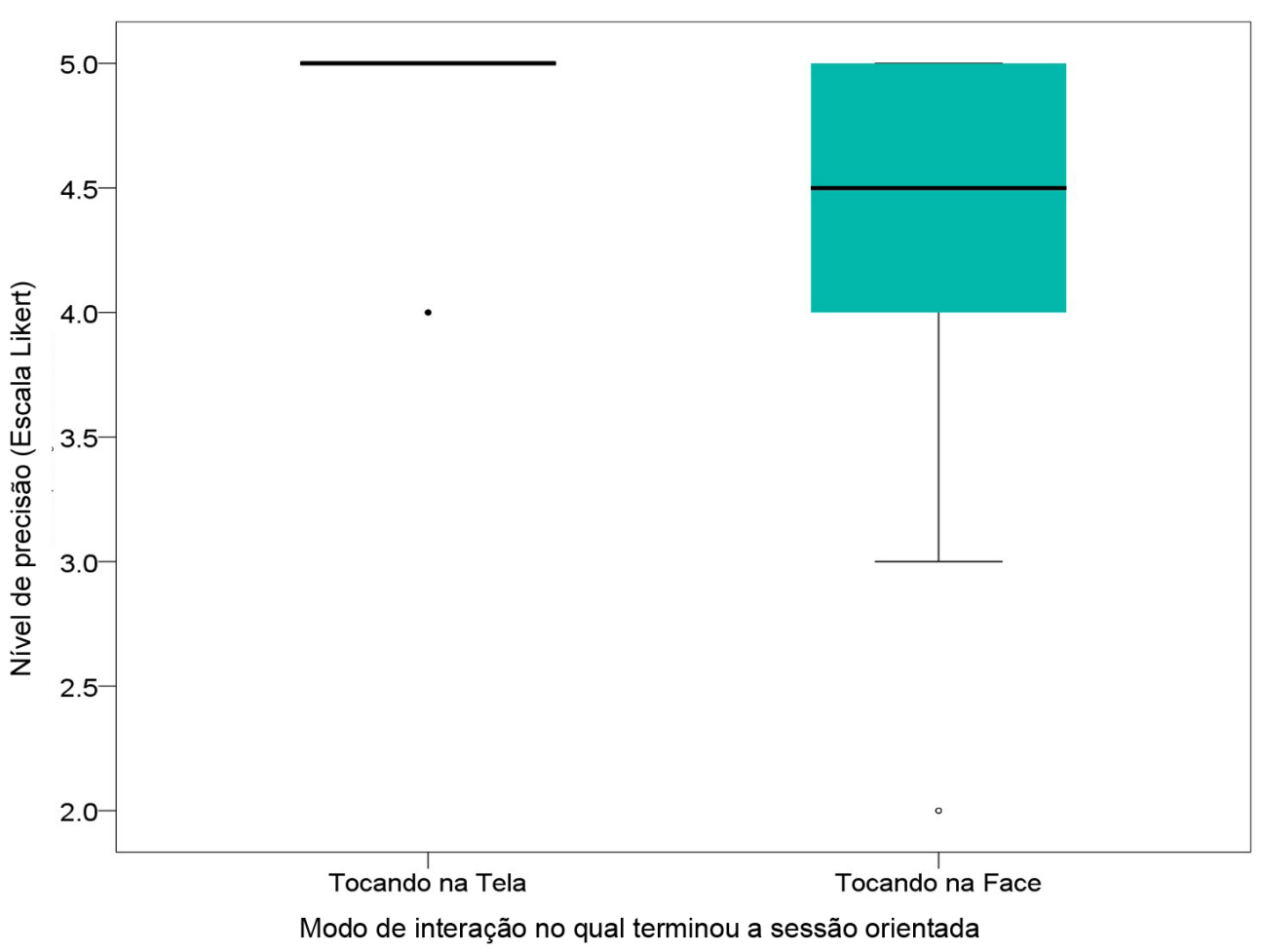

Figura 5.4: Resultado experimental do efeito significativo entre o modo de interação em que a sessão orientada terminou e o nível em que os participantes acharam agradável autoaplicar maquiagem virtual tocando na face. Para cada grupo é mostrado como extremos os níveis máximo e mínimo em que o modo de interação tocando na face foi agradável, os quartis inferior e superior como sendo extremos da caixa sombreada e a mediana como uma linha dentro da caixa.

autoaplicar maquiagem virtual.

No que tange ao nível de facilidade na interação expressado pelos participantes por meio de uma escala Likert de 1 (muito difícil) a 5 (muito fácil), o modo de autoaplicação de maquiagem virtual tocando na tela ficou com $3 \pm 1.91$, enquanto o modo tocando na face $4.06 \pm 0.88$ (figura 5.5). Além disso, 24(75\%) consideram mais fácil autoaplicar maquiagem virtual tocando na face (figura 5.6).

Em relação ao nível em que foi natural a autoaplicação de maquiagem virtual, dentro de uma escala Likert de 1 (muito baixo) a 5 (muito alto), o modo tocando na face foi avaliado com $4.28 \pm 1.02$ e o modo tocando a tela com $3.09 \pm 1.4$ (figura 5.5). A maioria dos participantes (78.1\%) considerou mais natural e mais rápido autoaplicar maquiagem virtual tocando na face (figura 5.6).

Quanto ao nível de precisão em que os modos de interação permitiram a autoaplicação de maquiagem virtual no local desejado, por meio de uma escala Likert de 1 (muito distante) a 5 (muito perto), os participantes avaliaram o modo tocando na face com $4.34 \pm 0.653$ e o modo tocando na tela com $3.34 \pm 1.23$ (figura 5.5). Para a maioria dos participantes (81.3\%), o modo tocando na face foi o mais preciso (figura 5.6). Usando também uma escala Likert de 1 (muito baixo) a 5 (muito alto), os participantes consideram o modo tocando na face com o nível de agradabilidade de $4.53 \pm 0.842$, enquanto julgaram o modo tocando na tela com $3.28 \pm 1.276$ (figura 5.5).

No que tange ao modo de interação que permitiu ao usuário se sentir mais satisfeito com o resultado final, o modo de interação tocando na face foi escolhido por 26 (81.3\%) participantes (figura 5.6).

Por fim, o modo tocando na face foi considerado o modo de interação que 26 (81.3\%) participantes gostaram mais e escolheriam para autoaplicar maquiagem virtual. Entretanto, na sessão livre, 29 participantes $(90.6 \%)$ usaram o modo tocando na face para autoaplicar maquiagem virtual. Esses resultados são 


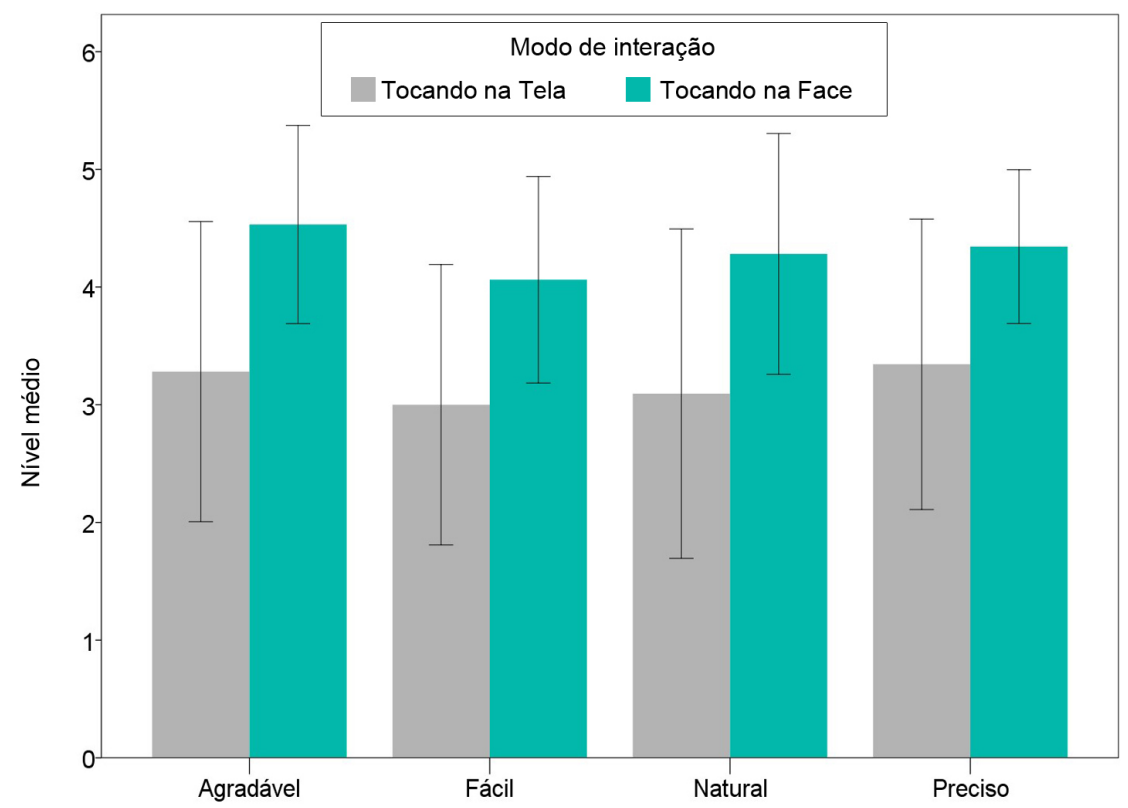

Figura 5.5: Opinião dos participantes sobre o nível em foi agradável, fácil, natural e preciso autoaplicar maquiagem virtual usando os dois modos de interação.

apresentados na (figura 5.6).

\section{Análise das entrevistas e da observação}

Para que fosse possível analisar as opiniões dos participantes expressadas na entrevista e durante o experimento, primeiramente, as respostas à entrevista e anotações com base na observação foram avaliadas e categorizadas.

A variedade das respostas acarretou na criação de seis categorias para o que os usuários consideram mais interessante na interação com o SelfMakeup, quais sejam: realismo na interação tocando na face; possibilidade de experimentar produtos; realismo da maquiagem virtual; liberdade de escolha da região facial na qual aplicar a maquiagem virtual; precisão na autoaplicação de maquiagem virtual tocando na face; e realismo na interação tocando na face em conjunto com o realismo da maquiagem virtual. Em relação às sugestões dos usuários e problemas encontrados, foram criadas seis categorias: possibilidade de mover o aplicador mais rapidamente para o modo de interação tocando na face; existência de mais produtos para experimentar; possibilidade de correção automática de contorno nas áreas faciais menores; possibilidade de espalhar a maquiagem virtual; existência de ícones nos botões; possibilidade de aplicar a maquiagem virtual sem o passo de inicialização do aplicador.

Utilizando as categorias criadas, foram analisadas as características ressaltadas como interessantes pelos participantes e, em seguida, averiguados os problemas encontrados por eles no experimento piloto. Ainda, foi possível compreender reações dos usuários em relação aos modos de interação com o SelfMakeup, como se sentiram sobre o sistema em geral e como se sentiram quando algo não aconteceu como esperado.

Sobre o modo de interação para autoaplicar maquiagem virtual tocando na face, 3 participantes $(9.4 \%)$ acharam interessante a precisão para autoaplicar a maquiagem virtual, 12 participantes (37.5\%) ressaltaram sobre o grau de realismo na interação tocando na face e 4 participantes (12.5\%) gostaram do realismo na interação em conjunto com o realismo da maquiagem virtual. Essas respostas estão relacionadas também com as reações dos participantes observadas durante a autoaplicação da maquiagem virtual tocando na face. 


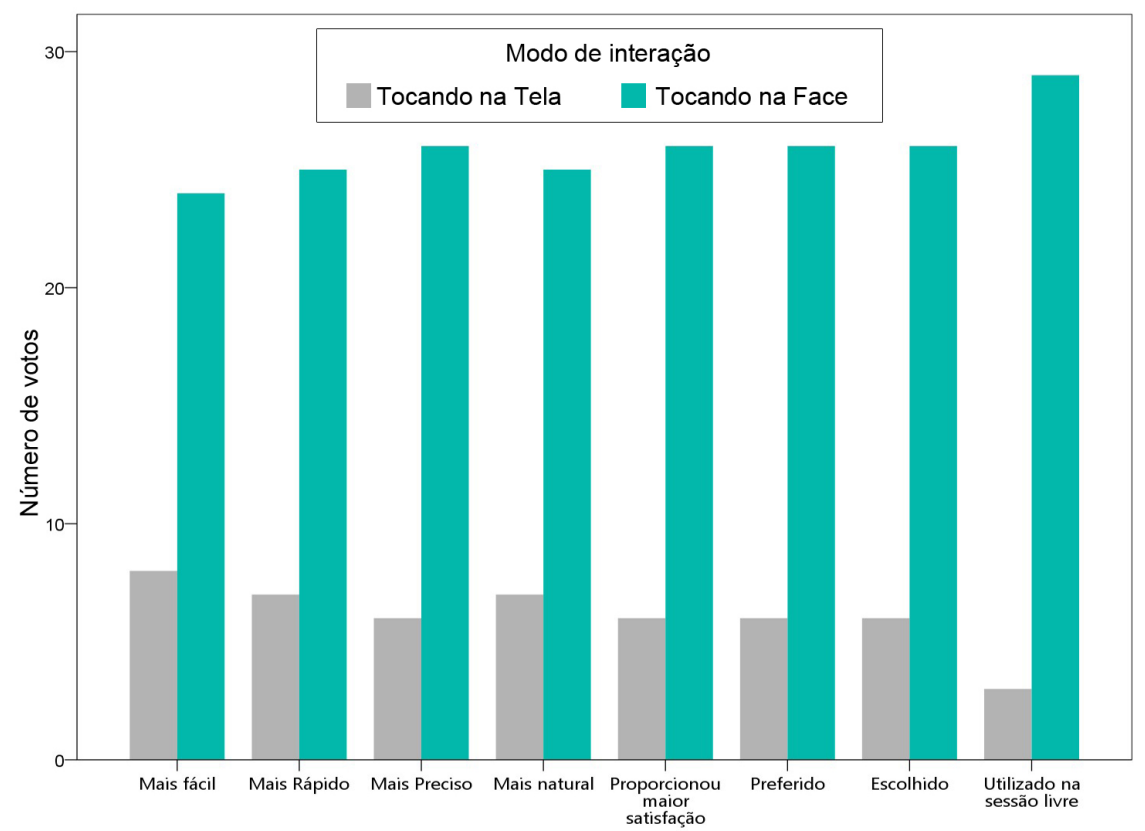

Figura 5.6: Votos dos trinta e dois participantes (100\%) sobre o modo de interação que foi mais fácil, mais rápido, mais preciso e mais natural. São mostrados também os votos para o modo de interação que proporcionou maior satisfação com os resultados da autoaplicação de maquiagem virtual, para o modo que seria escolhido, caso possível e para o modo que realmente foi utilizado na sessão livre.

Alguns comentários foram:

"Nossa, não estou acreditando, estou com a sensação de que essa maquiagem está em mim... É incrível sentir meu dedo tocando a minha face e ao mesmo tempo ver meu rosto sendo maquiado onde toquei"(P10).

"...eu não imaginava poder usar uma tecnologia assim. É tão real que eu estou me sentindo assustada, mas estou achando muito interessante. Estou sentindo que a tecnologia está controlando meu pensamento. Não estou discernindo o que é real. Parece que que meu rosto vai continuar assim depois que eu sair de frente do computador."(P27).

No que tange as opiniões, expressadas na entrevista, relacionadas aos dois modos de interação, três participantes $(9.4 \%)$ consideraram interessante a liberdade de escolher a região facial na qual aplicar a maquiagem virtual, três participantes $(9.4 \%$ ) comentaram sobre o grau de realismo na renderização da maquiagem virtual e sete participantes (21.9\%) gostaram da possibilidade de experimentar vários produtos e comparar os resultados. As opiniões dos participantes exteriorizadas na entrevista sobre as características que consideraram interessantes podem ser visualizadas na figura (5.7).

Durante o experimento foram observados alguns comentários dos participantes que se encaixam as categorias acima citadas:

"É muito bom poder escolher onde vou aplicar a maquiagem. Ainda dá para comparar algumas cores..."(P1).

"Sabe o que eu estou achando legal? Parece que essa maquiagem é real, estou conseguindo ver as minhas marcas de expressão e as características do meu rosto, mesmo onde tem maquiagem...eu consigo ver as dobras do meu olho. A maquiagem acompanha a profundidade do meu rosto"(P6).

"...muito natural a forma que aparece a maquiagem, é muito mais real que os outros aplicativos que já usei (P32).

"Nossa eu estou pensando como seria mais fácil ter esse sistema para experimentar maquiagens. 


\section{Posso experimentar várias cores de batom sem ter que ficar limpando meu rosto"(P8).}

"Estou adorando poder ver minha face de formas diferentes. Nunca tinha tido coragem de passar um batom escuro assim. É interessante poder ver o resultado e saber que não estou sujando meu rosto (P30).

Além disso, por meio da observação, foram notadas ações dos usuários que são naturais do processo de automaquiagem com produtos físicos como: passar o dedo para acertar o contorno do batom, mexer os lábios para misturar o batom, passar a mão na bochecha para espalhar o blush e passar o dedo na sombra para esfumar o contorno.

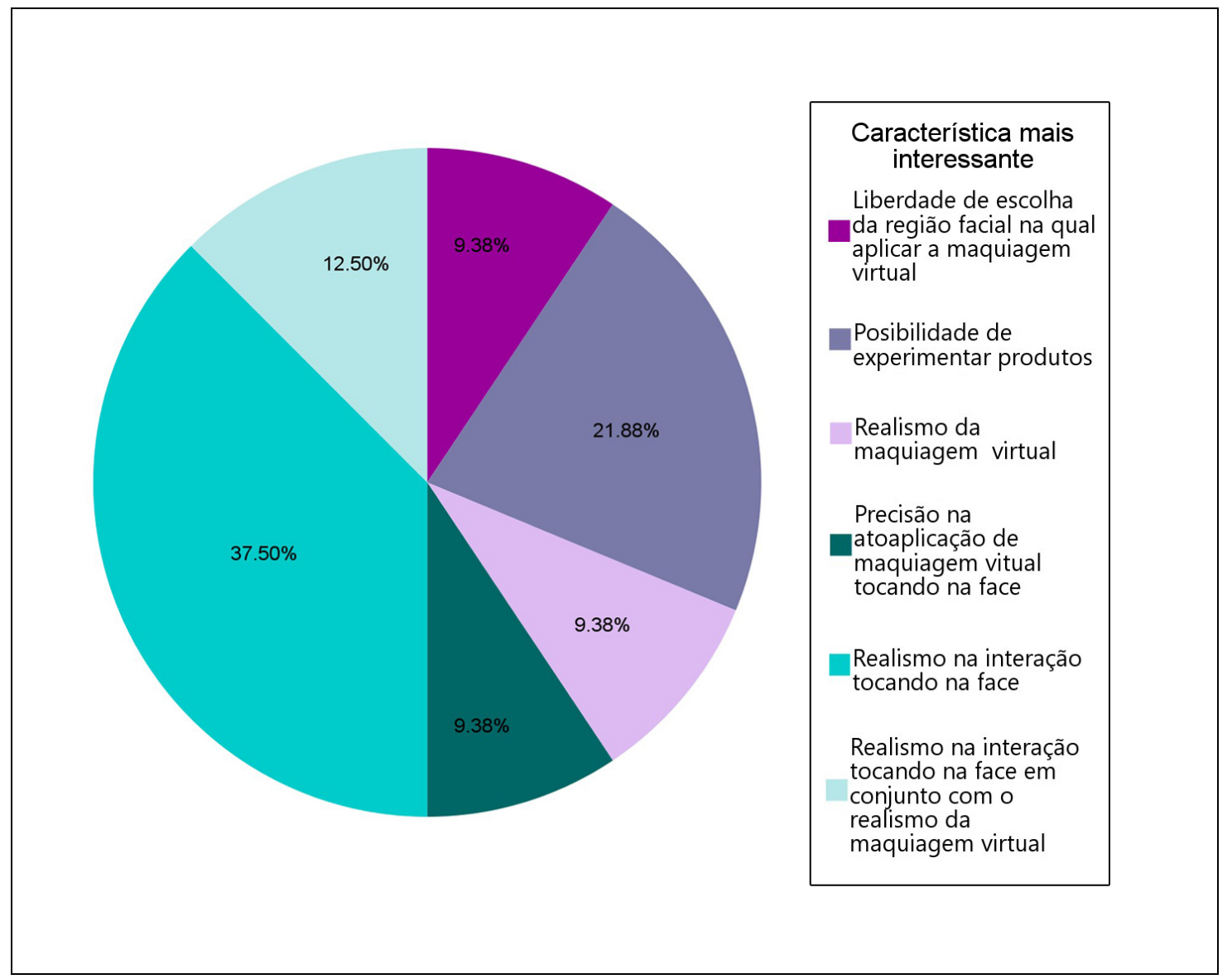

Figura 5.7: Opinião dos participantes sobre características que consideraram interessantes ao interagir com o AutoMakup no experimento piloto. As características representadas em tons de roxo são referentes aos dois modos de interação e as que estão em tons de verde são relacionadas ao modo de interação tocando na face.

Quanto às respostas para a questão sobre o que deveria ser alterado ou adicionado na interação com o SelfMakeup, um participante (3.1\%) sugeriu colocar ícones nos botões dos produtos, um participante (3.1\%) apontou que seria interessante ter uma funcionalidade para espalhar a maquiagem já aplicada, três participantes (9.4\%) gostariam de contar com correção automática nos contornos das áreas faciais menores como os olhos e sete participantes (21.9 \%) apreciariam a possibilidade de mais produtos para experimentar. Em relação ao modo de autoaplicar a maquiagem virtual tocando na face, seis participantes (18.8\%) gostariam de poder mover a mão mais rapidamente sem perder o aplicador e três participantes (9.2\%) disseram que seria bom usar o modo tocando na face sem ter o passo de inicialização do aplicador.

Essas sugestões, apresentados na figura 5.8, confirmaram algumas reações e comentários observados durante o experimento:

"NosSa, ESQUECI DE PEGAR O APLICADOR..."(P11) 
"Aí, movi muito rápido, perdi o aplicador... Vou ter que pegar novamente. "(P17)

"O aplicador médio é um pincel para sombra?.."(P4)

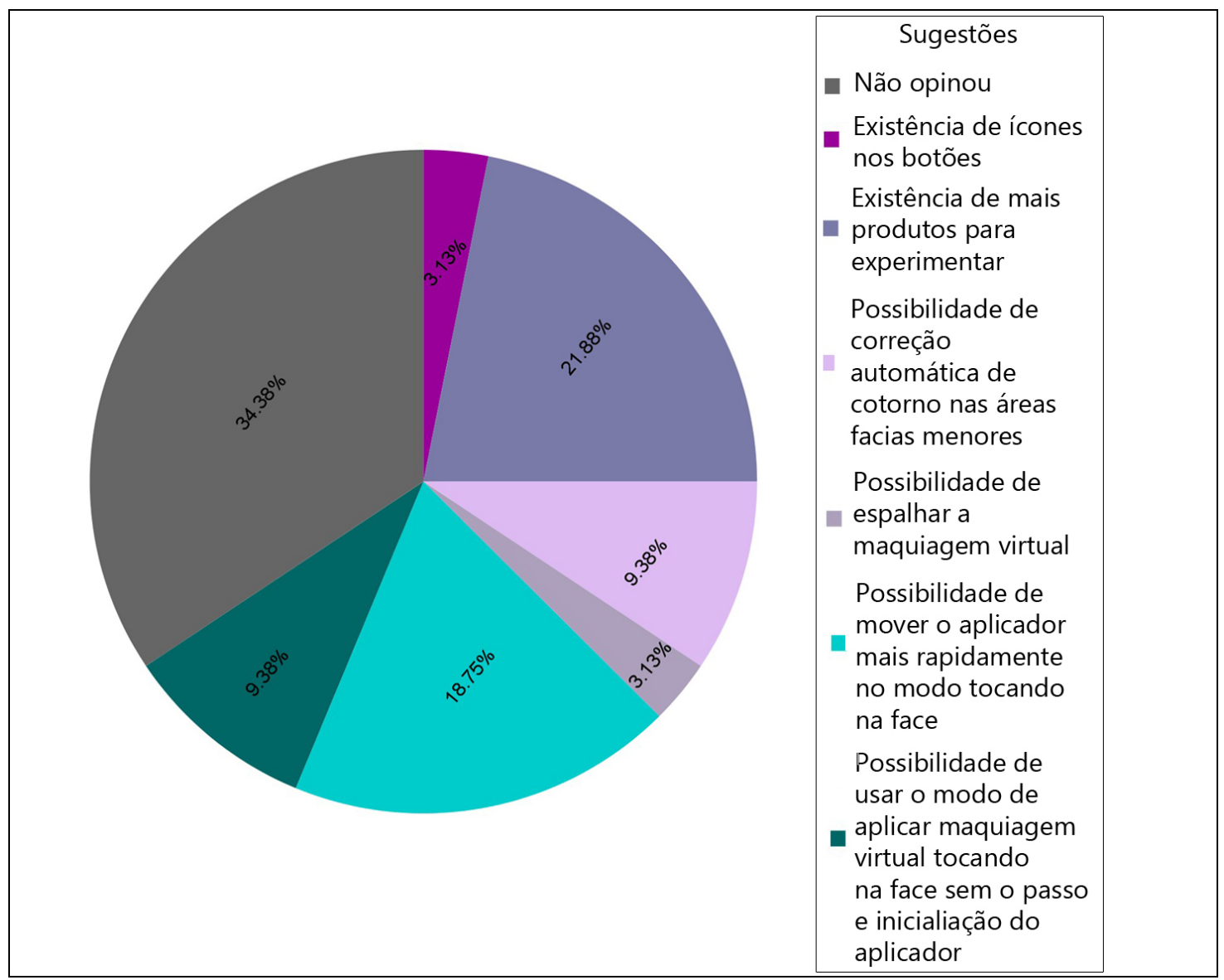

Figura 5.8: Sugestões dos participantes de melhorias que consideram importantes. As características representadas em tons de roxo são referentes aos dois modos de interação e as que estão em tons de verde são relacionadas ao modo de interação tocando na face. A parte cinza representa os participantes que não opinaram.

Apesar de certas sugestões terem partido de alguns participantes, estão relacionadas à reações de outros participantes observadas durante o experimento. A falta de ícones nos botões do aplicador, por exemplo, fez com que sete participantes (21.9\%) não soubessem qual o tamanho de aplicador mais adequado aos produtos escolhidos na sessão livre. Sobre a funcionalidade de espalhar a maquiagem virtual, quatro participantes $(12.5 \%)$ perguntaram sobre sua existência durante a sessão livre.

\subsubsection{Discussão}

O estudo piloto foi conduzido com o objetivo de verificar a viabilidade da nossa proposta de permitir ao usuário autoaplicar maquiagem virtual tocando na sua própria face, com base na hipótese: permitir que o usuário autoaplique maquiagem virtual tocando sua própria face é mais natural que usando toques na tela. Particularmente, proporcionar ao usuário fidelidade na interação, melhora sua experiência na utilização de um sistema de realidade aumentada para autoaplicação de maquiagem virtual.

Partindo da natureza dos sujeitos do nosso estudo, houve predominância de participantes (68.7\%) com mais de 12 anos de experiência na automaquiagem, que se maquiam com uma frequência aproximada de 21 a 30 dias por mês e que se sentem muito contente com sua habilidade na automaquiagem. Os resultados obtidos com base no perfil amostral e nas respostas do questionário mostraram que a habilidade e a experiência do 
indivíduo no processo de automaquiagem com produtos físicos tem associação com a sua experiência de usuário na autoaplicação de maquiagem virtual. Entretanto, apesar desse efeito significativo, essa habilidade e experiência adquiridas com ações no mundo real não influenciaram na escolha dos participantes sobre o modo de interação com o SelfMakeup.

Dos trinta e dois participantes (100\%), seis (18.8\%) responderam ao questionário expressando a preferência por aplicar maquiagem virtual tocando tela, mas três deles (50\%) aplicaram maquiagem virtual tocando na face durante a sessão livre. Durante a observação, desses seis participantes (18.8\%) que demonstraram inclinação pelo modo de interação tocando na tela, três $(9.37 \%)$ alegaram que gostariam de usar o modo tocando na face mas sem tem que inicializar o aplicador; dois (6.25\%) comentaram que o modo de interação tocando na face proporciona uma sensação mais interessante, mas que depende de maior habilidade manual e mais paciência; um (3.12\%) alegou ser estranho tocar a face em frente ao computador.

Relacionando essas opiniões com as indicações de melhorias feitas pelos participantes, apresentadas na 5.8, é possível inferir que as restrições identificadas para o modo de aplicação de maquiagem virtual tocando na face são acarretadas principalmente pelas limitações tecnológicas do protótipo, não pelo modo de interação em si. Adicionalmente, ainda que tenham sido identificados alguns problemas de usabilidade, vinte e seis participantes $(81.25 \%)$ escolheriam o modo de autoaplicação de maquiagem virtual tocando na face e vinte e nove participantes $(90.62 \%)$ realmente usaram esse modo de interação na sessão livre. Portanto, os resultados do estudo piloto indicam que a proposta de autoaplicar maquiagem virtual por meio de toques na face é viável e promissora. Além disso, os resultados do estudo piloto indicam que o protocolo experimental é adequado para investigar sobre a experiência do usuário em estudos futuros, considerando os aspectos éticos. 


\section{Capítulo 6}

\section{Conclusão}

Este estudo teve como objetivo arquitetar e implementar um sistema de realidade aumentada (SelfMakeup) como forma de verificar a hipótese apresentada na sessão introdutória de que a experiência do usuário ao aplicar maquiagem virtual por meio de toques na face é melhor que ao utilizar toques na tela.

Para viabilizar a nossa pesquisa, propomos um método para estimar a posição do toque do aplicador na face. $\mathrm{O}$ aplicador pode ser um dedo da mão do usuário ou qualquer bastão com forma semelhante a pincéis utilizados na aplicação de produtos reais. Fazendo uso de uma câmera RGBD para capturar a imagem de cor e de profundidade, a face do usuário e a ponta do aplicador são detectados e rastreados. O toque é detectado quando a distância entre a ponta do aplicador e a face está dentro de um limiar pré-definido. A posição do toque na face é dada em coordenadas faciais que são mapeadas em um espaço facial normalizado, que contém o mapa da face em 2D.

Para testar a experiência do usúario, desenvolvemos a interface gráfica (GUI) do SelfMakeup para permitir ao usuário ações básicas como configurar o tamanho e intensidade do aplicador e escolher o tipo de produto virtual que deseja aplicar. Cada produto virtual disponibilizado na GUI possui uma textura correspondente, denominada maquilet.

Quando um toque na face é detectado, sua respectiva coordenada facial, juntamente com as informações do aplicador e do produto virtual selecionado, é utilizada para adicionar o maquilet a um espaço de textura contendo todos os maquilets já aplicados. Esse espaço de textura consiste em uma imagem criada a partir do espaço facial normalizado.

Com base nas informações obtidas com o rastreamento da face, a textura contendo os maquilets já aplicados é mapeada para a imagem facial do usuário capturada em tempo real. Esse passo possibilita que a maquiagem virtual seja renderizada a cada quadro de acordo com a pose ou expressão facial do usuário.

Para aplicar a maquiagem virtual, propusemos uma nova abordagem que combina aspectos do método de (Campos, 2014), que aplica maquiagem, com características do método de (Guo e Sim, 2009), que efetua a transferência de maquiagem. Inicialmente, com a intenção de manter alguns detalhes e características faciais, a imagem da face é dividida em camadas de acordo com faixas de frequência. Então, considerando os efeitos provocados pelos produtos de maquiagem física, a aplicação da maquiagem virtual consiste na alteração da cor da imagem facial do usuário nas regiões maquiadas. A base virtual é a única dos produtos virtuais utilizados que necessita de uma etapa inicial de suavização de algumas camadas da imagem facial do usuário para que o tom de sua pele fique mais homogêneo.

Antes de investigar a interação, realizamos um experimento para avaliar a acurácia do método de estimação da posição do toque do aplicador na face. Os resultados de acurácia de $0.0186 \pm 0.0091$ unidades do espaço facial normalizado obtidos mostram que o método proposto é adequado para o contexto de autoapli- 
cação de maquiagem.

Para investigar aspectos da experiência do usuário, realizamos um experimento piloto que comparou o modo de autoaplicação de maquiagem virtual tocando na face com o modo de autoaplicação tocando na tela. Apesar de termos constatado que a experiência e habilidade dos participantes na automaquiagem com produtos físicos tenha efeito significativo sobre aspectos da experiência de autoaplicar maquiagem virtual nos dois modos de interação, os resultados mostram que o perfil do participante não influenciou na escolha pelo modo de interação por ele preferido.

Do ponto de vista subjetivo, os usuários acharam o modo de interação tocando na face mais fácil, mais agradável, mais natural, mais rápido e mais preciso. Além disso, consideraram que o modo de interação proposto neste estudo proporcionou maior satisfação com resultados da automaquiagem virtual. Ainda, 81.25\% dos participantes escolheriam o modo de autoaplicação de maquiagem virtual tocando na face e $90.62 \%$ dos participantes usaram esse modo de interação na sessão livre. Entretanto, dos participantes que escolheriam o modo tocando na tela, $15.63 \%$ gostaria de aplicar maquiagem tocando na face se não fossem as limitações tecnológicas na inicialização e movimentação rápida do aplicador.

Como contribuição principal deste estudo, o método para estimar a posição do toque na face que, além de oferecer precisão e acurácia necessárias para o contexto de autoaplicação de maquiagem, funciona em tempo real com recursos computacionais limitados, demonstrando potencial uso em aplicativos sem demanda de hardwares de alto custo. Além disso, contribuímos com o método para aplicar maquiagem virtual, que em relação aos trabalhos de simulação de aplicação e transferência de maquiagem, traz resultados mais realistas e possibilita a aplicação livre de maquiagem em qualquer região do rosto, permitindo a comparação ou a mistura de dois ou mais produtos. Esse método opera em tempo real sem usar paralelização ou GPU.

Outra contribuição foi a arquitetura e implementação do SelfMakeup, que permite ao usuário aplicar maquiagens virtuais tocando na face ou na tela, em tempo real. Os resultados obtidos com o estudo piloto mostraram o potencial de ser utilizado em diversos contextos, quais sejam: em lojas de produtos de maquiagem, permitindo a experimentação virtual de produtos, reduzindo os custos com produtos físicos e possibilitando a experimentação online; por maquiadores profissionais, possibilitando que, antes de aplicar a maquiagem, os clientes possam visualizar os resultados de diferentes maquiagens em sua própria face e possam efetuar suas escolhas; para uso doméstico, poderia auxiliar os usuários a selecionarem uma combinação de produtos de acordo com a ocasião, preço e outros parâmetros diretamente relacionados a lojas virtuais de cosméticos. Pode ser utilizado também como uma forma de entretenimento.

Por meio dos resultados do estudo piloto, mostramos que é possível melhorar a experiência do usuário na interação com um sistema de maquiagem virtual ao permitir a autoaplicação por meio de toques na face. Apesar das limitações tecnológicas encontradas, os resultados indicam que nossa proposta é viável e promissora.

Para trabalhos futuros, sugerimos a avaliação da experiência do usuário considerando o tempo e o número de erros na realização de tarefas para aplicar a maquiagem virtual. Em relação ao modo de interação, pensamos na possibilidade de a escolha dos produtos pelo usuário ser feita também com interação 3D. Outra possibilidade é proporcionar ao usuário uma interação "mágica", na qual as suas limitações no mundo real sejam sanadas pela tecnologia. Como exemplo, considerar as sugestões dos participantes do estudo piloto para a correção automática no contorno da maquiagem virtual, o que pode compensar a falta de habilidade manual do usuário na autoaplicação de maquiagem. 


\section{Apêndice A}

\section{Equações para os pontos fiduciais}

$$
\begin{gathered}
p_{78}(x, y)=\left(p_{26}(x), p_{73}(y)\right) \\
p_{79}(x, y)=\left(\left|p_{5}(x)-p_{26}(x)\right| / 2+p_{26}(x), p_{26}(y)\right) \\
p_{80}(x, y)=\left(\left|p_{26}(x)-p_{0}(x)\right| / 2+p_{0}(x), p_{26}(y)\right) \\
m_{1}=\left\{\begin{array}{cc}
\left(p_{79}(y)-p_{32}(y)\right) /\left(p_{79}(x)-p_{32}(x)\right) \\
\left(p_{79}(y)-p_{32}(y)\right) /\left(p_{32}(x)-p_{79}(x)\right) \\
\text { caso contrário }
\end{array}\right. \\
\left.p_{81}(x, y)=\left(\left|p_{28}(x)-p_{32}(x)\right| / m_{1}\right]+p_{32}(x), p_{28}(y)\right) \\
p_{82}(x, y)=\left(\left|p_{27}(x)-p_{32}(x)\right| / m_{1}+p_{32}(x), p_{27}(y)\right) \\
m_{2}=\left\{\begin{array}{cc}
\left(p_{80}(y)-p_{30}(y)\right) /\left(p_{80}(x)-p_{30}(x)\right) \\
\left(p_{80}(y)-p_{30}(y)\right) /\left(p_{30}(x)-p_{80}(x)\right) \\
p_{85}(x)>p_{30}(x) \\
p_{84}(x, y)=\left(p_{78}(x), p_{78}(y)-\left(p_{78}(y)-p_{97}(y) / 2\right)\right)
\end{array}\right. \\
p_{83}(x, y)=\left(\left|p_{28}(x)-p_{30}(x)\right| / m_{2}+p_{30}(x), p_{28}(y)\right) \\
\left.m_{38}(x), p_{78}(y)-\left(p_{31}(y)-p_{78}(y)\right)\right)
\end{gathered}
$$




$$
\begin{gathered}
p_{87}(x, y)=\left(p_{6}(x), p_{97}(y)-\left(\left(p_{97}(x)-p_{6}(x)\right) * m_{3}\right)\right) \\
m_{4}=\left(p_{97}(y)-p_{3}(y)\right) /\left(p_{97}(x)-p_{3}(x)\right) \\
p_{88}(x, y)=\left(p_{1}(x), p_{97}(y)-\left(\left(p_{97}(x)-p_{1}(x)\right) * m_{4}\right)\right) \\
p_{89}(x, y)=\left(p_{8}(x), p_{97}(y)\right) \\
p_{90}(x, y)=\left(p_{3}(x), p_{97}(y)\right) \\
p_{91}(x, y)=\left(p_{9}(x), p_{98}(y)\right) \\
p_{92}(x, y)=\left(p_{4}(x), p_{98}(y)\right)
\end{gathered}
$$




\section{Apêndice B}

\section{Instruções para o experimento piloto com o SelfMakeup}

1- Posicione-se na frente da tela do computador com sua face a aproximadamente $50 \mathrm{~cm}$;

2- Clique na sua imagem para ampliá-la;

3- Mova sua cabeça cerca de $10 \mathrm{~cm}$ aproximando-se da tela;

4- No menu "Aplicador", escolha o tipo de borda "Suave", tamanho "Grande" e intensidade "Forte";

5- Selecione "Base" e escolha a segunda cor;

6- Aplique a base virtual selecionada;

7- No menu "Aplicador", escolha intensidade "Fraca";

8- Selecione "Blush" e escolha a segunda cor;

9- Aplique o blush virtual selecionado;

10- No menu "Aplicador", escolha o tipo de borda "Suave", tamanho "Médio" e intensidade "Forte";

11- Selecione "Sombra" e escolha a segunda cor;

12- Aplique a sombra virtual escolhida;

13- No menu "Aplicador", escolha o tipo de borda "Definida", tamanho "Pequeno" e intensidade "Forte";

14- Selecione "Batom" e escolha a segunda cor;

15- Aplique o batom virtual escolhido;

16- Selecione a terceira cor de "Batom";

17- Aplique o batom virtual na bochecha;

18- Selecione "Removedor" e escolha a opção "Remover Último Produto". 


\section{Apêndice C}

\section{QUESTIONÁRIO}

Com base na sua experiência de auto aplicação de maquiagem responda as seguintes questões:

1) Qual a sua idade?

2) Há quanto tempo você se maquia?

3) Com qual frequência você se maquia com batom?
( ) Todos os dias
( ) 1 vez por semana
( ) A cada 15 dias
( ) Mensalmente

4) Com qual frequência você se maquia com base?
( ) Todos os dias
( ) 1 vez por semana
( ) A cada 15 dias
( ) Mensalmente

5) Com qual frequência você se maquia com blush?
( ) Todos os dias
( ) 1 vez por semana
( ) A cada 15 dias
( ) Mensalmente

6) Com qual frequência você se maquia com sombra?
( ) Todos os dias
( ) 1 vez por semana
( ) A cada 15 dias
( ) Mensalmente

7) Com base na sua habilidade para auto maquiagem, após se maquiar você se sente:

\begin{tabular}{|l|l|l|l|l|}
\hline & & & & \\
\hline Descontente & \multicolumn{3}{|c|}{ Contente } \\
\hline
\end{tabular}

8) Você já utilizou algum sistema ou aplicativo para aplicar maquiagem virtual?
( ) $\operatorname{Sim}$
( ) Não
Qual?

Com base na sua experiência usando o sistema para auto maquiagem virtual:

1) Em relação ao modo de interação para aplicação de maquiagem virtual, o que você achou? Marque um "X" no quadrado correspondente.

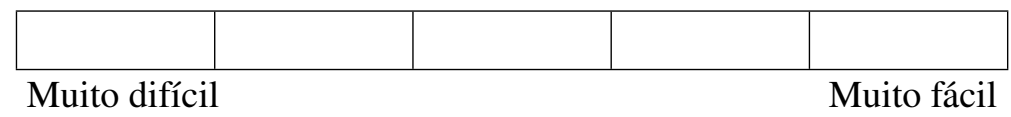

2) Em que nível os modos de interação foram naturais de usar? Marque um "X" no quadrado correspondente. 


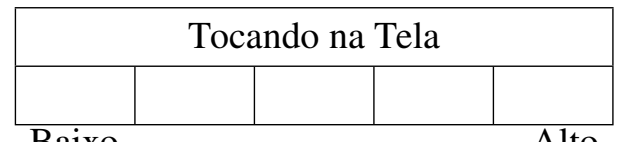

Baixo

Alto

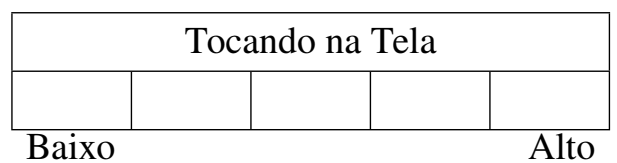

3) Em que precisão os modos de interação possibilitaram que você aplicasse a maquiagem virtual no local desejado? Marque um "X" no quadrado correspondente.

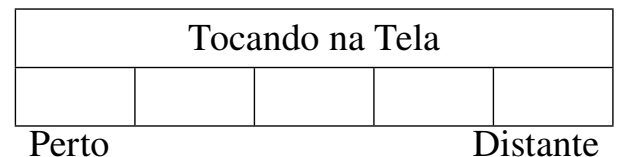

Distante

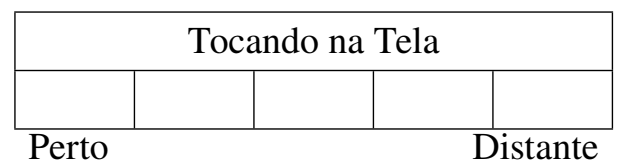

4) Em que nível os modos de interação foram agradáveis de usar? Marque um " $X$ " no quadrado correspondente.
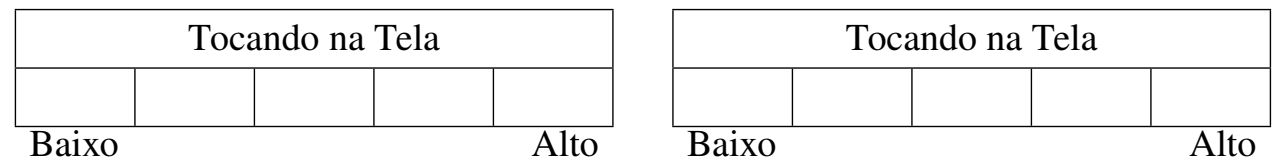

5) Em relação ao modo de interação, qual você achou mais fácil de usar?
( ) Tocando sua face
( ) Tocando a tela

6) Qual modo de interação permitiu que você obtivesse resultados mais precisos?
( ) Tocando sua face
( ) Tocando a tela

7) Com qual modo de interação você se sentiu mais satisfeito com o resultado final?

( ) Tocando sua face

( ) Tocando a tela

8) Qual modo de interação você achou mais rápido?
( ) Tocando sua face
( ) Tocando a tela

9) Qual o modo de interação você gostou mais?
( ) Tocando sua face
( ) Tocando a tela

10) Qual modo de interação você achou mais natural?
( ) Tocando sua face
( ) Tocando a tela

11) Se você tivesse que escolher um dos modos de interação para a auto aplicação de maquiagem virtual, qual desses dois escolheria?
( ) Tocando sua face
( ) Tocando a tela 


\section{Referências Bibliográficas}

Aristidou e Lasenby (2010) A. Aristidou e J. Lasenby. Motion capture with constrained inverse kinematics for real-time hand tracking. Em 2010 4th International Symposium on Communications, Control and Signal Processing (ISCCSP), páginas 1-5. doi: 10.1109/ISCCSP.2010.5463419. Citado na pág. 27

Avancini (2011) Mattia Avancini. Using Kinect to emulate an interactive whiteboard. Dissertação de Mestrado em Ciências, University of Trento. Citado na pág. 28, 29

Barrow e Tenenbaum (1978) Harry G. Barrow e J. Martin Tenenbaum. Recovering intrinsic scene characteristics from images. Relatório Técnico 157, AI Center, SRI International, 333 Ravenswood Ave., Menlo Park, CA 94025. Citado na pág. 7

Bookstein (1988) F Bookstein. Thin-plate splines and the decomposition of deformation. IEEE Trans. Patt. Anal. Mach. Intell, 10. Citado na pág. 8

Bowman et al. (2012) Doug A. Bowman, Ryan P. McMahan e Eric D. Ragan. Questioning naturalism in 3d user interfaces. Commun. ACM, 55(9):78-88. ISSN 0001-0782. doi: 10.1145/2330667.2330687. URL http://doi.acm.org/10.1145/2330667.2330687. Citado na pág. 33, 58

Burstone (1967) Charles J Burstone. Lip posture and its significance in treatment planning. American journal of orthodontics, 53(4):262-284. Citado na pág. 47

Campos (2014) Filipe Morgado Simões de. Campos. Espelho virtual interativo para simulação de maquiagem. Dissertação (Mestrado em Ciências), Universidade de São Paulo. São Paulo/SP. Citado na pág. vi, vii, $4,6,12,13,14,19,20,30,31,48,50,69$

Chuang et al. (2001) Yung-Yu Chuang, Brian Curless, David H Salesin e Richard Szeliski. A bayesian approach to digital matting. Em Computer Vision and Pattern Recognition, 2001. CVPR 2001. Proceedings of the 2001 IEEE Computer Society Conference on, volume 2, páginas II-264. IEEE. Citado na pág. 6

de La Gorce et al. (2011) M. de La Gorce, D. J. Fleet e N. Paragios. Model-based 3d hand pose estimation from monocular video. IEEE Transactions on Pattern Analysis and Machine Intelligence, 33(9):17931805. ISSN 0162-8828. doi: 10.1109/TPAMI.2011.33. Citado na pág. 27

de Sousa e Morimoto (2015) Alexandre M. F. de Sousa e Carlos H. Morimoto. 5* magic wand: An rgbd camera-based 5 dof user interface for 3d interaction. Em XVII Symposium on Virtual and Augmented Reality (SVR), páginas 15-22. doi: 10.1109/SVR.2015.10. Citado na pág. 28, 29

Dhall et al. (2009) Abhinav Dhall, Gaurav Sharma, Rajen Bhatt e Ghulam Mohiuddin Khan. Adaptive digital makeup. Em Advances in Visual Computing, páginas 728-736. Springer. Citado na pág. 10, 29, 30

Dilguerian (1998) Ana Maria Dilguerian. Michaelis: moderno dicionário da língua portuguesa. Citado na pág. 4

F. Henriques et al. (2014) João F. Henriques, Rui Caseiro, Pedro Martins e Jorge Batista. High-speed tracking with kernelized correlation filters. 37. Citado na pág. 42

Ferreira (1993) AB de H Ferreira. Dicionário aurélio eletrônico. Ed. Nova Fronteira. Citado na pág. 4 
Guo e Sim (2009) Dong Guo e Terence Sim. Digital face makeup by example. Em Computer Vision and Pattern Recognition, 2009. CVPR 2009. IEEE Conference on, páginas 73-79. IEEE. Citado na pág. vi, 7, 8, $9,10,12,29,30,48,51,52,69$

Hamer et al. (2009) H. Hamer, K. Schindler, E. Koller-Meier e L. V. Gool. Tracking a hand manipulating an object. Em 2009 IEEE 12th International Conference on Computer Vision, páginas 1475-1482. doi: 10.1109/ICCV.2009.5459282. Citado na pág. 27

Hanafusa et al. (2010) Akihiko Hanafusa, Shuri Terada, Yuuri Miki, Chiharu Sasagawa, Tomozumi Ikeda e Teruhiko Fuwa. Makeup support system for visually impaired persons: Overview of system functions. Em Computers Helping People with Special Needs, páginas 338-345. Springer. Citado na pág. vi, 16, 17, 18, 31

Hassenzahl (2012) Marc Hassenzahl. User experience and experience design. Em The Encyclopedia of Human-Computer Interaction. The Interaction Design Foundation. Citado na pág. 2

Huang et al. (2013) Cheng-Guo Huang, Tsung-Shian Huang, Wen-Chieh Lin e Jung-Hong Chuang. Physically based cosmetic rendering. Computer Animation and Virtual Worlds, 24(3-4):275-283. Citado na pág. $11,12,30$

Intel (2014) Intel. Sdk design guidelines, 2014. URL https://software.intel.com/sites/default/files/managed/ 27/50/. Citado na pág. 35

Iwabuchi et al. (2009) Eriko Iwabuchi, Maki Nakagawa e Itiro Siio. Smart makeup mirror: Computeraugmented mirror to aid makeup application. Em Human-Computer Interaction. Interacting in Various Application Domains, páginas 495-503. Springer. Citado na pág. vi, 13, 15, 16, 31

Jang et al. (2013) In-Su Jang, Jae Woo Kim, Ju-Yeon You e Jin Seo Kim. Spectrum-based color reproduction algorithm for makeup simulation of 3d facial avatar. ETRI Journal, 35(6):969-979. Citado na pág. vi, 12, 30

Jimenez et al. (2009) Jorge Jimenez, Veronica Sundstedt e Diego Gutierrez. Screen-space perceptual rendering of human skin. ACM Transactions on Applied Perception (TAP), 6(4):23. Citado na pág. 12

Keskin et al. (2013) Cem Keskin, Furkan Kıraç, Yunus Emre Kara e Lale Akarun. Real time hand pose estimation using depth sensors. Em Consumer Depth Cameras for Computer Vision, páginas 119-137. Springer. Citado na pág. 28

Kim e Choi (2008) Jeong-Sik Kim e Soo-Mi Choi. Interactive cosmetic makeup of a 3d point-based face model. IEICE transactions on information and systems, 91(6):1673-1680. Citado na pág. vi, 11, 13, 15, 29, 30,31

Kim e Choi (2007) Jeong-Sik Kim e Soo-Mi Choi. A virtual environment for 3d facial makeup. Em Virtual Reality, páginas 488-496. Springer. Citado na pág. vi, 13, 14, 31

Kortüm (2012) Gustav Kortüm. Reflectance spectroscopy: principles, methods, applications. Springer Science \& Business Media. Citado na pág. 11

Krejov e Bowden (2013) P. Krejov e R. Bowden. Multi-touchless: Real-time fingertip detection and tracking using geodesic maxima. Em 2013 10th IEEE International Conference and Workshops on Automatic Face and Gesture Recognition (FG), páginas 1-7. doi: 10.1109/FG.2013.6553778. Citado na pág. 28

Kwatra et al. (2003) Vivek Kwatra, Arno Schödl, Irfan Essa, Greg Turk e Aaron Bobick. Graphcut textures: Image and video synthesis using graph cuts. Em ACM SIGGRAPH 2003 Papers, SIGGRAPH '03, páginas 277-286, New York, NY, USA. ACM. ISBN 1-58113-709-5. doi: 10.1145/1201775.882264. URL http://doi.acm.org/10.1145/1201775.882264. Citado na pág. 7

Lee (2008) Johnny Chung Lee. Hacking the nintendo wii remote. IEEE Pervasive Computing, 7(3):39-45. ISSN 1536-1268. doi: 10.1109/MPRV.2008.53. URL http://dx.doi.org/10.1109/MPRV.2008.53. Citado na pág. 28 
Liang et al. (2012) Hui Liang, Junsong Yuan e Daniel Thalmann. 3d fingertip and palm tracking in depth image sequences. Em Proceedings of the 20th ACM International Conference on Multimedia, MM '12, páginas 785-788, New York, NY, USA. ACM. ISBN 978-1-4503-1089-5. doi: 10.1145/2393347.2396312. URL http://doi.acm.org/10.1145/2393347.2396312. Citado na pág. 28

Melax et al. (2013) Stan Melax, Leonid Keselman e Sterling Orsten. Dynamics based 3d skeletal hand tracking. Em Proceedings of Graphics Interface 2013, GI '13, páginas 63-70, Toronto, Ont., Canada, Canada. Canadian Information Processing Society. ISBN 978-1-4822-1680-6. URL http://dl.acm.org/ citation.cfm?id=2532129.2532141. Citado na pág. 27

Milborrow e Nicolls (2008) Stephen Milborrow e Fred Nicolls. Locating facial features with an extended active shape model. Em Computer Vision-ECCV 2008, páginas 504-513. Springer. Citado na pág. 8

Nakagawa et al. (2011) Maki Nakagawa, Koji Tsukada e Itiro Siio. Smart makeup system: Supporting makeup using lifelog sharing. Em Proceedings of the 13th International Conference on Ubiquitous Computing, UbiComp '11, páginas 483-484, New York, NY, USA. ACM. ISBN 978-1-4503-0630-0. doi: 10.1145/2030112.2030182. URL http://doi.acm.org/10.1145/2030112.2030182. Citado na pág. vi, 17, 18, 19,31

Neverova et al. (2014) Natalia Neverova, Christian Wolf, Graham W Taylor e Florian Nebout. Hand segmentation with structured convolutional learning. Em Asian Conference on Computer Vision, páginas 687-702. Springer. Citado na pág. 28

Oikonomidis et al. (2011) I. Oikonomidis, N. Kyriazis e A. A. Argyros. Full dof tracking of a hand interacting with an object by modeling occlusions and physical constraints. Em 2011 International Conference on Computer Vision, páginas 2088-2095. doi: 10.1109/ICCV.2011.6126483. Citado na pág. 27

Oikonomidis et al. (2014) Iason Oikonomidis, Manolis I. A. Lourakis e Antonis A. Argyros. Evolutionary quasi-random search for hand articulations tracking. Em Proceedings of the 2014 IEEE Conference on Computer Vision and Pattern Recognition, CVPR '14, páginas 3422-3429, Washington, DC, USA. IEEE Computer Society. ISBN 978-1-4799-5118-5. doi: 10.1109/CVPR.2014.437. URL http://dx.doi.org/10. 1109/CVPR.2014.437. Citado na pág. 27

Qian et al. (2014) Chen Qian, Xiao Sun, Yichen Wei, Xiaoou Tang e Jian Sun. Realtime and robust hand tracking from depth. Em Proceedings of the 2014 IEEE Conference on Computer Vision and Pattern Recognition, CVPR '14, páginas 1106-1113, Washington, DC, USA. IEEE Computer Society. ISBN 9781-4799-5118-5. doi: 10.1109/CVPR.2014.145. URL http://dx.doi.org/10.1109/CVPR.2014.145. Citado na pág. 27

Rahman et al. (2010) ASMM Rahman, Thomas T Tran, SK Hossain e Abdulmotaleb El Saddik. Augmented rendering of makeup features in a smart interactive mirror system for decision support in cosmetic products selection. Em Distributed Simulation and Real Time Applications (DS-RT), 2010 IEEE/ACM 14th International Symposium on, páginas 203-206. IEEE. Citado na pág. vi, 16, 17, 30,31

RealSense (2016) Documentação Intel RealSense. Sdk design guidelines, 2016. URL https://software.intel. $\mathrm{com} / \mathrm{sites} /$ landingpage/realsense/camera-sdk/v1.1/documentation/html/index.html? Citado na pág. vii, 38

Rehg e Kanade (1994) James M. Rehg e Takeo Kanade. Visual tracking of high DOF articulated structures: An application to human hand tracking, páginas 35-46. Springer Berlin Heidelberg, Berlin, Heidelberg. ISBN 978-3-540-48400-4. doi: 10.1007/BFb0028333. URL http://dx.doi.org/10.1007/BFb0028333. Citado na pág. 27

Rogers et al. (2013) Yvonne Rogers, Helen Sharp e Jennifer Preece. Design de Interação: além da interação humano-computador. [Trad. Isabela Gasparini]. Citado na pág. 2

Scherbaum et al. (2011) Kristina Scherbaum, Tobias Ritschel, Matthias Hullin, Thorsten Thormählen, Volker Blanz e Hans-Peter Seidel. Computer-suggested facial makeup. Em Computer Graphics Forum, volume 30, páginas 485-492. Wiley Online Library. Citado na pág. vi, 10, 11, 29, 30 
Schmidt et al. (2015) Tanner Schmidt, Richard Newcombe e Dieter Fox. Dart: Dense articulated realtime tracking with consumer depth cameras. Auton. Robots, 39(3):239-258. ISSN 0929-5593. doi: 10.1007/s10514-015-9462-z. URL http://dx.doi.org/10.1007/s10514-015-9462-z. Citado na pág. 27

Sharp et al. (2015) Toby Sharp, Cem Keskin, Duncan Robertson, Jonathan Taylor, Jamie Shotton, David Kim, Christoph Rhemann, Ido Leichter, Alon Vinnikov, Yichen Wei, Daniel Freedman, Pushmeet Kohli, Eyal Krupka, Andrew Fitzgibbon e Shahram Izadi. Accurate, robust, and flexible real-time hand tracking. Em Proceedings of the 33rd Annual ACM Conference on Human Factors in Computing Systems, CHI '15, páginas 3633-3642, New York, NY, USA. ACM. ISBN 978-1-4503-3145-6. doi: 10.1145/2702123. 2702179. URL http://doi.acm.org/10.1145/2702123.2702179. Citado na pág. 27

Shirley e Marschner (2009) Peter Shirley e Steve Marschner. Fundamentals of Computer Graphics. A. K. Peters, Ltd., Natick, MA, USA, 3rd ed. ISBN 1568814690, 9781568814698. Citado na pág. 4

Sridhar et al. (2013) S. Sridhar, A. Oulasvirta e C. Theobalt. Interactive markerless articulated hand motion tracking using rgb and depth data. Em 2013 IEEE International Conference on Computer Vision, páginas 2456-2463. doi: 10.1109/ICCV.2013.305. Citado na pág. 27

Stenger et al. (2001) B. Stenger, P. R. S. Mendonca e R. Cipolla. Model-based 3d tracking of an articulated hand. Em Proceedings of the 2001 IEEE Computer Society Conference on Computer Vision and Pattern Recognition. CVPR 2001, volume 2, páginas II-310-II-315 vol.2. doi: 10.1109/CVPR.2001.990976. Citado na pág. 27

Stenger et al. (2006) B. Stenger, A. Thayananthan, P. H. S. Torr e R. Cipolla. Model-based hand tracking using a hierarchical bayesian filter. IEEE Transactions on Pattern Analysis and Machine Intelligence, 28 (9):1372-1384. ISSN 0162-8828. doi: 10.1109/TPAMI.2006.189. Citado na pág. 27

Sun et al. (2015) Xiao Sun, Yichen Wei, Shuang Liang, Xiaoou Tang e Jian Sun. Cascaded hand pose regression. Em Proceedings of the IEEE Conference on Computer Vision and Pattern Recognition, páginas 824-832. Citado na pág. 28

Tang et al. (2014) D. Tang, H. J. Chang, A. Tejani e T. K. Kim. Latent regression forest: Structured estimation of 3d articulated hand posture. Em 2014 IEEE Conference on Computer Vision and Pattern Recognition, páginas 3786-3793. doi: 10.1109/CVPR.2014.490. Citado na pág. 28

Tang et al. (2013) Danhang Tang, Tsz-Ho Yu e Tae-Kyun Kim. Real-time articulated hand pose estimation using semi-supervised transductive regression forests. Em Proceedings of the IEEE international conference on computer vision, páginas 3224-3231. Citado na pág. 28

Tompson et al. (2014) Jonathan Tompson, Murphy Stein, Yann Lecun e Ken Perlin. Real-time continuous pose recovery of human hands using convolutional networks. ACM Trans. Graph., 33(5):169:1-169:10. ISSN 0730-0301. doi: 10.1145/2629500. URL http://doi.acm.org/10.1145/2629500. Citado na pág. 28

Tong et al. (2007) Wai-Shun Tong, Chi-Keung Tang, Michael S. Brown e Ying-Qing Xu. Example-based cosmetic transfer. Em Proceedings of the 15th Pacific Conference on Computer Graphics and Applications, PG '07, páginas 211-218, Washington, DC, USA. IEEE Computer Society. ISBN 0-7695-3009-5. doi: 10.1109/PG.2007.21. URL http://dx.doi.org/10.1109/PG.2007.21. Citado na pág. vi, 6, 7, 8, 9, 10, 29, 30

Tori et al. (2006) Romero Tori, Claudio Kirner e Robson Augusto Siscoutto. Fundamentos e tecnologia de realidade virtual e aumentada. Editora SBC. Citado na pág. 2

Turk e Pentland (1991) Matthew A Turk e Alex P Pentland. Face recognition using eigenfaces. Em Computer Vision and Pattern Recognition, 1991. Proceedings CVPR'91., IEEE Computer Society Conference on, páginas 586-591. IEEE. Citado na pág. 10 
Viola e Jones (2001) Paul Viola e Michael Jones. Rapid object detection using a boosted cascade of simple features. Em Computer Vision and Pattern Recognition, 2001. CVPR 2001. Proceedings of the 2001 IEEE Computer Society Conference on, volume 1, páginas I-511. IEEE. Citado na pág. 10

Wang e Popović (2009) Robert Y. Wang e Jovan Popović. Real-time hand-tracking with a color glove. Em ACM SIGGRAPH 2009 Papers, SIGGRAPH '09, páginas 63:1-63:8, New York, NY, USA. ACM. ISBN 978-1-60558-726-4. doi: 10.1145/1576246.1531369. URL http://doi.acm.org/10.1145/1576246. 1531369. Citado na pág. 27

Xiao et al. (2013) Robert Xiao, Chris Harrison e Scott E. Hudson. Worldkit: Rapid and easy creation of adhoc interactive applications on everyday surfaces. Em Proceedings of the SIGCHI Conference on Human Factors in Computing Systems, CHI '13, páginas 879-888, New York, NY, USA. ACM. ISBN 978-14503-1899-0. doi: 10.1145/2470654.2466113. URL http://doi.acm.org/10.1145/2470654.2466113. Citado na pág. 29

Xu e Cheng (2013) Chi Xu e Li Cheng. Efficient hand pose estimation from a single depth image. Em Proceedings of the IEEE International Conference on Computer Vision, páginas 3456-3462. Citado na pág. 28 